\title{
CHANGE, CHOICE AND DIFFERENCE: \\ THE CASE OF RN TO BN DEGREE PROGRAMMES FOR REGISTERED NURSES
}

\author{
by \\ Tina Lynette Smith \\ A thesis submitted to the Victoria University of Wellington \\ in fulfilment of the \\ requirements for the degree of \\ Master of Nursing
}

Victoria University of Wellington

2008 


\begin{abstract}
Bachelor of Nursing (BN) programmes for Registered Nurses (RNs) were developed in New Zealand in the 1990s. With the introduction of pre-registration degree programmes, transition arrangements that recognised the prior learning of RNs were established allowing existing $\mathrm{RNs}$ to obtain an undergraduate nursing degree through a shortened course. Many RNs entered these programmes, despite there being no requirement to obtain a degree qualification and with other education options available to them. Professional debate exists regarding the need or value of RNs undertaking such study and whether these programmes should continue. A case study approach utilising mixed methods was used to examine the personal meaning and the national professional significance of $\mathrm{RN}$ to $\mathrm{BN}$ programmes.
\end{abstract}

While ultimately the outcome of earlier professional efforts, these programmes occurred as a result of change, change within the socio-political and economic context of New Zealand and nursing education. Change at this macro level affected the individual choices of RNs. These choices were further complicated by a lack of professional consensus and a landscape of difference, with programme requirements and availability differing between institutions, while employers varied in the amount of support and recognition they gave those who chose this option. There were personal and financial costs to completing a $\mathrm{RN}$ to $\mathrm{BN}$ programme, yet the RNs in this study all believed it was worth it, reporting positive personal and professional outcomes.

The professional and educational environment has changed since the introduction of $\mathrm{RN}$ to $\mathrm{BN}$ programmes and the numbers of individuals and institutions involved with them have greatly reduced. Currently decisions regarding the continuation or demise of these programmes are made by individual educational institutions based mainly on economic rationale. Consensus and direction is required nationally and professionally regarding the place of these programmes within post-registration education. While these programmes have provided benefits for individual RNs, their time in nursing education may be coming to an end.

Key Words: Nursing education, post-registration degree, case study, mixed methods. 


\section{DEDICATION}

This thesis is dedicated to all Registered Nurses who have studied for a nursing related degree or higher qualification, in acknowledgement of the personal sacrifice, the juggling of work and family commitments and the effort involved in a quest for knowledge that advances nursing.

It is also dedicated to Gill Presland, a great nurse, educationalist and true friend who was one of too many who lost the battle against breast cancer. And it is dedicated to the memory of Bruce Smith (my father) who valued knowledge, learning and the pursuit of qualifications. And to the memory of Mum, Angus and Elaine, whose love and presence surround me every day. 


\section{ACKNOWLEDGEMENTS}

Many people have contributed to this thesis and I am grateful to all of them. I wish to thank the people who provided the rich data of the study. In particular, the eight participants who shared their experiences of having completed a degree through a RN to BN programme. Thank you for your time, willingness and contribution. Thank you also to the heads of Schools of Nursing and their staff who completed my questionnaire and provided statistics. To those at Nursing Council of New Zealand who found archival information and provided statistical data, thank you for your time. Thank you to Barry, who explained to me the complexity of the Nursing Council database.

Other people helped me in practical ways. Warm thanks to my supervisors, especially Kathy Nelson and Pamela Wood who with other staff and students provided useful feedback and encouragement. I was grateful to receive a Victoria University of Wellington research grant. A special thank you to the library staff at UCOL who were always pleasant, helpful and obtained lots of interloan literature for me. Thank you also to my employer, UCOL, who assisted with fees and approved study leave. Thanks to Gaby who did extra tasks and always kept things in perspective. And an especially big thank you to my colleagues who listened and encouraged but mainly picked up the load when I was on leave. You are special people with heavy workloads, so I was doubly appreciative of your continued support. Thank you.

And most importantly, thank you to my family and whanau. To Vanya, Mark, June, Olwyn and Marty, thanks for being who you are. To Elyse and James, you are my reason for being, my inspiration and my grounding. It is your love and hugs that sustain me. And to Tim, my rock, the most special thanks for the ongoing support, for taking over jobs and even asking about and trying to understand research! Your efforts were appreciated. 


\section{TABLE OF CONTENTS}

\section{Chapter One: Introduction and Overview}

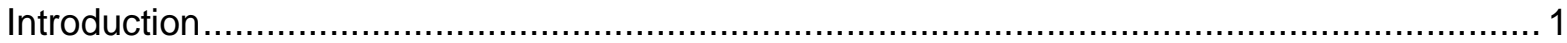

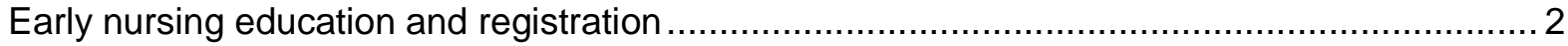

Comprehensive registration and the move to the tertiary sector...........................................

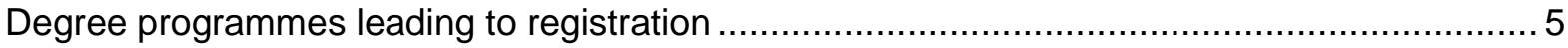

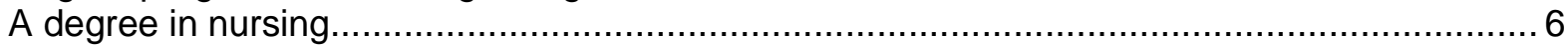

An option for RNs: RN to BN programmes...........................................................

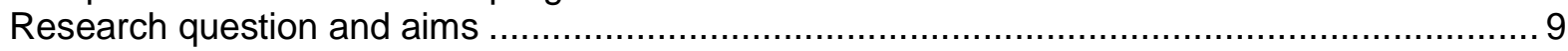

The position of the researcher in this study .................................................................. 11

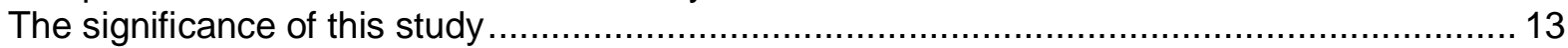

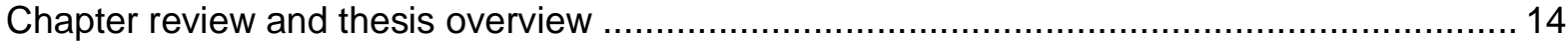

\section{Chapter Two: Literature Review}

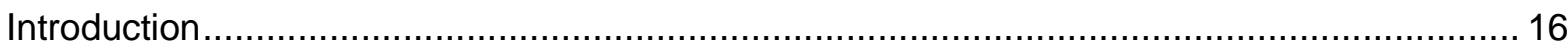

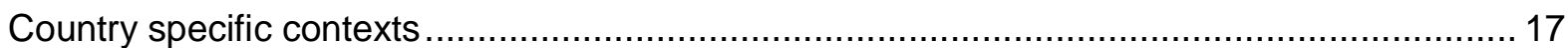

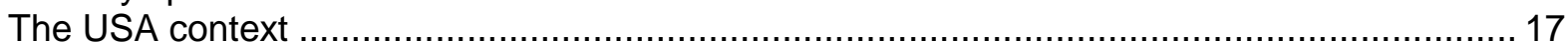

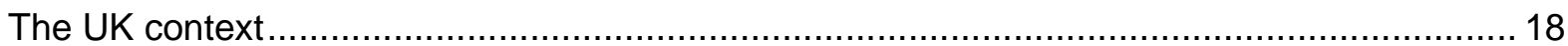

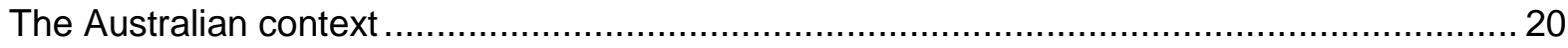

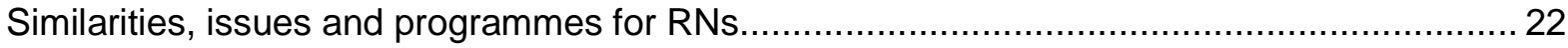

Debates surrounding a degree as a requirement for nursing practice ................................. 25

Professional attitudes and tension ............................................................................. 29

Motivation and barriers for RNs ............................................................................... 31

The experience, challenges, benefits and outcomes.......................................................... 37

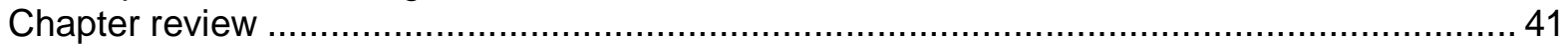

\section{Chapter Three: Research Strategy}

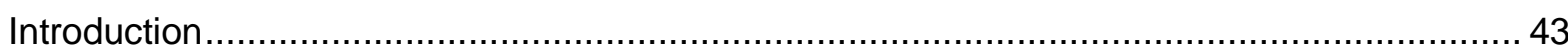

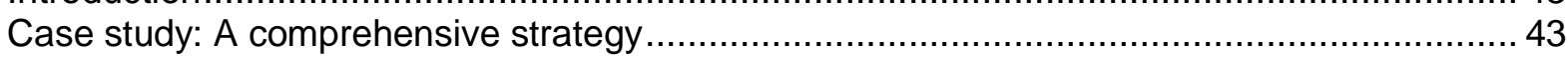

Case study as a research strategy for this research ........................................................ 46

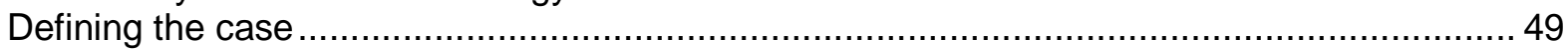

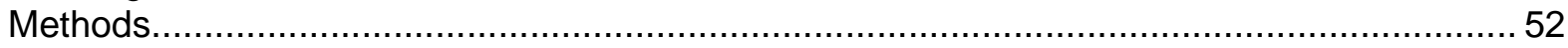

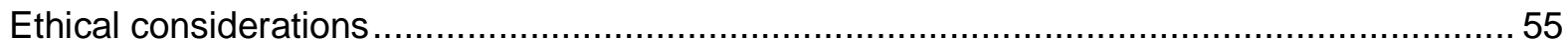

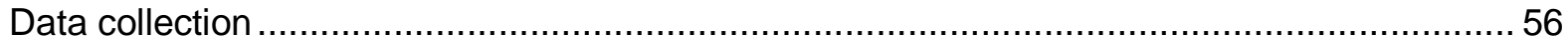

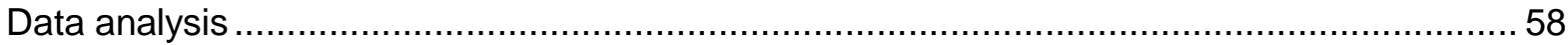

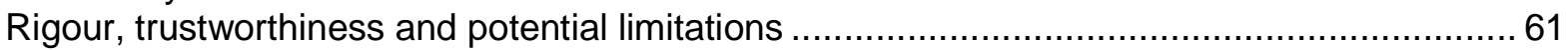

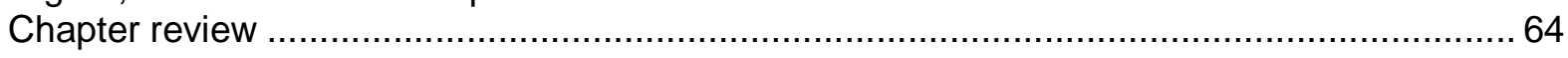

\section{Chapter Four: The National and Professional Perspective}

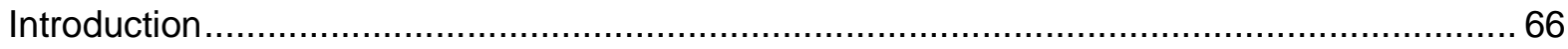

Consideration and professional efforts for RN education ................................................. 66

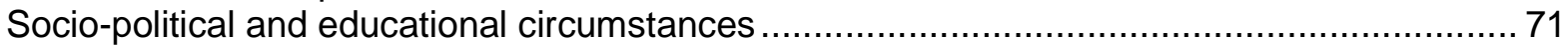




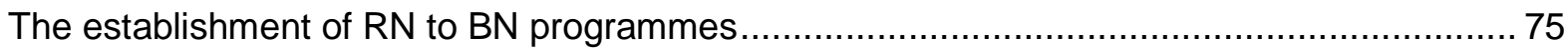

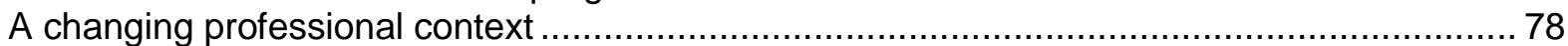

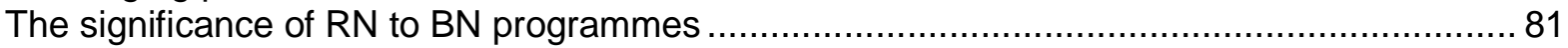

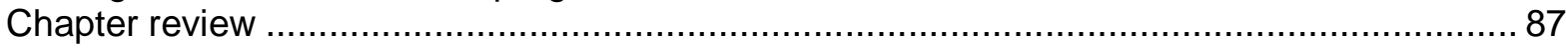

\section{Chapter Five: The Personal Perspective: Climbing Mountains}

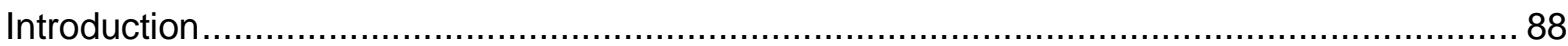

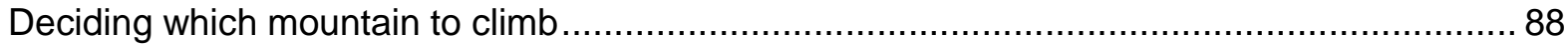

The right time

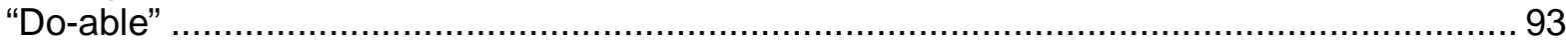

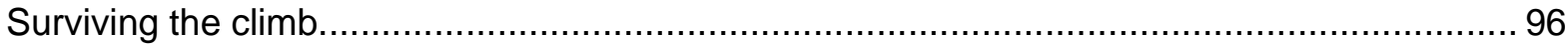

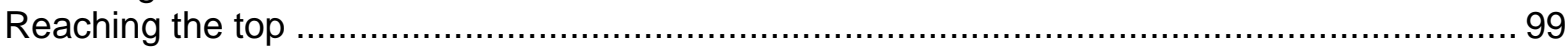

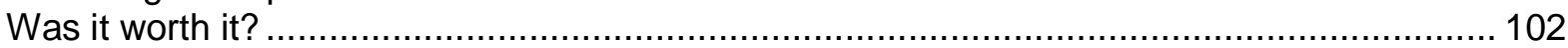

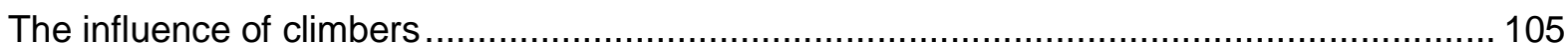

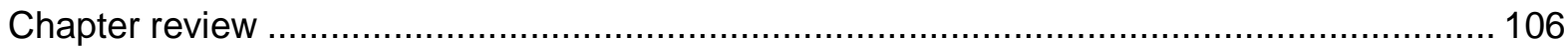

\section{Chapter Six: The Personal Perspective: Diversity and Difference}

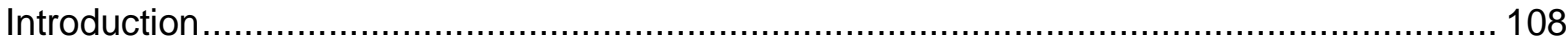

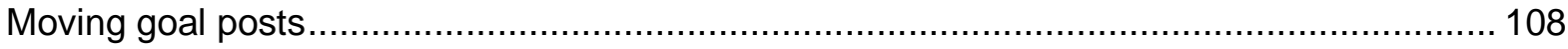

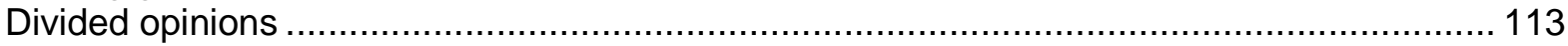

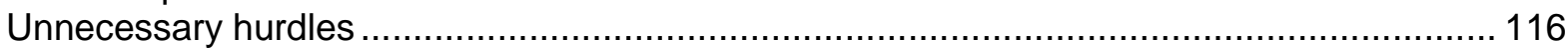

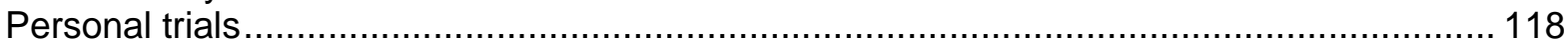

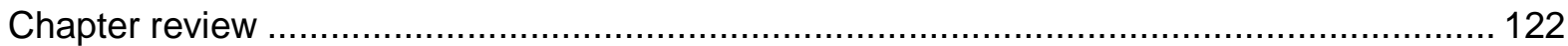

\section{Chapter Seven: Discussion and Conclusions}

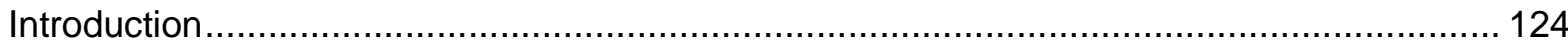

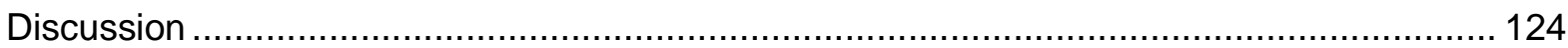

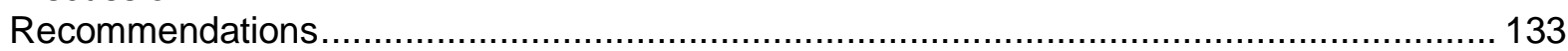

Implications for managers, employers and educational institutions ................................... 132

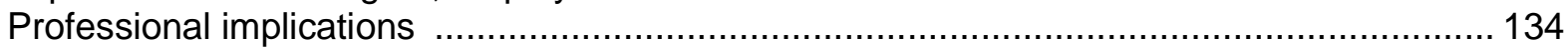

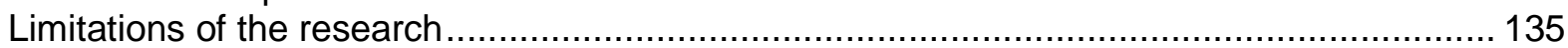

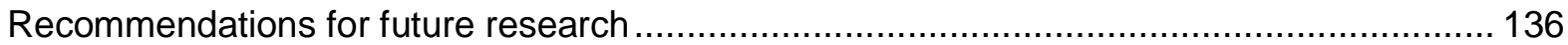

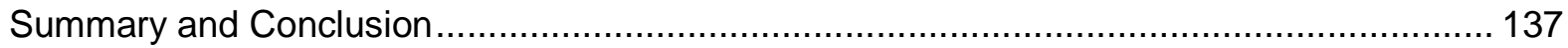

\section{Appendices}

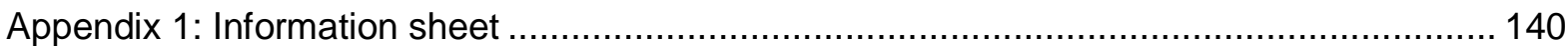

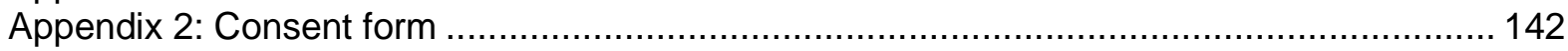

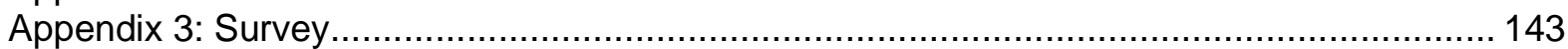

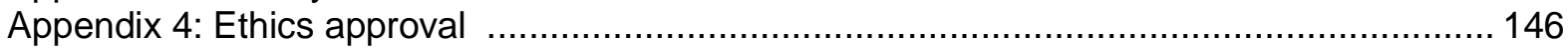

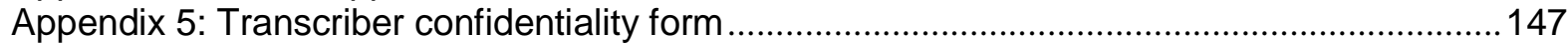

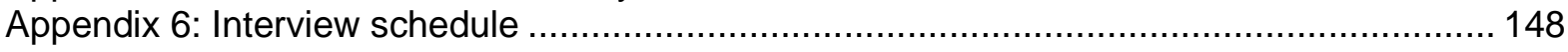

\section{References}




\section{LIST OF TABLES}

Table 1: Overview of nursing education and entry to practice in UK, USA and Australia.

Table 2: Characteristics of participants. .57

Table 3: Description of degree programmes for RN. .77

Table 4: Requirements and RPL given to RNs for an undergraduate nursing degree.

Table 5: Nurses with degree qualifications, 2002. .83

Table 6: Nurses and midwives studying for further qualifications, 2002. .84

Table 7: Registrations per year from NZ and overseas .85

Table 8: Numbers of graduates, by year, from institutions offering $\mathrm{RN}$ to $\mathrm{BN}$ programmes. .86

Table 9: Qualifications and employment of participants. 109 


\section{CHAPTER ONE}

\section{Introduction and Overview}

\section{Introduction}

Entry to the New Zealand (NZ) nursing profession is now only by Bachelor degree. The first preregistration degree programmes were introduced from 1992. This led to a new standard being established when, in April 1998, the Nursing Council of New Zealand (NCNZ) made the formal decision that entry to the profession would only be by Bachelor degree, once existing diploma programmes were phased out. At this time approximately $18 \%$ of all registered nurses (RNs) held a Bachelor degree (NCNZ, 2000). To allow existing RNs to obtain a degree, most preregistration degree programmes included transition arrangements that recognised the prior learning of RNs. This provision was commonly marketed as a RN to Bachelor of Nursing (BN) programme. There was no requirement for RNs to meet this new standard and other educational options existed, yet many took up the opportunity these programmes provided to obtain an undergraduate nursing degree. Little data exist regarding these programmes or their graduates. These $\mathrm{RN}$ to $\mathrm{BN}$ programmes provide the case that is examined in this research.

Change has been a common feature of nursing education as pre-registration courses have gradually moved from vocationally-based hospital training to the tertiary education sector and a Bachelor degree leading to registration as a Comprehensive Nurse. With each development existing RNs were not expected to meet the new requirements. However, change at a national level has personal implications which can often take individuals on new journeys. Hence, some consideration was often given to those affected by change. The establishment of RN to BN programmes was both a personal and a national professional response to changing educational qualifications required for registration. The phenomenon of RNs obtaining an undergraduate nursing degree also occurs internationally but debate exists regarding the need or value of RNs undertaking such study. This thesis examines the place and significance of $\mathrm{RN}$ to $\mathrm{BN}$ programmes, for individuals and for the nursing profession, within the wider framework of nursing education and practice.

Nursing education includes both pre-registration courses and post-registration opportunities. This introductory chapter firstly provides an overview of the changes in pre-registration nursing education that culminated in degree programmes leading to registration. Details of how 
consideration was given to existing RNs during these changes are discussed in Chapter Four alongside information on the professional efforts to achieve tertiary-level post-registration educational opportunities. This first chapter also outlines the establishment of degree programmes leading to registration and clarifies the difference between registration and qualifications. The origin of $\mathrm{RN}$ to $\mathrm{BN}$ programmes is described and terminology is clarified. The reasons for choosing this area of study and the position of the researcher are then explained, along with the justification, aim and significance of this research.

\section{Early nursing education and registration}

The Nurses Registration Act 1901 aimed to standardise nursing with a standard curriculum, state examination and national register of nurses. Student nurses underwent three-year apprentice style training based in hospitals, following the system of training initiated by Florence Nightingale. Although different types of registration were established from the late 1930s to 1950s, all preregistration courses occurred in hospital-based schools of nursing until the 1970s, despite concerns over nursing education. Different reviews and reports highlighted the reality that hospital-based training no longer matched the needs of a changing health environment or the needs of nursing students (Burgess, 1984). Overseas consultants were used to advise the Government and the nursing profession on possible options for nursing education. Alma Reid, who visited in 1965, was the first of these consultants but her recommendations appear to have had little impact. Chick and Kinross (2006) explain that from 1967 to 1972 the nursing team in the Department of Health worked with NCNZ, the New Zealand Nurses Association (NZNA) and the medical profession to achieve one goal - the transfer of nursing education from hospital boards to tertiary education institutions.

Canadian World Health Organisation (WHO) consultant Dr Helen Carpenter's report An Improved System of Nursing Education for New Zealand (Carpenter, 1971) had more influence. The Department of Health's review of the transition of nursing education (Workforce Development Group, 1988) commented that Carpenter's report had received an overwhelming response and substantial agreement from all interested groups. However, nursing sources note that the ideas proposed were well debated and there were significant disagreements (Burgess, 1984; Chick \& Kinross, 2006). The recommendation to transfer three-year nursing education to the university setting, with the 18-month community nurse programme going into polytechnics (also known as technical institutes), was not achieved. A committee established by the Minister of Health in 
1971, known as the '1.6 Committee' because it was charged to consider recommendation 1.6 from Carpenter's report on the most suitable educational setting for colleges for the preparation of nurses, did not achieve consensus agreement on the location of nursing education (Papps \& Kilpatrick, 2002). Chick and Kinross blame political pressure, particularly from the polytechnics, for the 1972 Cabinet decision that the three-year programme would transfer to the polytechnic sector and the 'second level' one-year programme would remain in hospital schools of nursing.

Chick and Kinross (2006, p. 40) describe how "all was not lost for those of us who believed that a university setting was the proper place for nursing education" as recommendations for the establishment of post-basic university education, contained in both Reid's (1965) and Carpenter's (1971) reports, supported the establishment of programmes at Victoria and Massey universities. These programmes were the culmination of earlier efforts by the profession that are outlined in Chapter Four. A nursing lecturer, Beatrice Salmon, was appointed at Victoria University of Wellington in late 1972 to begin a stage-three nursing studies course for 1973. Massey University also commenced a nursing programme in 1973. Both programmes had a requirement that students were registered nurses. More detail around post-registration education is provided in Chapter Four but the establishment of post-registration education in universities at the same time pre-registration programmes moved into the polytechnic sector supported the common perception that universities had a higher status than polytechnics.

\section{Comprehensive registration and the move to the tertiary sector}

The transfer of nursing education away from hospital-based programmes into the education sector heralded the biggest change in NZ nursing education to date. Two pilot programmes commenced in March 1973 with intakes at Christchurch and Wellington Polytechnics. These three-year programmes were at diploma level and led to registration as a Comprehensive Nurse, enabling the RN to work in medical, surgical, psychiatric, psychopaedic, community and maternal/child health areas of nursing. The clinical or practical requirement of the course was to be approximately $50 \%$ of the programme (Taylor, Small, White, Hall, \& Fenwick, 1981). By May 1973 it appeared that the programmes were running satisfactorily and moves were made to extend the scheme the following year (Workforce Development Group, 1988). Although initially a strategy was developed for the expansion of comprehensive courses, no commitment was given past 1979. According to Papps (1997) further establishment did take place but "without any significant long term planning or policy on the part of Government" (p. 96). Between 1973 and 
1986, the number of programmes within polytechnics increased from two to 15 . Funding of nursing education changed as money to finance comprehensive programmes now came from the government's education budget. Hospital-based training had come under the health budget.

Corresponding with the establishment of new programmes was the phasing out of hospital-based nursing programmes. For a number of years a dual system of preparing nurses for registration existed. Papps (1997) believed that this was because of "a general unease about the change in nursing education" (p. 100). The decision to no longer accept students into hospital-based programmes was essentially up to individual hospital boards. The majority of hospital-based schools had accepted their final intakes by March 1984, but Auckland Hospital Board, the final hospital-based programme to be offered, continued defiantly, with the last students graduating in 1990 (Papps). This programme persisted despite there being three polytechnics in the region offering pre-registration nursing programmes, the first having commenced in 1975 and the second in 1980. Resistance to change was evident in clinical situations with Burgess (1984) describing how students and tutors, particularly the pioneers, "weathered some painful experiences at the hands of professional colleagues" (p. 68). Papps argues that this tension was only superficially buried and that it was resurrected during later changes to nursing education and qualifications. The experimental status of polytechnic courses was lifted with the enactment of the Nurses Act 1977 (Papps \& Kilpatrick, 2002).

With the transfer of nursing education to polytechnics there was a marked change in the composition of the hospital nursing workforce which became predominantly qualified staff rather than student nurses. The proportion of qualified nursing staff in general and obstetric hospitals increased from $41.3 \%$ in 1975 to $78.8 \%$ in 1985 , but in psychiatric and psychopaedic hospitals the increase was not so great (38.9\% to 50.3\%) (Workforce Development Group, 1988). Qualified nursing staff now included a mixture of hospital-trained and comprehensive RNs. Those registered as a Comprehensive Nurse were able to work in any setting (psychiatric, psychopaedic, obstetrics) whereas hospital-trained staff were only meant to work in their area of registration, which was general and obstetric settings. This was despite the fact that most hospital-trained nurses had usually completed mental health and psychopaedic components within their programmes. However, there were RNs working in settings not consistent with their registration, most commonly RGONs working in mental health services. Waikato and Nelson polytechnics offered the first 'bridging' courses in 1980 (Burgess, 1984), a one-year programme to enable hospital-trained single registration nurses (psychiatric, general or obstetric) to become 
registered as Comprehensive Nurses and thus practise in all settings. Eventually seven polytechnics offered the 'bridging' programme with up to 140 places available nationally per year but this programme was always planned to be phased out from 1989 (Workforce Development Group). There is a dearth of literature about the numbers who took up this option and no research about their experience. This appears to be another group of nurses who were affected by change in education and registration standards but whose experience has not been researched.

By the late 1980s, the dual systems of nursing education were coming to an end and nursing education leading to comprehensive registration appeared to finally gain acceptance. Lingering concerns regarding nursing education were confirmed at a national workshop reviewing the preparation and initial employment of nurses (Department of Health, 1986) where attrition rates and difficulties in recruiting appropriately qualified teaching staff were highlighted. Issues within nursing and nursing education were influenced by the Lange-led Labour Government economic reforms of the 1980s. A market-driven approach to healthcare and education resulted in an era of restructuring, cost cutting and often redundancy for nurses that continued into the 1990s (Williams, 2000).

\section{Degree programmes leading to registration}

One outcome of this socio-political change was reforms within education that led to the Education Amendment Act 1990, which aimed for a more seamless tertiary sector. To achieve this, polytechnics were given the right to award degrees as approved by the newly established New Zealand Qualifications Authority (NZQA), a right previously only available to the country's (then) seven universities. The NZQA sought to develop a framework with clear levels from secondary school (Level One) through to a degree which would be at Level Seven, through to post-graduate level study (Level Eight) (NZQA, 1991).

The concept of registration from degree programmes received a mixed reaction from differing groups. Disagreement existed over whether it was possible to meet the requirements for registration and the requirements of an undergraduate degree in three years. A degree programme required a clear emphasis on the importance of research and many also saw this as an opportunity to move to more emancipatory teaching processes. Amidst the debate on whether the degree should be of three or four years duration, the Ministry of Education made it clear that 
funding would only be provided for a three-year degree programme (Papps, 1997). The NCNZ could not differentiate between diploma level and degree level programmes at this time. While NCNZ approved programmes leading to registration, in accordance with the Nurses Act 1977, its emphasis was on ensuring public safety and fitness to practise. Nursing Council focused on the quality of the 1500 hours of the clinical component and evidence that students could meet the requirements for registration as verified by a state final examination. Nursing degree programmes within polytechnics had to meet both the registration requirements of NCNZ and the NZQA degree requirements.

In 1992 three institutions, Auckland Institute of Technology, Wellington Polytechnic and Otago Polytechnic, became the first to offer undergraduate degree programmes leading to registration. From this time each of the then 15 educational institutes offering pre-registration nursing programmes progressively adopted a Bachelor degree in nursing. In less than 30 years, preregistration nursing education in NZ had moved from hospital-based training to diploma-level education based in the tertiary education sector, and now to a three-year Bachelor degree in nursing leading to registration as a comprehensive nurse. Clearly RNs already in practice would be affected by this change.

\section{A degree in nursing}

Undergraduate nursing degrees leading to registration added another factor to an already complicated mix. At this time there were five different types of RNs. Hospital-trained nurses could be Registered General Nurses (RGN), Registered General and Obstetric Nurses (RGON), Registered Psychiatric Nurses or Registered Psychopaedic Nurses. If they had completed a diploma-level comprehensive course they were a Registered Comprehensive Nurse (RCpN). Hospital-trained RNs could also become $\mathrm{RCpN}$, by completing a bridging programme to change their registration to comprehensive registration. For the purposes of this thesis all types of registered nurses will be considered under the term 'registered nurse' (RN).

With the introduction of pre-registration degree programmes to nursing in the 1990s, the academic level of education became important. A degree is considered at Level Seven by NZQA, with a diploma being at Level Six. Previous pathways to nursing registration were loosely given diploma or Level Six status. Nurses qualifying from a degree programme leading to registration were now considered 'graduates'. For the purpose of this thesis, the term 'graduate' 
will be used to describe RNs who have an undergraduate degree in nursing, whether this was gained pre or post-registration, consistent with the terminology of the international literature. Also the term Bachelor of Nursing (BN) will be used to describe all NZ undergraduate degrees leading to nursing registration, although the title of some programmes was Bachelor of Health Science.

A degree obtained through a polytechnic was considered by some people to differ in quality from a degree obtained through a university. This related to beliefs about universities being more academically focused, while polytechnics were more vocationally focused. As previously mentioned, Massey University and VUW had been offering registration studies in nursing since 1973. Initially Massey University offered a university diploma in Nursing Studies and this was conceived as an advanced qualification for students who were already registered nurses. Chick and Kinross (2006) discuss university education for RNs as aiming to "change attitudes and promote leadership abilities" (p. 73). Those nurses who completed an undergraduate degree through Massey or VUW usually completed a Bachelor of Arts degree in nursing studies. They gained little, if any, academic credit for their registration and experience, although being a RN was a prerequisite for the nursing papers. This was challenged as inequitable, as RNs were effectively required to do two three-year qualifications in order to obtain an undergraduate degree (Papps, 1997). When pre-registration degree programmes were introduced in the 1990s, nursing studies at VUW were already suspended but undergraduate and post-graduate courses offered through Massey University continued. Direct entry into post-graduate studies (Level Eight) was an option available to some RNs, but was not actively encouraged at that time.

\section{An option for RNs: RN to BN programmes}

From the introduction of the first three pre-registration degree programmes arrangements were established to enable existing RNs to gain the same degree ("Nursing by degrees", 1991/1992). How and why these occurred is discussed in more detail in Chapter Four. The curricula of BN programmes differed between institutions but fundamentally covered similar content as ultimately they had to meet both NCNZ registration and NZQA degree requirements. The NZQA requirements for each programme included having a recognition of prior learning (RPL) policy and a degree transition course for RNs (Adams, 2003). Transition, or RN to BN, programmes were essentially the same as undergraduate programmes, but RNs were effectively given recognition and academic credit for their prior learning gained from their registration and practice. Hence, while specifics varied because of different curricula, RNs usually only had to complete 
some theoretical components and did not have to undertake any practicum. Theoretical aspects to be covered generally included research, cultural safety and professional content related to advancing practice and perhaps a clinical specialty. With most programmes, approximately one third of the BN needed to be studied by RNs, although with RPL some nurses were able to do even less. Arrangements for RNs were usually marketed as separate RN to BN programmes, as delivery streams were different from those provided for undergraduate students. They were often run in the evening, by block course, distance mode or as a mixture of these in consideration of RNs' personal and employment constraints.

There was no requirement for RNs to achieve this new standard of a degree and there was little financial incentive to undertake such study. The financial cost of degree study was high with institution fees being in the vicinity of $\$ 3,000$ to $\$ 3,500$ for the $R N$ to $B N$ programme. Most nurses received little or no financial assistance, especially when these programmes were first offered. On attainment of a degree qualification there was no automatic salary increase for existing RNs. For many managers the value of a degree for a nurse who already had registration was unclear, so support, either financially or with release time, was erratic. Clinical career pathways were only just being developed in the 1990s. In the absence of a nationally consistent framework the value of a degree to a career pathway was questionable, although Adams (2003) believes it soon became apparent that holding a degree would affect promotion.

Because of the RPL and academic credit given to RNs on a RN to BN programme, nurses could gain an undergraduate degree in a shorter timeframe than the option of obtaining an undergraduate degree through a NZ university. A number of Australian universities, for example Charles Sturt University, also offered undergraduate nursing degree programmes that gave considerable recognition for registration and experience. These programmes were provided by distance mode or supported by block courses in New Zealand. Changes in the education sector, described further in Chapter Four, saw one NZ polytechnic gain university status and some existing universities offer pre-registration degree programmes and $\mathrm{RN}$ to $\mathrm{BN}$ programmes. For the purposes of this research, the term $\mathrm{RN}$ to $\mathrm{BN}$ programme, refers to all $\mathrm{NZ}$ transition programmes whereby RNs obtained an undergraduate nursing degree, whether offered by a polytechnic or a university. 


\section{Research question and aims}

The move to tertiary-based pre-registration education and degree-level programmes is not unique to NZ. It is part of an international trend linked with factors such as the push for ongoing learning, advancing practice and increasing the level of qualification of the nursing workforce (International Council of Nurses, 2006). In each country the establishment and type of programmes offered for $\mathrm{RNs}$ to obtain an undergraduate nursing degree relate to the country's progress with respect to requiring a degree as the standard for entry to the profession. This is also influenced by the way tertiary education is organised within the country. International comparisons are presented in Chapter Two. Internationally the issue of RNs obtaining a degree has been considered from many angles, but while these studies provide some useful insights, generally only aspects of programmes are considered with contextual features often ignored. Additionally, the international context is quite different from the NZ nursing context.

As becomes more evident in the next chapter, there is a paucity of literature and research related to $\mathrm{RN}$ to $\mathrm{BN}$ programmes or RNs obtaining an undergraduate nursing degree in NZ. A study by Seaton (1998) was the only research found specifically related to RNs obtaining a degree through a RN to BN programme. Her phenomenological study focused on the RNs' student experiences in order to reveal new possibilities for the teaching and learning in $\mathrm{RN}$ education. However, a feminist study considering the experience of nurses in paid work and further education (Blackie, 2001) did include one participant who was a RN studying towards an undergraduate nursing degree through a RN to BN programme. Also, a descriptive survey that was used to examine the continuing education needs of RNs in management and clinical practice (Benipal, 1999) provided some relevant data related to RNs obtaining an undergraduate nursing degree and polytechnic-based RN to BN programmes. There has been some NZ research into other nursing education programmes established in response to changing requirements (Kennedy \& Taylor, 1987; Wood, 1990) and studies undertaken with RNs involved in tertiary study (Idour, 1997; Spence, 2004a, 2004b). The experience of Enrolled Nurses (ENs) who returned to education to upgrade their qualifications to $\mathrm{RN}$ has also been researched (Adamson, 1997; Dixon, 1996). However, these few studies all called for more NZ research related to nursing education. 
The impact of $\mathrm{RN}$ to $\mathrm{BN}$ programmes on professional nursing and workforce qualifications is unknown. There is evidence that in 1998 only $18.2 \%$ of practising RNs held a Bachelor degree (NCNZ, 2000) and by 2002 the percentage of RNs and midwives who held an initial registration, a post-registration or a non-nursing/midwifery Bachelor degree had increased to $26.4 \%$ (NCNZ, 2002). However, the influence of $R N$ to $B N$ programmes on these figures is unknown. No published or centralised information on the numbers of graduates from $\mathrm{RN}$ to $\mathrm{BN}$ programmes was found. While some statistical information on qualifications is recorded by NCNZ, along with the number of graduates who receive their registration, only the latter information is published regularly. Rather (1993) argues that "the whole community of nursing benefits from the advanced learning of one of its members" (p. 111) yet little evidence exists related to the personal or professional outcomes of $\mathrm{RN}$ to $\mathrm{BN}$ programmes.

Since the inception of $\mathrm{RN}$ to $\mathrm{BN}$ programmes there have been ongoing developments in NZ nursing education and professional nursing. More RNs are gaining post-graduate qualifications and, increasingly, nurses are encouraged to embrace education as a strategy to advance practice and meet the continually changing needs within healthcare. Advanced practice and a scope of practice for Nurse Practitioners has become a reality. The introduction of the Health Practitioners Competence Assurance Act (2003) gave NCNZ the authority to require RNs to provide evidence of their ongoing education. How these changes have influenced the continued viability of $\mathrm{RN}$ to $\mathrm{BN}$ programmes is also unknown.

In short, little is generally known about $\mathrm{RN}$ to BN programmes. No literature was found that described how or why these programmes were established, other than that they were established alongside the development of pre-registration degree programmes. Information with respect to the numbers of these programmes, the length of time each has run or the numbers of graduates they produce is lacking. There is also an absence of data about why RNs would choose this particular education option, their experience of that choice and the personal and professional impact of having completed a $\mathrm{RN}$ to $\mathrm{BN}$ programme. 
My intention with this research was to fill some of these gaps, specifically to:

- identify the reasons RNs chose the option of an undergraduate nursing degree

- explore the personal and professional significance of obtaining an undergraduate nursing degree as a registered nurse

- begin to identify the place and significance of degree transition, $\mathrm{RN}$ to $\mathrm{BN}$, programmes for nursing education and professional nursing in NZ.

My aim was to consider both the personal and the national professional perspectives of $\mathrm{RN}$ to $\mathrm{BN}$ programmes. There was also a necessity to explore the complex context in which these programmes were embedded. The choices of individual RNs are inextricably linked to the contexts of nursing education, practice, professional nursing and historical change. Change is also ongoing, so there was a need to capture both the development of these programmes as a response to change and how subsequent changes have influenced the viability and place of these programmes. To achieve this in-depth view a case study approach was utilised, informed by the work of Stake $(1995,1998)$, using a mixed method design. Stake argues that case study is often "no "choice" at all" (1995, p. 3) because we need to learn about a particular case, as we have an intrinsic interest in that case. The focus of my interest was always $\mathrm{RN}$ to $\mathrm{BN}$ programmes in NZ. Case study is primarily about capturing the complexity of the case and it permits the "detailed, extensive study of a particular contextual, and bounded, phenomenon" (Luck, Jackson, \& Usher, 2006, p. 104). The use of mixed methods allowed the case to be explored from a personal, national and professional perspective. While the structure and detail of $\mathrm{RN}$ to BN programmes are unique to $\mathrm{NZ}$, the phenomenon of RNs obtaining an undergraduate degree is international and informed the understanding of this intrinsic case study. The research methodology is discussed further in Chapter Three.

\section{The position of the researcher in this study}

My interest in degree qualifications in nursing is both personal and professional. As a RN who commenced study towards a Bachelor degree before pre-registration degree programmes existed, I received almost no academic credit for my registration and experience. Like many, I juggled employment, a young family and study over a long period to achieve a Bachelor of Arts degree. With the introduction of pre-registration degree programmes in the 1990s, colleagues were obtaining academic credit for their registration, enabling them to achieve a Bachelor degree in less time, and to progress to post-graduate study. Employment as a nurse educator in the 
polytechnic sector, both prior to and following the introduction of pre-registration degree programmes, has provided personal experience of change in nursing education. As an educator I have worked extensively with RNs studying to obtain a BN degree, having been programme coordinator and facilitator of the core paper of the programme. This brought me into close acquaintance with the differing experiences and opinions surrounding RNs obtaining a degree. It included witnessing the struggles and achievements of RNs who chose this option. Additionally, I have a strong interest in the development of nursing as a profession, having observed and contributed to policy and initiatives to progress the scholarship and professionalism of the discipline.

This background and experience created a particular interest in the pathways taken by RNs to obtain an undergraduate degree. In my employing institution the $\mathrm{RN}$ to $\mathrm{BN}$ programme was considered from its inception to have a limited life. It was anticipated that those nurses who wanted to upgrade to a degree would take the opportunity relatively soon, and those who could, would go straight into post-graduate education. The numbers interested in the transition programme would then fall and the course would no longer be viable. Yet little data existed to confirm these predictions. The numbers of RNs locally or nationally without a degree or higher qualification who may require or be interested in an undergraduate degree option was not known. This dearth of information had implications for long term planning and discussions regarding the continuation of the RN to BN programme. Nationally and professionally there appeared little consensus regarding these programmes, with some institutions closing programmes while others continued to offer them. Anecdotally, evidence revealed differences in programme requirements and delivery format between institutions. At the commencement of this research, the programme at my employing institution was set to continue with increasing, rather than decreasing numbers. At the same time the demographics of students were changing, with increasing numbers of students having first registered overseas. 


\section{The significance of this study}

A highly professional, well-educated nursing workforce is required to meet the demands and complexities of the current healthcare environment. It has been demonstrated (Aiken, Clarke, Cheung, Sloane, \& Silber, 2003) that significantly better patient outcomes and lower mortality occur when nursing staff have a higher educational level. The move to degree-qualified nurses is an international trend related to the increasing professionalism of nursing, the need to develop nursing knowledge to match the complexity of modern nursing and healthcare, and the requirements for nurses to utilise critical reasoning and decision-making that is evidence-based, along with the drive for life-long learning (Davey \& Robinson, 2002). Change in professional nursing and nursing education is ongoing and this research will contribute to understanding individual and national professional responses to change.

For RNs without a Bachelor qualification, this study will illuminate the reasons and experiences of some RNs who have chosen the option of obtaining an undergraduate nursing degree via a RN to BN programme. Studies (Davey \& Robinson, 2002; Delaney \& Piscopo, 2004) have shown that many RNs do not see any value in completing further qualifications that do not bring financial or perceived career rewards. Gaining insight to the benefits and costs experienced by RNs who have completed a BN will better inform those who may be considering this option.

This study will also provide information for managers and employers of RNs on the outcomes, benefits and support required by RNs for the successful completion of an undergraduate nursing degree. International research has noted increased job satisfaction, improved practice outcomes and increased retention in employment as outcomes of RNs returning to study to obtain a degree (Hardwick \& Jordan, 2002). Such findings in the New Zealand context may encourage employers and managers to provide increased support for such study.

Similar to other responses to changing requirements, $\mathrm{RN}$ to $\mathrm{BN}$ programmes are perceived by many nurses and educators as having a limited life. For education providers to make informed decisions on the continuation of such options they need data on the numbers of RNs potentially interested in such programmes, the reasons RNs undertake this degree and the personal and professional benefits identified from completing the programme. Also, an understanding of RNs' experiences studying in a $\mathrm{RN}$ to $\mathrm{BN}$ programme and their perceptions of what supported their 
educational experience could assist education providers to offer appropriate assistance. It may also inform their programme evaluation processes.

Leaders of nursing need to be acutely aware that change in nursing requirements or nursing education impacts on individual nurses, and on the profession as a whole. They also need to have some inkling of the type of national and individual responses that may occur. By providing an example of a previous response to change, this research may encourage nursing leaders to give more consideration to the impacts of change and to put in place adequate policy or consensus to support possible responses. By providing data on the place and significance of $\mathrm{RN}$ to BN programmes, nursing leaders and institutions can make informed decisions as to whether these programmes should continue or how long they should continue. A clearer picture of these programmes and their worth for individuals may make the profession inclined to consider the issue of national consistency, such as ensuring the programme is offered in a more standardised form or that there are a designated number of institutions providing this option.

\section{Chapter review and thesis overview}

Change in nursing education is ongoing. This thesis concentrates on one response to the introduction of pre-registration degree programmes, $\mathrm{RN}$ to $\mathrm{BN}$ programmes, an arrangement established to enable existing $\mathrm{RNs}$ to obtain an undergraduate nursing degree. These programmes still exist today and their presence has significance for, and impact on individual RNs and the wider nursing profession. Currently, there is an aspect of invisibility surrounding both the programmes and the RNs who take advantage of this route to BN status. By utilising mixed methods in a case study approach that considers both personal and national professional perspectives, this research aims to provide a comprehensive description of $R N$ to $B N$ programmes, including their historical evolution through to their place in nursing education and practice today.

Chapter Two provides an overview of the literature related to this research. Given that much of the literature on $\mathrm{RN}$ to $\mathrm{BN}$ programmes is international in origin, an overview of the international context is provided. Debates surrounding an undergraduate nursing degree for RNs are explored, along with motivation and barriers experienced by those who undertake such study. The challenges, benefits and outcomes of these programmes are also investigated. This review of the literature provides many of the questions explored in developing the case. 
Chapter Three explains the choice of case study as the research strategy for this study. As controversy surrounds the use of case study for research, explanation is provided to validate the fit of the research strategy to this study. The case, the methods of data collection and analysis are then described. Ethical issues and questions of rigour are also discussed.

The fourth chapter of the thesis presents the findings from the national and professional perspective of the case. The historical, educational and professional environment surrounding the case is described along with the results from a survey of all Schools of Nursing. An analysis of the statistics available on the numbers of RNs with degree or higher qualifications is also presented.

Chapters Five and Six provide data from the personal perspective of this case. Interviews with eight graduates of an $\mathrm{RN}$ to $\mathrm{BN}$ programme reveal the reasons for, and experience of undertaking study towards a degree through a RN to BN programme. The findings highlight difference in the costs, benefits and outcomes of these programmes experienced by graduate RNs.

The final chapter discusses the findings of the research and considers how the different perspectives inform our understanding of the case. The future of RN to BN programmes is considered and recommendations are made. The limitations of this study are acknowledged and areas for further research are highlighted. 


\section{CHAPTER TWO}

\section{Literature Review}

\section{Introduction}

This chapter reviews the literature related to registered nurses (RNs) obtaining an undergraduate nursing degree. The majority of research in this area is international in origin, coming predominantly from the United States of America (USA), the United Kingdom (UK), and to a lesser extent Australia. To contextualise the literature and show the relationship between undergraduate degree programmes for RNs and the national and professional situation, it was considered necessary to outline each country's progress in establishing a degree as the requirement for entry to nursing. This also highlights the professional trends and commonalities between countries. Canada was not included, despite its links with New Zealand (NZ) nursing education, because even though programmes for $\mathrm{RNs}$ to gain an undergraduate degree are offered within the country, no research and little associated literature was found. The similarities, issues and debates arising from this overview are discussed and related to the programmes available to RNs interested in gaining a degree. The literature search explored material from nursing and educational sources which examined the motivation or reasons for choosing an undergraduate nursing degree, the challenges and barriers RNs faced, the characteristics of RNs returning to degree study and the outcomes and benefits of obtaining a degree. The review focused largely on material from the last 10 years as older material was mainly from the USA. Studies were critically explored for their relevance to this research.

As this research addresses both the personal and the professional significance of undergraduate degree programmes, both these aspects are considered in this literature review. Most research internationally has focused on one or other of these aspects, but not both. Specifically excluded from the discussion in this chapter is a substantial body of literature related to the curriculum and teaching and learning aspects of degree programmes for RNs. Seaton's (1998) NZ study considers possibilities for teaching and learning for returning RNs, while most other literature related to curriculum, learning and teaching is American in origin. Areas addressed in this body of work include innovative approaches and empowerment (for example: Diekelmann, 1993; Rodgers \& Nealand, 1993; Worrell, McGinn, Black, Holloway, \& Ney, 1996), ways of learning and teaching (for example: Callin, 1996; Cangelosi, 2004; Eyres, 1993; Hayes, Kienholz, Engel, \& Mishra, 1993; Hodges, 1996), student centred curricula (for example: Hegge, 1995; Rusin, 1993) 
and much more. Research related to adult education and returning adults to higher education, mainly found in the educational literature, was considered but is not specifically addressed because it provided similar themes to those described in literature related to returning $\mathrm{RNs}$ and was not deemed central to this study.

\section{Country specific contexts}

New Zealand is similar to the USA, the UK and Australia in that early nursing was built on the Nightingale model of hospital-based, apprenticeship-style nurse training. Each country subsequently developed its own standards and regulatory mechanisms for education and registration. However, since early times NZ nursing has been influenced by the trends and literature from these countries with nursing leaders and health managers frequent visitors. Nursing education in each country is shaped by their economic, educational and health systems as well as the influence of their own professional nursing bodies. As this context is inextricably linked to the decisions and experience of RNs who study for an undergraduate nursing degree, it is essential to provide some description of the context of these countries.

\section{The USA context}

The USA was the first to move nursing into academia with a degree programme at the University of Minnesota established by 1915 (Woolley, 2004). Despite this bold first move, the USA has made the slowest progress in advancing entry to the profession. During the 1920s and 1930s, university baccalaureate degree programmes for nurses were developed throughout the USA but their expansion was slow (Lusk, Russell, Rodgers, \& Wilson-Barnett, 2001). By the mid-1930s Yale University had a programme that "admitted only college graduates and granted a Master's degree after 30 months" (Woolley, p. 34). Several colleges also offered RNs what they called 'post-graduate education' but Woolley argues that this was mainly certificate programmes. By the 1940s some colleges offered a five-year programme that was really a three-year hospitalbased programme plus two years of college courses. A nursing shortage after World War Two and a lack of sufficient university programmes led to the introduction of nursing education in the less-expensive community colleges. A 1952 research project from Teachers College, Columbia University led to the establishment of two-year associate degrees based in community colleges. Fifty years later there are more than 800 associate degree programmes in the USA (Mahaffey, 2002). 
Currently the USA has three distinct educational nursing programmes that prepare applicants for registration. They are the three-year hospital diploma, the two-year associate degree, and the four-year baccalaureate degree, usually called a Bachelor of Science degree in Nursing (BSN). All nurses must pass the same national licensing examination to become registered and as RNs they undertake similar roles. In 1965 the American Nurses Association (ANA) recommended that a baccalaureate degree should be the entry standard for 'professional nurses' and that associate and diploma school graduates were to be called 'technical nurses' (Donley \& Flaherty, 2002). Individual states license nurses and with 51 state legislatures each must be convinced that changes are necessary for there to be unified entry to practice (Smith, 2005). A further resolution for degree level entry was passed in 1995 but while the number of diploma programmes has declined (Lusk et al., 2001) little else has changed. Warren (2004) notes that

In 2000, forty percent of nurses received their basic educational preparation as an $\mathrm{RN}$ from associate degree programs. Equal proportions of nurses (30 percent) received their basic degrees from diploma and baccalaureate programs.... Of those prepared at the AD level 16 percent returned to school and 24 percent of those prepared in diploma programs obtained post RN or nursing related degrees. The majority of practicing RNs, 56.6 percent, have less than 4 years of education. (p. 1)

One state, North Dakota, established the baccalaureate degree as the minimum requirement for entry to practice in 1987, granting transitional licensure to those who met the educational requirements. However, following legal action a bill was passed requiring the Board of Nursing to grant full licensure to nurses with transitional licensure and to approve programmes of fewer than four years (Smith, 2005). The Association of California Nurse Leaders (ACNL) developed a strategy of building coalitions and providing funding to support their position that by 2010 the baccalaureate degree will be the requirement for all new nurses. New York State has also discussed implementing a 10 year timeframe for RNs to gain a degree. These latter moves for change are yet to be tested.

\section{The UK context}

In the UK hospital-based training was the basis of nursing education until the 1960s and the majority of nurses were prepared in this way until 1989. However, as early as 1898 there were 
calls from Ethel Fenwick for degrees in nursing (Robinson, Murrells, Hickey, Clinton, \& Tingle, 2003). Attempts to set up courses in the early 1900s were thwarted and the first links with higher education occurred with a course developed at Edinburgh University in the mid 1950s (Owen, 1988). Integrated courses were later established at Manchester, Southampton and Surrey universities. While graduates received a degree and registration as a nurse, the degree courses were linked with other subjects rather than 'in' nursing. The first degree 'in' nursing was at Manchester University in 1969 (Robinson et al.). Degree linked schemes and nursing degrees expanded during the 1970s, with polytechnic degree courses in nursing starting in the mid 1970s. By 1982 there were 17 universities and polytechnics involved in the professional preparation of nurses and this number had doubled by 1990 (Akinsanya, 1990). Debate and only gradual acceptance surrounded the move of nursing education into tertiary education as proposed by the United Kingdom Central Council for Nursing, Midwifery and Health Visiting (UKCC) report "Project 2000: A New Preparation for Practice" (Akinsanya; Lusk et al., 2001; Owen; UKCC, 1986). With government acceptance of the "Project 2000" proposal, a relatively rapid transfer of education from hospital schools occurred from 1989 and was completed by 1996. At this time polytechnics and technical institutes amalgamated with or became fully fledged universities following the passing of the Further and Higher Education Act 1992.

Hence a three-year university-based diploma programme became the main route to registration as a qualified nurse. Students followed a common foundation programme in their first year, and then completed two years' activities specific to their registration in one of four branches, adult, children's, mental health or learning disabilities (Lusk et al., 2001). After some disagreement within the profession about whether it was possible to create a quality nursing degree in three rather than four years, the first three-year degree courses leading to registration were introduced in 1994 (Robinson et al., 2003). Since then there has been a steady increase in the number of three-year degree places available.

Currently a diversity of provision for nursing education exists. All programmes are universitybased but both three-year diploma and a three-year degree programmes leading to registration are available. A small number of four-year degrees still exist. Degree programmes have a higher entry criteria and different content and assessment than diploma programmes. There is no externally set or national examination on completion of either the degree or the diploma programmes. The statutory body reviews the assessment procedures of each university and curriculum. The majority of students qualify at university diploma level (Lusk et al., 2001) 
because they are eligible for a non-means-tested bursary and maintenance grant while degree students have a means-tested bursary and student loan. On graduation RNs with diplomas and degrees take on similar roles. Diploma-level students can transfer to degree courses or opt to 'top up' their diploma to a degree in nursing at a later stage through post-diploma, part-time programmes.

In the UK there has been extensive debate around making entry to the profession only by degree (e.g. Azuine, 2003; Glasper \& O'Connor, 1996). Arguments for this standard include enhancing recruitment, raising status for nursing and developing competencies for contemporary care, while arguments against include difficulty with recruitment, academic barriers to less-qualified staff and less diverse social backgrounds in applicants. Retention and the lack of sufficient practical skills are also mentioned (Robinson et al., 2003). Disagreement about what constitutes degree level, and difficulty distinguishing between diploma and degree RNs, have led to comments such as "if UK nursing diplomas are really at degree level, then why not call them degrees?" (Glasper \& O'Connor, p. 5). By 2003 Scotland and Wales had moved to degree as the requirement for entry to nursing, with Northern Ireland committed to abolishing their diploma-level courses (Parish, 2003). England, however, voted in 2003 to retain diploma programmes alongside degree programmes.

\section{The Australian context}

In Australia the transition to a degree as entry to the nursing profession is complete. This has occurred despite resistance to change from the system of hospital-based nurse training first introduced into Australia in 1868 by Lucy Osburn, a Nightingale trainee (Lusk et al., 2001; Russell, 1990). Hospital-based training had appeared successful in improving the quality of nursing services and providing a cheap, heavily disciplined workforce (Russell, 2005). Standardised government control occurred through the equivalent of statutory authorities in each state and territory. However, in the 1960s and 1970s nursing in Australia went through considerable professional and industrial turmoil. A plethora of expert committees and workshops investigated a number of aspects of nursing, including nursing education. Russell (2005) concludes that while little immediate action resulted, the ensuing vigorous discussion and debate, both within and outside the nursing profession, created a climate for change. 
By the late 1970s alternative patterns of pre-registration nursing education were introduced. Many were 'pilot' programmes or trials of a variety of alternatives for nursing education. These included regional hospital-based schools of nursing affiliating to the higher education sector; regional schools of nursing situating with the Department of Technical and Further Education (TAFE); combined nursing, arts or science degrees being established within universities; and undergraduate two and three-year programmes commencing within Colleges of Advanced Education. The newly developed Colleges of Advanced Education provided undergraduate, vocationally-orientated diploma programmes that were strongly linked to industry (Lusk et al., 2001).

A working party with representatives from all major nursing organisations across Australia was established in 1973 to develop clear goals for nursing education. This led to the publication of "Goals in Nursing Education: Part 2' in 1975, by the Colleges of Nursing (Marquis, Lillibridge, \& Madison, 1993). Russell (2005) believes this publication assisted the profession agreeing that nursing education "should be at undergraduate two (UG2) level with the Colleges of Advanced Education Sector throughout Australia" (p. 3). Marquis et al. claim that while there was little political opposition to this, neither was there a push by officials to make it happen. They assert that the catalyst came when the state of New South Wales faced a funding crisis in healthcare. Moving nursing education from the health budget to the education budget was a budgetary solution. On 7 November 1983 the State's Minister of Health made an announcement that all basic nurse education would transfer into the higher education sector by January 1985 . Nursing education would be at comprehensive UG2 level, preparing nurses to practise in all major areas, such as general, medical/surgical, psychiatric and developmental disability nursing. This was followed by the Federal government announcing in August 1984 that it gave in-principle support for the full transfer of nursing education into the tertiary education sector. While the transfer occurred at varying rates in each state and territory, the last hospital-based intake was in Queensland in 1990 (Lusk et al., 2001), completing the transfer of nursing education into the tertiary education sector by 1993 .

When nursing education was moving into the tertiary education sector, Australian higher education was effectively comprised of three tiers (Stein-Parbury, 2000). Technical and vocational educational institutions comprised one tier while traditional universities comprised another. In between these sat the third tier, referred to as Colleges of Advanced Education, which at the time of the transfer could not offer educational awards at the level of Bachelor 
degree or beyond. In 1989 the advanced education sector was abolished with the amalgamation of Colleges of Advanced Education into the university sector and the establishment of the Unified National System of Higher Education. According to Lusk et al. (2001) this change in national education provision placed a question mark over the future of newly established nursing diploma courses. They explain that the outcome was relatively positive.

It was finally proposed by the Australian Education Council that the initial qualification for those undertaking registered nurse education should be a threeyear bachelor degree. Efforts by the profession to secure a four-year (honors level) bachelor's degree as the norm were unsuccessful. The target year for all nursing programs in the higher education sector to be at degree level was set as 1992 - a target that has now been reached. (p. 199)

Across Australia there are 31 higher education institutions offering courses that lead to registration as a nurse (Fernandez, 2005); all are three-year undergraduate Bachelor of Nursing (BN) degree programmes. There is no national licensing examination. Each state or territory has its own statutory authority that accredits individual university programmes against the specific requirements of that authority. These statutory authorities, nurses' registration boards, are under the auspices of state and territory governments but function independently though state legislation (Stein-Parbury, 2000). Once nurses have completed their BN degree they apply to the statutory authority for registration. Changes are currently occurring with moves to establish a national registration system. As education standards changed, existing $\mathrm{RNs}$ had the option to upgrade their qualification to a BN. According to the Australian Institute of Health and Welfare (News, 2002, p. 6), "commencements reached a maximum of 3,778 in 1995, making up $57 \%$ of all post-basic nursing commencements in that year, and have declined steadily since then". Australia is acknowledged as the global leader in the movement to higher education and degreelevel entry to the profession, because in 1994 they were the only country to have upgraded all $\mathrm{RN}$ preparation to Bachelor degree level.

\section{Similarities, issues and programmes for RNs}

This overview shows that changes in nursing education, while significant, have obvious similarities across each of the three countries and with the changes that have occurred in NZ. Countries have moved from hospital-based training to tertiary-based education in varying ways 
and at different rates. The current forms of nurse education and entry requirements of each country are directly attributable to the type and pace of change in nursing education (see Table 1). Both the USA and the UK continue to have the majority of their nurses register without a degree-level qualification, hence the need for, and literature related to degree programmes for registered nurses. Australia's nursing education is similar to that in NZ with entry to the profession only by degree, so programmes for RNs are only applicable to those who registered prior to this change, which for Australia is before 1992. Of note from this review is that Australia and the UK, like NZ, initially wanted a four-year degree programme leading to registration and there were significant changes within their tertiary education sector that positively influenced the availability of degree level programmes for nursing. This connection between the education sector, nursing and qualification escalation is further explored in Chapter Four. The USA, which did not undergo the same philosophical educational change, has yet to achieve degree-only entry for nursing.

Table 1: Overview of nursing education and entry to practice in USA, UK and Australia

\begin{tabular}{|c|c|c|c|}
\hline & USA & UK & Australia \\
\hline $\begin{array}{l}1^{\text {st }} \text { degree } \\
\text { programme }\end{array}$ & $\begin{array}{l}1^{\text {st }} \text { degree programme } \\
1915\end{array}$ & $\begin{array}{l}1^{\text {st }} \text { degree programme } \\
1950 \text { s }\end{array}$ & $\begin{array}{l}\text { 1960s-1970s 'pilot' } \\
\text { alternatives in tertiary } \\
\text { sector }\end{array}$ \\
\hline $\begin{array}{l}\text { Transfer to } \\
\text { tertiary sector }\end{array}$ & & $1989-1996$ & $1985-1993$ \\
\hline $\begin{array}{l}\text { Routes of entry } \\
\text { to nursing }\end{array}$ & $\begin{array}{ll} & 3-y r \text { hospital diploma } \\
& (30 \%) \\
\text { - } & 2-y r \text { associate degree } \\
& (40 \%) \\
\text { - } & 4-y r \text { baccalaureate } \\
& \text { degree }(30 \%) \\
\end{array}$ & $\begin{array}{l}\text { - 3-yr university-based } \\
\text { diploma (majority) } \\
\text { - 3-yr university-based } \\
\text { degree } \\
\text { - 4-yr university-based } \\
\text { degree (few) }\end{array}$ & $\begin{array}{l}\text { 3-yr university-based } \\
\text { Bachelor degree } \\
\text { since } 1992\end{array}$ \\
\hline $\begin{array}{l}\text { National } \\
\text { licensing exam }\end{array}$ & Yes & No & No \\
\hline $\begin{array}{l}\text { Role of different } \\
\text { types of } R N s\end{array}$ & $\begin{array}{l}\text { All RNs undertake } \\
\text { similar roles }\end{array}$ & $\begin{array}{l}\text { All RNs undertake } \\
\text { similar roles }\end{array}$ & $\begin{array}{l}\text { All RNs undertake } \\
\text { similar roles }\end{array}$ \\
\hline $\begin{array}{l}\text { Change in the } \\
\text { tertiary education } \\
\text { sector }\end{array}$ & & $\begin{array}{l}1992 \text { Further \& Higher } \\
\text { Education Act }\end{array}$ & $\begin{array}{l}1989 \text { Unified National } \\
\text { System of Higher } \\
\text { Education }\end{array}$ \\
\hline $\begin{array}{l}\text { Degree } \\
\text { programmes for } \\
\text { RNs }\end{array}$ & $\begin{array}{l}\text { RN to BSN programmes } \\
\text { for hospital diploma and } \\
\text { associate degree nurses } \\
\text { via a variety of options }\end{array}$ & $\begin{array}{l}\text { Credit accumulation and } \\
\text { transfer schemes (CAT) } \\
\text { Modules worth varying } \\
\text { credits are available to } \\
\text { RNs to 'top up' their } \\
\text { diploma to a degree }\end{array}$ & $\begin{array}{l}\text { For RNs registered } \\
\text { before } 1992- \\
\text { conversion programmes } \\
\text { Enrolments peaked in } \\
1995\end{array}$ \\
\hline
\end{tabular}


Programmes for RNs to obtain a nursing degree reflect the diversity evident in education leading to nursing registration within and between countries. In the USA mobility programmes for RN graduates from diploma and associate-degree programmes developed in the late 1960s (Horne, 1993). In some cases, a separate track within the four-year generic baccalaureate programme was developed and in others an upper division degree programme that admitted only RNs was established. The RN student group was mixed, with diploma graduates outnumbering associate degree graduates two to one and the average age of students being 28.2 years (MacLean, Knoll, \& Kinney, 1985). It was evident from the literature that programmes have changed and developed over time but some themes remain. The description of an early RN to BSN programme identified granting credit for previous learning as a difficult issue (MacLean et al.). A solution for some courses was for students to demonstrate knowledge by examination and gain credit, but this caused a high level of anxiety. A number of American authors (e.g. Beeman, 1990; Horne; VanCott \& Lengacher, 1993) have highlighted the frustration felt by returning RNs and critiqued the educational obstacles that these nurses face. Difficulties include the denial of credits to students, the duplication of nursing knowledge and experience, and the variance in total numbers of units or credit hours required for graduation. Horne says that the denial of credit to students is just another example of "institutional chauvinism" (p. 63). Many universities now offer credit automatically on successful completion of certain papers or because of arrangements with training institutions.

How programmes are offered has also changed. MacLean et al. (1985) reported that students were required to undertake at least two of the four clinical practicum papers and could complete the four-year baccalaureate degree in as little as 16 months, though most RNs took four to nine terms (with a maximum of three terms a year possible). Descriptions of more recent programmes demonstrate a variety of study options such as on-campus, online delivery and blended delivery, where students do a mixture of online and classroom learning (Benjamin-Coleman, Smith, Alexy, \& Palmer, 2001; Bentley, Cook, Davis, Murphy, \& Berding, 2003; Brownson, 2005; Cragg, Plotnikoff, Hugo, \& Casey, 2001; Waddell \& Hayes, 2000). External degree programmes, including televised and self-study courses, focus on independent study and skills testing (Brownson, 1997). Often students are still required to take a challenge test and some schools require one or more campus visits, called residencies, for a day or a long weekend. Supervised practicum does not appear to be included in online or blended delivery options, but are included in some on-campus courses. Changes to the way programmes for RNs are offered also occurred in NZ and are discussed in Chapter Four. 
The UK system is more recent and less diverse. RNs can upgrade to a degree through credit accumulation and transfer schemes (CAT) by undertaking short programmes of study (Davey \& Robinson, 2002). They effectively 'top up' to a degree by gaining the number of credits required. Courses are made up of a series of modules for which a number of 'credits', usually 10 or 15 , can be obtained. Currently a diploma is considered level two, 240 credits, with a degree being at level three, 360 credits. Accreditation of prior learning exists. While most degree study is generic, specialist pathways are also available with credits at different levels. Specialist pathways include areas such as critical care, mental health or care of the older person (Thompson, 2001). The NZ system is similar to this, with existing RNs being considered at diploma level and usually required to complete units or papers that are worth varying credits to bring them up to the total number of credits required for a degree.

A range of terms appear in the literature to describe the phenomenon of RNs obtaining a degree. Articles from the USA use terms such as 'going back to school', RN to BSN and RRNs while the UK literature talks about post-registration education and degree programmes for qualified nurses. Australian literature talks about conversion programmes and upgrading to a degree. Few Australian articles were found, probably due to the relatively rapid introduction of pre-registration degree programmes. There were more discussion and less research articles in the UK literature while the reverse appeared the norm for American literature. Literature on perspective transformation, motivating factors, incentives and curriculum debates was more likely to come from the USA, while consideration of the difference between diploma and degree nursing education and the significance of level appeared more often in UK articles. Arguments for and against a degree as entry level to the nursing profession is regularly intertwined in the USA and UK literature that considers degree programmes for RNs.

\section{Debates surrounding a degree as a requirement for nursing practice}

The international disagreements on whether a degree-level qualification should be the standard for nursing registration are underpinned by certain beliefs and opinions about nursing, many of which exist in NZ. These opinions create the attitudes that surround RNs and ultimately influence their decisions on whether or not to obtain a degree. Glass (1998) identifies the contested workplace' as the environment RNs studying towards a degree must face. Within the RN workforce there are different views about whether any nurse requires a degree-level qualification 
for nursing practice. The basis of arguments for and against the preparation of nurses at degreelevel are essentially the same reasons used to justify positions on RNs obtaining a degree and so need to be considered.

One factor influencing this debate is the tension between academic knowledge and practice. While often framed as the 'theory-practice gap', there are many aspects to this debate. Chandler (1991) argues that different types of knowledge attract different levels of social kudos with knowledge and power connected, so discussion on changes in nurse education concern power and the debate on the professionalisation of nursing. The status of a discipline is closely associated with the length and rigour of the education required for entry to practice, with these requirements progressively increasing for the traditional professions of law and medicine (Joel, 2002). In nursing, where professional status is debated, changes in educational requirements have been constrained by service needs and the employee status of nurses. More status is given to abstract and theoretical knowledge, so nursing's desire for a degree as the entry standard was part of a trend for more theoretical knowledge and status that occurred in a number of disciplines. Arguments have consistently been made (Akinsanya, 1990) that professional autonomy for nurses necessitates the acquisition of educational qualifications comparable with other health professionals. Multidisciplinary working depends on a team of equals, so nursing will never be accorded the respect given to other professions until they have graduate status (Glasper \& O'Connor, 1996; Joel). The hallmark of a true profession is adaptability and Glasper and O'Connor insist that the future will focus on professional roles that involve shared learning. Nursing requires educational parity to join "the other professions who are already members of that club" (p. 6).

Other arguments for nurses having a degree level qualification include the significant changes in healthcare that have occurred worldwide. In the past 20 years more than 30 new diseases have been identified with increasing risk of devastating international pandemics (Domino, 2005). Globally populations are growing and aging, technology is producing increasingly complex and sophisticated equipment and need is outstripping resources. A new consumerism, diminished use of in-patient facilities along with increased focus on quality assurance, patient education and service utilisation are changing practice requirements. Health professionals must cope with continuous change and be able to respond swiftly. Life-long learning and higher education are proposed as the strategies to maintain safety and competency in these conditions (Domino). 
Increasing emphasis on and availability of education has occurred worldwide, meaning many professions have been experiencing qualification escalation.

Nursing's move to tertiary education institutions has had advantages and disadvantages for the profession. The broader learning environment has allowed more emphasis on primary healthcare principles and incorporating research findings into practice. There are frequent challenges from within and outside the nursing profession that an academic idealist approach and theoretical knowledge will not make a good practical nurse. Papps (1997) identifies that the "over education" (p. 94) of nurses is a recurring theme in nursing education, particularly arising when requirements are raised. Additionally, a less occupationally subordinate nurse is not always desired by other health professionals and management. Battles for status, reward and autonomy have followed changes in nursing education. The move to higher education for nursing is supported by the International Council of Nurses (ICN) who note that "university preparation is essential if nursing is to receive the public trust as a profession and, accordingly, be granted the accountability and rewards of professionals" (ICN, 2006, p. 12).

While the argument for a well-educated, professional nursing workforce to meet the demands of increasingly complex health needs seems obvious, some dispute the value of a degree. Opponents argue that attempts to professionalise nursing encourage elitist approaches to education so 'closing' nursing to many potentially suitable recruits (Scott, 1998). In both the USA and the UK many of the arguments against degree programmes centre on recruitment and retention issues. In the USA, where diploma-level programmes provide $60 \%$ of $\mathrm{RNs}$, lower tuition fees, more geographical locations, and a greater representation of minorities are used to justify the retention of these programmes (Mahaffey, 2002). Recruitment fears in the UK are based on the perceived difficulty of degree study, academic barriers to less-qualified staff and a lack of diversity in social backgrounds (Robinson et al., 2003). An argument is also made that with more transferable qualifications graduates are less likely to stay in the profession. Other concerns relate to degree students not developing practical skills and placing more emphasis on technical rather than caring practices. These arguments against a degree-level qualification for preregistration students are also used as reasons for not requiring or expecting RNs to obtain a degree. Fears exist that the expectation to obtain a degree will cause RNs to leave, that some would not achieve this standard or that those who did may choose other employment, and that RNs with a degree will be more theoretical and technically focused and less caring (Glass, 1998). 
Research to distinguish between graduate and non-graduate nurses is problematic, as there are many different degree options available that are frequently altered (Bircumshaw, 1989). A study by Giger and Davidhizar (1990) in the USA found associate and baccalaureate-degree programmes varied in approaches to nursing care with nurses who were degree-qualified more concerned about research methodology, teaching, and assessment. Nurses with a degree were knowledgeable in nursing diagnosis, theoretical identification and process-driven nursing tasks. In contrast, associate-degree nurses were more interested in content driven nursing tasks and technical aspects of nursing, including maintenance of equipment and direct nursing care. Bircumshaw, who reviewed studies that compared the performance of graduates, also found that degree-qualified nurses were more likely to practise professional nursing and consider patients' psychological and social needs. In more explicit research Aiken, Clarke, Cheung, Sloane and Silber (2003) concluded that in "hospitals with higher proportions of nurses educated at baccalaureate level or higher, surgical patients experienced lower mortality and failure-to-rescue rates" (p. 1617). This often-quoted research was based on outcome data, though adjusted for differences in patient circumstances, hospital structures, nurse staffing and nurse experience. Better quality practice and improved patient outcomes provide reasons for RNs to obtain a degree-level qualification.

In the UK, where there is less difference between the types of nursing education, the research does not find conclusive differentiation. Research on what constitutes diploma and degree 'level' and the distinctiveness between them has found that level statements are illusionary with nurse educators unable to recognise the level to which the statements are supposed to relate (Ashworth, Gerrish, Hargreaves, \& McManus, 1999). Purchasers of education in the UK, when asked for their views on an all graduate nursing profession, commented that "nursing is about hands on care" and that graduates "might be unwilling to carry out basic nursing care duties" (Burke \& Harris, 2000, p. 625), yet research (Davis \& Burnard, 1992; Girot, 2000; Jinks, 1994) has consistently shown RNs with degree qualifications provide the same or better quality patient care. Little difference was found in the role orientation and socialisation of graduates (Taylor, Westcott, \& Bartlett, 2001). Research on the careers and competencies of nurses that compared $\mathrm{RNs}$ from three-year degree and three-year diploma programmes at 6, 18 and 36 months after registration found the two groups were objectively similar, with little difference in measurable employment history or ability, but were subjectively different, as graduates had higher career expectations, were less satisfied with their working life and had more intention to leave the profession (Robinson et al., 2003). The conclusion of this study was that the health system does 
not support higher expectations and ambitions. These findings have implications for RNs considering degree-level study. The lack of conclusive evidence on the difference between a degree or a diploma-level qualification further questions the value of a degree qualification for RNs.

\section{Professional attitudes and tension}

The debate and mixed research on the value of a degree for nurses highlight tension and nursing attitudes about professionalism, education, elitism, status and practice. A major point of division is between those who proclaim a degree enhances practice and those who claim it adds nothing (Lillibridge \& Fox, 2005). Esmond and Sandwich (2004), in arguing that fear and niceness are responsible for the division in the USA, claim nurses have a disdain for education along with "fear of unemployment, fear of education and fear of change" (p. 1). These fears and attitudes are evident in NZ where Lowe (2003) says "seemingly every month Kai Tiaki (NZ Nursing Journal) publishes a letter from a nurse frustrated by the requirement for nurses to have university qualifications ... my experience is that university qualifications do not necessarily make better nurses" (p. 4). These reactions are part of what Thompson (1992) calls 'nursing's anti-education bias', a bias which has roots in the belief that nursing is not an academic discipline, does not belong in universities, and glorifies the practical. Thompson identified this attitude in a number of her study participants and noted that it influenced "thinking about returning to school" (p. 99). According to Horne (1993) attitudes of 'professional elitism' contribute to a number of pervasive historical and ideological factors that form barriers for RNs considering returning for a degree. Wilkinson (2007), in discussing the establishment of Nurse Practitioners in NZ, believes concerns of elitist education creating divisions within the profession are firmly embedded within the unionist discourse which aims to value those who want to remain in practice, learning through on-the-job study.

Australian research (Glass, 1998) investigated the attitudes of RNs not participating in degree study as well as those who were and found a high level of hostility and tension in the workplace. This mixed methods research surveyed $529 \mathrm{RNs}$ and interviewed $20 \mathrm{RNs}$. The study identified anti-intellectual and anti-educational feelings in a majority of nurses as well as a perception that studying and caring are dichotomous. RNs without a degree were threatened and defensive, believing they were already 'good nurses' and that they were the 'real' nurses, who cared for and were skilled at looking after people, unlike academic nurses. Seaton's (1998) NZ research with 
11 RNs who returned to study to gain an undergraduate polytechnic degree confirms that a similar situation exists here as "many RN students shared experiences of suffering hostile reactions from colleagues not undertaking the degree course" (p. 128). Additionally, participants in a NZ feminist research study by Blackie (2001), who were RNs working part-time or full-time while also studying, identified negative reactions from both managers and colleagues that ranged from indifference, to resistance and hostility. These RNs made sense of their colleagues' attitudes by understanding that some RNs may feel threatened or fearful. Horizontal violence amongst nurses is well documented. When nurses harbour feelings of a lack of autonomy and powerlessness, they are more fearful and threatened by change. Nurses who perceived that the standing of their education or qualification was being devalued by a system or individuals who were pursuing further education were more likely to demonstrate resistance and react negatively with criticism and undermining comments (Blackie; Glass; Melosh, 1989).

Changing requirements contribute to both fear and motivation. In Seaton's (1998) study some RNs drew a comparison between the phasing out of enrolled nurses (ENs) and the future of nurses without a degree qualification, with one person describing the "realisation that further down the track our experience was going to count for nought" (p. 85). Fear may also come from change that others did not want to have to be involved in and the "fear that they may have to do something else themselves one day" (Blackie, 2001, p. 107). Along with fear, there appeared to be a belief by some that nurses were studying to benefit themselves and not the wider nursing community. Another perspective to emerge from the literature was that colleagues did not understand why RNs took on study when there were no financial rewards, the argument being that "once you were a nurse, you were always a nurse and you don't need to do any further study" (Blackie, 2001, p. 107). This idea that further education is not needed appeared in Dixon's (1996) research with ENs who had undertaken study to gain a RN qualification. Friends and colleagues were surprised at the ENs' plans to upgrade their qualifications saying things like "what are you doing that for, you're already a nurse?" (p. 200). Rather (1993) describes how RNs receive mixed messages as they are given the same positions and responsibilities with or without a degree which resulted in RNs viewing a degree as a credential, "a piece of paper" (p. 105). This sense that a degree really does not mean much leads to the question of this research, which is 'why do some RNs undertake this study?'

Blackie (2001) argues that this lack of understanding or indifference, stemming from seeing little value in doing a degree, actually devalued the worth of what those studying were doing. 
Nicolson (2003), in recounting her experience as an RN studying for a degree in the USA, describes her anger at being told by a colleague that "BN stood for 'Big Nothing'" (p. 10), especially as she and others often undertook study for years to achieve their degree. Studies that reported negative behaviours by non-studying RNs towards those who were undertaking study (Blackie; Glass, 1998), also showed that the support of other colleagues engaged in education ameliorated many of these unpleasant reactions. Nursing is not alone in experiencing these diverse attitudes and tensions. Other health professions, such as physiotherapy and occupational therapy (OT), who have moved from diploma to degree level pre-registration programmes, have also experienced controversy. A UK questionnaire of OTs found a large proportion with the conviction that the academic level of the diploma was equivalent to that of the degree (Gape \& Hewin, 1995).

\section{Motivation and barriers for RNs}

Despite this professional environment of mixed attitudes and tension, many nurses have chosen to study for a post-registration undergraduate degree. The reasons why RNs wished to obtain a degree have been considered from a range of perspectives by a number of research studies and reviews (eg. Carlisle, 1991; Currie \& Bennett, 2000; Dowswell, Hewinson, \& Hinds, 1998; Gould, Smith, Payne, \& Aird, 1999; Warren, 2004). Research by Chiu (2005) confirmed the findings of earlier studies that the motivation for formal learning emanates from RNs' personal and professional lives but that on the whole nurses were self-motivated learners seeking knowledge to increase their professional development. The reasons nurses were willing to commit time and energy, and add stress to already busy lives are multifaceted and interrelated (Currie \& Bennett; Sinclair, 2002). According to Chiu, these reasons include the desire for work-related stimulation, self-growth, compliance with management requirements, professional advancement and keeping up with the profession. Thompson (1992), who explored RNs' participation in baccalaureate degree programmes and interviewed 18 students in pursuit of their degree, confirmed that the nine reasons RNs gave for enrolling in a BSN programme were similar to the rationale given by other adult students returning to study. These reasons included to increase or broaden professional competence, gain a sense of personal achievement, have access to better job opportunities and higher pay, be prepared for new roles and to be prepared should a degree become mandatory. 
Within the personal and professional domains Dowswell et al. (1998) found that motivation was either future orientated (pull factors) or related to perceptions about their past (push factors). Using the findings from semi-structured interviews with 29 nurses, midwives and allied professional staff in the UK they identified four categories to describe motivations and reasons for being involved in a post-registration degree programme. For example, in the category of the personal domain the push to participate described how approximately a third of the participants undertook the course because they identified gaps or failings in their previous education and felt "the need to 'catch up' for personal reasons" (p. 1329). Likewise professional or job-push factors were related to the belief that "they were being 'left behind' by others with higher education" ( $p$. 1330), while personal pull factors included the desire to enhance their own personal continuing development and professional pull factors related to aspirations about future work roles. Dowswell et al. found that professional factors dominated as motivation. The study also noted that many individuals felt pressure from work to attend courses but received little employer support resulting in the effects of the course being felt in the private sphere of home and family rather than the individual's professional role as employee. These findings may have been biased because some participants were enrolled nurses who may have had extra pressure as their qualification had been phased out, and because all participants were working full-time and studying part-time. However, most NZ RNs undertaking RN to BN programmes are working and studying concurrently.

Other UK research (Currie \& Bennett, 2000; Gould et al., 1999; Hardwick \& Jordan, 2002) also identified professional extrinsic motivation, such as enhancing career prospects and staying current, as the prime influence for RNs undertaking degree level study. Currie and Bennett identified "academic insecurity" (p. 34) and "the fear of being left behind" (p. 35) as significant factors for RNs. Although the research was a small scale descriptive survey completed by 37 RNs from one institution, these concepts are supported in other literature. Changes in nurse education meant those who qualified pre-project 2000 "thought they might be 'out-classed' by the new" graduates (Hill, Dewar, \& MacGregor, 1996, p. 328). Using a postal questionnaire of RN graduates Hardwick and Jordan determined that $58 \%(n=25)$ of RNs were influenced by the introduction of higher level pre-registration courses while $51 \%(n=22)$ were motivated by prospects of promotion. Gould et al. who gained data by group interview with $62 \mathrm{RNs}$ from eight different courses, concluded that that the RNs in their study had internalised the state of the healthcare market and the need to fulfil expectations of employers and the public while pursuing professional and career trajectories. These RNs also had a desire to provide high quality care 
and were hopeful that an improved knowledge base would enhance clinical practice. With the UK government backing the philosophy of life-long learning, continuing professional development and the introduction of a new, four level career framework, Dixon and Bramwell (2000) contend that higher education is a necessity for RNs. RNs wishing to achieve level two and above of the career structure outlined in 'Making a Difference', require a first degree or higher. Professional survival is a concept Carlisle (1991) identifies as contributing to enrolments on post-registration degree courses and particularly applies this to nurse teachers, who in the UK are required to be graduates. In NZ there is also a general expectation that nursing lecturers will have a qualification higher than those in undergraduate education. No NZ research was found that specifically explored the motivation of RNs undertaking degree-level study. However, participants in Seaton's (1998) NZ study mentioned some reasons why they had undertaken study while discussing their experience of learning and teaching. These included the comment that they "must now have a degree to 'keep up' with new graduates" (p. 85), and concerns about job security, decreased employment mobility and staying current.

Professional motivations, while still evident, were less significant in research coming from the USA. Wanting 'to 'have an edge' on jobs and career mobility" was a major reason to return to school for RNs on an on-campus part-time BSN programme (Lillibridge \& Fox, 2005, p. 13) but only one third of 36 respondents gave career promotion or professional reasons for undertaking an online BSN in an informal survey by Leonard (2003). Another survey of 101 practising RNs (Delaney \& Piscopo, 2004) found responses focused on personal and professional growth as reasons to gain a degree. A raised level of professionalism was identified but was outweighed by personal satisfaction, improved self-image, feelings of achievement and success and an expanded knowledge base. In the USA organisational incentives and rewards to motivate RNs to return to school were considered. Using a mixed mode survey design to examine demographics, barriers and perceptions to incentives, Warren (2004) concluded that reduced career satisfaction and/or increased professional commitment and a perception that a BSN would lead to greater job opportunities would motivate some RNs to return to school but that only potentially costly organisational incentives would increase these numbers.

Professional extrinsic motivation was not the only force behind the decision to undertake a degree. Personal satisfaction was the highest rated of three main reasons for returning to study in an American survey of RNs enrolled in two online BSN courses (Leonard, 2003). Intrinsic motivation for RNs who have returned to study has been described as the pursuit of learning for 
learning's sake (O'Callaghan, Hau, \& Lebold, 1993), the love for learning, a desire for new knowledge or an inner drive (Seaton, 1998), and intrinsic pressure to achieve (Blackie, 2001). The desire to attend graduate school (Leonard) or the status of having a degree (Pelletier, Donoghue, \& Duffield, 2005) were other aspects of personal motivation. Thompson (1992) argues against studying components of participation, believing it is a holistic phenomenon that is not synonymous with motivation. From in-depth interviews with 18 RNs she identified "commitment - the coming together of attitudes, feelings, and goals in a way that made them 'really want' to participate in an educational program" (p. 103) and the role of life transitions (personal and career) as 'enabling' the opportunity to participate. Commitment and life transitions as enablers develop over time, often years, culminating in "finding the right time" (p. 97), and ultimately enrolment, but are unique to each participant.

Many studies which investigated the reasons RNs undertook study towards a degree also identified barriers to participation (Davey \& Robinson, 2002; Delaney \& Piscopo, 2004; Dowswell, Bradshaw, \& Hewinson, 2000; Leonard, 2003; Thompson, 1992; Timmins \& Nicholl, 2005). Thompson identified three categories of barriers, situational, dispositional and institutional, confirming many barriers are similar to those cited by other groups of adult students. Situational barriers derive from the student's situation in life and consist of family responsibilities and strain on the family due to expense and time demands. Domestic responsibilities, and in particular child care requirements, have been shown to inhibit the uptake of education (Dowswell et al; Price, 2003) and influence the experience of post-registration study (Blackie, 2001; Dowswell et al., 1998; O'Callaghan, et al., 1993; Seaton, 1998). What is less clear is how varying personal and domestic situations impact on RNs. Dowswell et al. $(1998,2000)$ who investigated the influence of domestic responsibilities on motivations and the impact of course participation on home and family life, confirmed that those without children perceived education more positively than those with children, and that study invariably had a negative impact on home and family life.

Most RNs fulfil multiple roles such as homemaker, partner, mother/parent and paid worker, and tend to be older with busy, complex lives (Blackie, 2001; Loustau, 1993; Seaton, 1998). Utilising the literature on social roles and role strain, Dowswell et al. (1998) noted that the demands of different social roles influence the opportunities that people perceive to be open to them. Adding the role of student to a RN's already busy life invariably results in role strain and tension in relationships because of the time and energy requirements. One participant in a study from the USA (O'Callaghan et al., 1993) felt she would still be married if she had not chosen to study 
because "there was just a lot going on" (p. 187). Also, many RNs who undertook formal postregistration study were older women facing change and transitions related to their age and developmental stage, such as children leaving home and aging parents. Blackie's feminist analysis of NZ women nurses engaged in study as well as part or full-time paid work, argues that most women in paid work complete a "second shift" (p. 33) as they undertake the domestic tasks related to families and complete their study during their scarce leisure time. Dowswell et al. contend that while more flexible learning opportunities are being promoted, in reality these courses expect people to take up learning in their 'spare' time and this effectively moves the burden and responsibility from the employer onto the individual. They also argue that structural inequalities in access are turned into attributes of individuals, so that factors constraining participation, such as domestic responsibility, are presented as matters of personal choice. Then ' 'taking the opportunity' is generally interpreted as a sign of failure to 'take responsibility' and evidence of lack of commitment" (2000, p. 447).

Those with domestic responsibilities are less likely to put themselves forward because they perceive the costs, in terms of the effects on other areas of their lives, are not outweighed by putative benefits, such as career advancement. Balancing the cost against the benefit also applies to those who identify advancing age as a barrier (Delaney \& Piscopo, 2004). Other situational barriers include financial cost and inflexible work arrangements. Tertiary level study is expensive with fees, study material and travel costs, yet Oulton (1997) believes that in most countries nurses bear the costs of their own continuing education. Dowswell et al. (1998) found 16 of 29 UK participants were paying the full course fees themselves and that only one participant was fully funded. The majority (19) also had no release time from work. They noted that although most of these students were happy to pay some contribution to costs, fees were associated with real hardship and that a lack of employer support was a source of resentment. Although there is generally agreement, plus infinite rhetoric, amongst the nursing establishment and employers that continuing education "is a "good thing"' (p. 1332), Dowswell et al. argue that staff receive mixed messages because there is little agreement on how much education is needed, what should be provided, who should pay, and how achievement at each particular level is recognised and rewarded.

Similar findings came from another UK study (Hardwick \& Jordan, 2002) where 35\% (15/43) had no study leave and 33\% (14/43) received no funding. In Seaton's (1998) NZ study all participants undertook study initially without employer support, although some did receive financial or time 
assistance as they progressed. Other literature (Blackie, 2001; Gould et al., 1999; Lillibridge \& Fox, 2005) acknowledges variable and inconsistent institutional support related to managers being unsure about the worthiness of a degree, limited resources and the need to meet service needs ahead of perceived individual needs. Staff shortages compound difficulties with approving courses and supporting attendance requirements. However, it is also noted that where RNs were given employer support or acknowledged with increased remuneration, they felt positive and valued. Educational support has been linked with job satisfaction and effectiveness, is a key aspect in Magnet hospitals and is also something that nurses are regularly vocal about (Lillibridge \& Fox).

Dispositional barriers refer to the learner's attitudes towards study and perceptions of themselves. Late returnees to formal education have often experienced failure in the past and built lives around a non-academic self-image (Hill et al., 1996). A lack of confidence in their academic ability to undertake a degree was cited by 53 of 283 respondents who were not planning to obtain a degree (Davey \& Robinson, 2002). McGuire (2004) notes that a lack of confidence is one of the greatest barriers faced by adults returning to education and quotes one returning $\mathrm{RN}$ as saying "I did not want to get left behind but at the same time I was absolutely terrified of studying" (p. 20). A fear of failure and a lack of ability with academic writing skills in returning RNs was also noted (Timmins \& Nicholl, 2005).

Institutional barriers, where aspects of institutions exclude or discourage some students, compound these issues. The difficulties RNs face with admission procedures and recognition of prior learning have already been noted, with other issues characterised as lack of faculty support and respect (Beeman, 1990; Cangelosi, 2004), inconvenient scheduling, inaccessibility and ideological barriers (Horne, 1993), denigration of previous nursing education (Rather, 1994) and content repetition and a lack of clear applicability to practice. Respondents in Delaney and Piscopo's (2004) study wanted simplified processes, more practical courses that were flexible, accessible and supported with financial aid or scholarships. Those in Lillibridge and Fox's (2005) study expressed a desire for special treatment as RNs. They wanted integration and academic socialisation with their peers, not with novices. The majority of research found in this area utilised RNs who had undertaken degree level study, rather than those who had not. Also, no studies were found with RNs who had commenced study but had been unable to continue. This leaves a gap in the literature and lack of evidence about why many RNs choose not to pursue further study. Exceptions to this were Delaney and Piscopo's study, where $10 \%$ of participants saw no 
benefits in obtaining a degree, and UK research (Davey \& Robinson, 2002) found $46 \%$ of a cohort of $620 \mathrm{RNs}$ surveyed eight years post-registration were not planning to undertake degree level study. Some RNs in Blackie's (2001) NZ research had gone straight into post-graduate study without a degree and identified that a degree was of no advantage to them, but details and reasons for this perspective were not explored. More research is required, particularly in the NZ context, with those who have chosen not to gain a degree, to fully understand the barriers and reasons many $\mathrm{RNs}$ do not engage in this study.

\section{The experience, challenges, benefits and outcomes}

Research into the characteristics of RNs studying towards a degree used demographic information, most commonly age, gender, number of years qualified, marital status and whether the RNs had children. The findings of early research (Baj, 1985; Loustau, 1993; vanCott \& Lengacher, 1993) that compared RN students with generic undergraduate nurses are similar to more recent research that identified RNs as mainly women who were older, with children. They were mainly married or divorced, with considerable variation in age and years qualified. Of the 23 RNs who replied to Lillibridge and Fox's (2005) survey, ages ranged from 35 to 52 years, with 4 to 15 years of nursing experience. The average age of $36 \mathrm{RN}$ students in an online BSN programme (Leonard, 2003) was 38.8 years, 66.7\% were married, 69.4\% were parents, $88.9 \%$ worked full-time in nursing and $83.3 \%$ worked in hospitals. UK nurses surveyed (Gould et al., 1999) appeared to have fewer years of post-registration experience with an average of three to five years, despite a range of 1 to 30 years since registration. No NZ demographic information was found other than Seaton (1998), who noted that the participants in her study had been in practice between one and over 25 years and that they worked in a variety of clinical areas in hospitals and the community. vanCott and Lengacher also identified personality, developmental and motivational characteristics of participants, and concluded that RN students were mature, forceful, aggressive and independent with leadership potential. According to Loustau, most were multiple role women who had busy lives but they were highly motivated and academically able students who perceived their education as a life-long process as well as an investment for their future. A limitation of this literature was the decontextualising of characteristics, with no regard given to factors such as culture or ethnicity.

The experience of returning to study to obtain a degree as a RN has been investigated phenomenologically both in the USA (Rather, 1993, 1994) and more recently in the UK (Stanley, 
2003). Rather interviewed 15 RNs from three different schools of nursing and called RRNs "harbingers of entry into practice" (p. 103) because the "entry" issue constituted an important aspect of their experience. They also carried the message to their colleagues that either baccalaureate education was meaningful, or that it was a mistake, depending on whether they perceived their education as transforming their thinking and practice or as boring, repetitious and oppressive. She identified that RNs considered they were already professional nurses and that they did not consider baccalaureate education as remedial but expected advanced learning. RNs enter BSN education with an understanding of nursing practice and what it means to be a nurse so Rather argues that they are more like Masterate students and that their movement into graduate studies needs to be expedited. While this research highlights the significance of the 'entry to practice' issue in the USA, later qualitative research (Lillibridge \& Fox, 2005) noted a decrease in the debate with no participants mentioning this as an issue.

Stanley (2003) used the analogy of a journey to describe the passage nine nurses had undertaken. Four major themes were described as 'the traveller', 'the guide', 'the journey' and 'the journey's end'. Participants described the great pressures they were under, combining work and study, often running a home and caring for children or relatives. The RNs in Loustau's (1993) study also described the stress school added to their lives and talked of the "balancing act, walking the fine line of being happily busy or over the edge" (p. 202). Timmins and Nicholl (2005) described the "constant juggling" (p. 481) RNs do to balance commitments while studying. Strain and tension were identified by Stanley as outcomes of the unrelenting nature of a long part-time course that made nurses vulnerable to ill health. No details were given of any ill health experienced by the participants. Blackie (2001) noted the connection between stressors and health problems in the literature and was surprised to find only one of her participants attributed a health setback to the additional effects of study. She concluded that despite the women describing difficulty surviving at times, they had successfully used coping strategies such as support from partners, family or paid help and decreasing paid work. Stanley also identified the traveller as using coping strategies such as planning, time management and deferral of studies.

Support networks were crucial to successful completion of the journey and these included the tutor, family, colleagues and managers (Stanley, 2003). Feeling supported reduced anxiety and motivated RNs to continue, despite difficulties. Participants required a relationship with their tutors that stretched and encouraged them, while support from managers was mainly through financial help, study leave and encouragement. Price (2003) concluded that lay support 
contributed a significant amount to RNs' progress. Research that included 41 interviews, 59 field observations and 24 tutorial observations identified that the bulk of lay support lies hidden from view. Family and friends provided relief duties, taking over chores or responsibilities; protection duties, such as fending off demands upon the student; and reading duties, critically reading draft work and commenting on ideas and clarity of expression. For study time to be available there needed to be successful negotiation plus supporters committed to take on new responsibilities with students being tolerant of the supporters' mistakes en route. This research demonstrated that males understood the stresses associated with study for RNs but that families had to work very hard with the multiple demands of work, family and study (Price). NZ research (Blackie, 2001) also found support from partners, family and friends reduced the feelings of stress experienced by RNs while studying. RN students felt supported when their efforts were acknowledged, and when others provided assistance or were accepting of their lack of availability.

The journey taken "was often undulating, not linear, suggesting that personal development and growth involve complex transformations as opposed to incremental stages" (Stanley, 2003, p. 67). Measuring the outcomes of such a journey is complex. The desired outcomes of RN degree study include professionalism, career orientation, autonomy and intellectual ability (Maltby \& Andrusyszyn, 1997). As RNs are already socialised into nursing the aim of many degree programmes is to challenge or transform the RNs' perspective of nursing. Perspective transformation, which focuses on integration of experience and new knowledge to construct new understandings and behaviour change based on the new learning, has been repeatedly studied in the USA (Harrington, 1996; Maltby \& Andrusyszyn; Morris \& Faulk, 2007; White \& Gomez, 2002). Most studies identified professional change except research by White and Gomez which found no significant differences in the critical thinking and professional attitudes of a class of 20 RN/BSN students who were tested at the beginning and end of year-long study. Morris and Faulk used a qualitative descriptive open-ended questionnaire with 10 graduates three months after graduation. Although only a small sample, the study showed increased collaboration with healthcare team members, increased patient advocacy, increased confidence in the role of teacher of patients and families, increased consumption of research, and increased autonomy, delegation skills, membership in professional organisations and pursuit of advanced education. Harrington found that professional change was a result of the interrelatedness of personal growth, a body of knowledge, critical thinking skills and communication skills and that while all 
participants felt they had changed, many did not realise this until asked to consider it by the researcher.

The journey's end, finishing the degree, was a key feature of the experience of obtaining a degree (Stanley, 2003). It created a long-forgotten freedom to pursue leisure, family or work pursuits with renewed vigour. This study identified that some graduate RNs felt constrained when wanting to implement changes but that most stayed working in clinical posts, albeit with promotions. In other UK research with a much larger sample, Davey and Robinson (2002) found that over one-third of the $65 \mathrm{RNs}$ who had obtained a degree said it "enabled them to consider job opportunities outside of nursing, although only eight percent had obtained such a job" (p. 629). Nearly two-thirds would consider a wider range of job opportunities within nursing, believing the degree helped career plans and half thought it had contributed to promotions. This may have been related to the fact that for $80 \%$ the major effect of having a degree was increased self confidence. Other benefits were enhanced clinical skills, with more than two-thirds identifying increased autonomy, improved clinical judgement and more effective discussion on treatment. Negative effects were also mentioned with one-third believing having a degree had created tension with colleagues and senior colleagues who did not have a degree.

While obtaining a degree as an RN had personal and professional benefits, only one study was found that specifically investigated the impact of post-registration degrees on practice (Hardwick \& Jordan, 2002). This UK research surveyed graduates from post-registration Bachelors and Masters courses, with 19 of the 43 respondents being Masterate graduates, limiting the applicability to this study. Respondents felt their graduate skills were used in practice and that their clinical practice had changed as a result of their studies but had difficulty giving practical examples, despite specific questioning. Many examples of academic and research skills acquired were cited leaving the authors to question whether degree courses provide academic rather than clinical knowledge or whether workplaces impede the application of knowledge acquired on the courses. Although problems in workplaces were identified, such as not being valued by managers or difficulty implementing changes, these were not universal and it appeared resentment of graduate status was declining. Acknowledging that graduates gain confidence and an improved appreciation and use of research, Hardwick and Jordan contend that this only has an indirect impact on care and patient outcomes. They highlighted that the academic skills component of a degree met the needs of the significant number (13/43) of nurse lecturers but not 
necessarily those in clinical posts. They argue for greater development of clinically focused modules, in addition to research skills, but do note that this was now beginning to occur.

The impact on practice of RNs gaining a post-registration degree remains unclear. A study done in the USA by Aiken et al. (2003) reported a positive impact on patient mortality when more nurses had degrees, but this research was not specifically focused on RNs who had gained an undergraduate nursing degree. Reports from individuals (Konrad, 2005; Richardson, 2001; Struthers, 2003) who have experienced studying for a degree as an RN include comments such as "my degree has given me the ability to provide better care for my patients" (Struthers, p. 3), yet no studies were found that considered any overall or profession-wide improvement in practice, related to increasing qualifications. A gap in the research exists in this area. Additionally, no NZ research has considered the impact of post-registration degrees on practice. Another limitation in the literature was a lack of quantifiable data related to broader professional outcomes from RNs returning to gain a degree, such as the impact of these nurses to overall levels of qualifications, or the numbers who chose to continue on with graduate education. Hardwick and Jordan (2002) comment that their data reflects "a workforce in transition, possibly en route to becoming an allgraduate profession" (p. 530), and that as more managers become graduates, the resentment and barriers described in their study may lessen and opportunities may increase for graduates to deploy their knowledge and skills in the clinical areas. While there is a significant body of literature related to the phenomenon of RNs gaining a post-registration undergraduate degree, most is international in origin and context specific with limited applicability to the NZ context. No studies have considered the impact of this group of RNs on professional nursing in New Zealand.

\section{Chapter review}

In this chapter literature related to RNs obtaining a degree has been presented and this informed the research questions and issues examined during the study. The literature review has shown that the move to an undergraduate degree as the level for entry to practice is not unique to NZ, but has occurred at different rates internationally. Change in the wider tertiary education sector assisted the move to a pre-registration degree in both Australia and the UK, similar to what happened in New Zealand. Also evident, and in common with NZ, was the professional tension and anti-intellectual and anti-educational attitudes that surrounded such change in nursing education. These tensions and attitudes have contributed to the debate on whether experienced RNs should obtain a degree. The mixed research on the difference between a degree and a 
diploma for practice, combined with variable employment support and obstacles from academic institutions, results in confused messages to those RNs considering degree study. The literature showed that those who do choose this option usually have both professional and personal motives, seeking to keep up to date, to advance their careers and to gain personal satisfaction. Most were older women with families, who continue in paid nursing employment and for whom adding the additional role of student also adds tremendous stress as they juggle priorities in an effort to meet all their responsibilities. Also evident from the literature was that having support and good coping mechanisms was crucial to surviving the journey, as RNs face many barriers such as family responsibility and lack of workplace support. A limitation of the literature was that little research was done with RNs who either chose not to study, or with those that started but did not complete. The effects and outcomes of having a degree were usually considered from a personal, rather than a wider professional perspective, leaving another gap in the literature. While information on motives, barriers, support and outcomes for RNs undertaking an undergraduate degree exists, there was evidence that the country specific contexts were an influence. How RNs undertaking an undergraduate degree in NZ compare with this literature is unknown. The only NZ study that specifically looked at RNs gaining a degree focused on teaching and learning possibilities, and no NZ research considered the outcomes of this group on practise or on the wider profession. This supports the need to explore the case of RN to $B N$ programmes in New Zealand.

The following chapter explains why case study is the research approach best suited to this study. The historical and current perceptions of case study are outlined, along with the reasons it fits the aims of this research. The case is outlined and the choice of methods is justified. The ways data were collected and analysed, and how ethical issues and questions of rigour were handled, are then all described. 


\section{CHAPTER THREE}

\section{Research Strategy}

\section{Introduction}

As case study has the potential to provide holistic, meaningful, context-bound knowledge and an understanding about real life events (Yin, 2003), it is well suited to investigate the case of registered nurse $(\mathrm{RN})$ to Bachelor of Nursing $(\mathrm{BN})$ programmes in New Zealand (NZ) nursing education. It provides a comprehensive approach for research and can be both the process and end product of investigation (Luck, Jackson, \& Usher, 2006). Although there is a lack of consensus on some aspects of case study, it has exciting features that made it appropriate for this research. In this chapter the historical roots of case study are outlined and the match between this strategy and the research aims are highlighted. Of the two main proponents on how case study can be used, Robert Yin and Robert Stake (1995), this study follows the perspectives outlined by the latter, where there is a single case and qualitative inquiry dominates. A feature of case study design is the ability to use mixed methods to obtain data from different aspects of the case. Mixed methods were employed in this research to capture the different perspectives of RN to BN programmes. Through a combination of interview, survey, document analysis, personal experience and reflection on both personal and national professional perspectives, a comprehensive understanding of the case was able to emerge. Also in this chapter ethical considerations and the ways data were collected and analysed are described. The concluding section deals with rigour, trustworthiness and potential limitations of the research approach.

\section{Case study: A comprehensive strategy}

Case study is used by different disciplines and can be used in a number of ways. Hence, a single accepted definition of case study does not exist and it is considered by some to be a contested concept (Luck et al., 2006). It has been called a method, a design and an approach to research, but Jones and Lyons (2004) argue that it is a comprehensive research strategy. Rosenberg and Yates (2007) describe it as a methodologically flexible approach to research design that focuses on a particular case. It is expected to "catch the complexity of a single case" (Stake, 1995, p. xi) and is most commonly applied where the phenomenon of interest is complex and highly contextualised. Aspects of what is generally accepted about case study include that it is an "intensive, detailed, in-depth study, examination or investigation of a single unit - the case - 
where the focus is on the particular" (Luck et al., p. 104). It describes and interprets the meaning of people's lives in their real world and uncovers rich, thick, complex and embedded descriptions that are a re-presentation of the phenomenon of interest, or the case (Denzin \& Lincoln, 2000; Stake, 2005). The case is "a specific, a complex, functioning thing" (Stake, 1995, p. 2) that has specific boundaries, such as time, place or activity. To reveal the complexity of the case, mixed methods with multiple data sources are utilised. These are pragmatically chosen by the researcher to match the case and the research question (Rosenberg \& Yates; Yin, 2003). While this flexibility and allowance of paradigmatic diversity is now seen by some as the strength of case study, it has also made this approach vulnerable to criticism from those who believe in epistemological and ontological purity. The historical debates around case study reflect changing attitudes to research and the lack of clear definitions of case study.

The notion of case study was historically not restricted to the research context so its exact origins are unclear. Case study has been traced back to the medical model while others link it to social workers' "case history" or "case work" (Gomm, Hammersley, \& Foster, 2000). The long history is confirmed by Bryar (1999) who documents Le Play undertaking case studies of families in 1839 in Europe, while Gomm et al. refers to a study in the USA from 1918 that uses social work records. Pegram (1999) believes there are mixed origins, including psychology, medicine, law and experimental research, thus accounting for the wide spectrum of philosophical stances inherent in the method. While the exact origins of case study are unclear, there is agreement (Mitchell, 2000; Tellis, 1997a) that the early methodology is associated with sociology and Chicago, where aspects of immigration for different national groups were studied.

The University of Chicago Department of Sociology was the pre-eminent source of case study methodology from the early 1900s until 1935. Tellis (1997a) contends that in 1935 there was a public dispute between those championing the scientific method, predominantly from Colombia University, and supporters of case study and the Chicago School. The outcome was that the scientific method was upheld and there was a consequential decline in the use of case study as a method. Mitchell (2000) acknowledges this division of belief and notes the debates in the journals of the mid 1930s, but he believes it was in the early to mid 1950s that the method lost its appeal. While there is a lack of agreement about some details, it is clear that the demise of case study was influenced by the dominance of quantitative research and, correspondingly, the resurgence has been linked to increasing awareness of the limitations of the positivist paradigm. 
Multiple authors (Gomm et al., 2000; Jones \& Lyons, 2004; Luck et al., 2006; Pegram, 1999; Soy, 1997; Tellis, 1997a) now attest to increasing interest in case study. Definitions of case study have changed over time and the terms case study, case study method and case method are used interchangeably causing confusion (Bryar, 1999). Disagreement still exists regarding whether case study is a research method, a research design or a research strategy. Yin (1994, 2003) contends that case study is a research strategy, comprising an all-encompassing method with the logic of design creating specific approaches for data collection through to data analysis. Yet he does, in places, also call case study a 'research tool'.

The current diversity of opinion concerning case study is in part because the two main proponents of case study, Yin and Stake, hold different perspectives on this research approach. Yin has a background in experimental psychology which probably explains his insistence that case study conform to the goals and methods of science. He argues that case study is stereotyped as a weak method among social science methods so his objective is to guide researchers to do case study as a rigorous method of research (Yin, 2003). This view of case study as an empirical inquiry paints with a positivist brush. While acknowledging that "case studies can be based on any mix of quantitative and qualitative evidence" (p. 15), he comments "case study strategy should not be confused with 'qualitative research"' (p. 14). Yin does not define what a case is. Rather, in keeping with his positivist approach, he discusses the 'unit of analysis'. He describes the difficulty in defining the unit of analysis as a fundamental problem in doing case study. While he provides rationale for using a single-case design, he argues that multiple-case designs are preferred over single-case designs.

In contrast, Stake (1995) takes a strong qualitative stance. While noting there are many ways to do case study, what he describes is a disciplined, qualitative mode of inquiry to capture the complexity of the single case. Throughout his work Stake refers to philosophical underpinnings. He remarks that the primary characteristic of qualitative research is the centrality of interpretation along with the distinction between knowledge discovered and knowledge constructed. From his interest and research background in education, Stake describes researching cases as "we are interested in them both for their uniqueness and commonality. We seek to understand them. We would like to hear their stories" (p. 1). His focus is to place the reader of case study to the fore and to promote understanding through thick description, a term for emic interpretations originally coined by the anthropologist Clifford Geertz, that involves conveying to the reader what the experience itself would convey. 
The philosophical positioning of case study is regularly discussed. Hammersley and Gomm (2000) argue that in one sense all research is case study, but note that the term case study usually identifies a specific form of inquiry. They describe how many commentators regard case study as more than a method and note that "it is seen as a distinct research paradigm" (p. 5). This may be formulated in terms of a contrast between positivism or as a kind of portrayal of the social world. The debate about where case study as a comprehensive strategy lies paradigmatically was explored by Jones and Lyons (2004). They contend that because of the emphasis on multiple sources of evidence and the potential to uncover multiple realities, a case study approach can provide balance with regard to philosophical stances. This discussion was advanced by Luck et al. (2006) who argue that case study is a "bridge across the paradigms" (p. 107) because any set of methods that will help to develop understanding can be used. Rather than sitting comfortably within one paradigm, case study can use both qualitative and quantitative methods and allow each paradigm and their assumptions to remain distinct, like the structures on either side of a bridge. They reason that flexibly defining case study is consistent with present movements that endorse a paradigm of choices.

\section{Case study as a research strategy for this research}

For the purpose of this thesis case study is considered a research strategy and was utilised because it best suited the aims of the study. The selection of case study starts with defining the case or area to be studied. Indeed, Stake (1998) believes that "case study is not a methodological choice ... we choose to study the case" (p. 86). The case of interest for this study is $\mathrm{RN}$ to $\mathrm{BN}$ programmes. The shape of these programmes was described in Chapter One. How the case will be examined and constructed flows from the definition of the case and the aims of the research. The programmes, although differing within each School of Nursing, are seen as one entity, a single case (Stake, 1995). This research aims to understand why RNs choose this option and the place and significance of these programmes, for individuals and nursing in NZ. These programmes were a response to change occurring at two levels, the individual or personal level and the national professional level. Both perspectives need to be explored to provide a complete picture. To fully understand a case, to probe its particularity, would involve at a minimum exploring the nature of the case, its historical background and the context that surrounds it. The case of RN to BN programmes sit in the contexts of nursing in NZ, nursing education and the country's socio-political framework. These contexts are explored. Because of 
the scope of this study, some aspects of the case, such as specific curriculum issues, teaching styles and stake-holder perspectives, are not addressed.

A review of the literature on case study confirmed the 'fit' of this research approach to the study. Lubbe (2003) argues that the philosophy behind case study is that by looking carefully at practical, real-life instances, a full picture of the interaction of the variables or events can be obtained, providing a three-dimensional picture. Case studies are naturalistic, holistic and have the potential to provide rich, detailed, descriptive data together with contextual information (Kent, 1992). According to Pegram (1999), case study gives a holistic perspective to research and she notes that "by using multiple data collection tools, researchers gain a rich picture" (p. 5). Luck et al. (2006) define case study as "a detailed, intensive study of a particular contextual, and bounded, phenomena that is undertaken in real life situations" (p. 104).

Case study can address the questions of nursing and healthcare (Jones \& Lyons, 2004; Luck et al., 2006). As a practice-based profession, nurses require knowledge of and insights into subjective lived experiences of those they nurse. Dale (1995), a nurse researcher, believes case study is a valuable strategy for the complex world of nursing because "it provides a framework for systematic and holistic exploration of personal experience, so generating the understanding of the 'particular"' (p. 1129). It allows "an in-depth insight into personal experience and meaning because it focuses upon the particular" (p. 1130). This emphasis on the personal perspective was confirmed by another nurse researcher, Zucker (2001), who studied men with chronic coronary heart disease. She identified the use of case study method in psychology, sociology and education to develop rich and comprehensive understanding about people. Case study has been used by nurses to "give a voice to the powerless and voiceless" (Tellis, 1997b, p. 2) because it provides "multi-perspectival analyses" that consider the voice and the perspective of the individual and the group. Tellis also notes that case studies are designed to bring out the details from the viewpoint of the participants by using multiple sources of data. These comments highlight the suitability of case study to the present investigation as an aspect of the study aimed to capture the experience of individual RNs who gained their degree through a $R N$ to $B N$ programme and to make their endeavours visible. According to Merriam (1998) case study gets as close to the subject of interest as is possible.

While case study has been shown to be useful in education (Stake, 1995, 2005), it is increasingly being seen as valid and appropriate for nursing research (Luck et al., 2006; Pegram, 1999; 
Rosenberg \& Yates, 2007). Case study has also been used as a research strategy by NZ nurses (eg. Aitcheson, 2002; De Vore, 1995; Nelson, 2003; Skinner, 1998). In a study related to nursing education Sims (2004) used case study to explore the benefits and challenges of an undergraduate clinical education model from a ward manager's perspective. Dixon (1996) deemed critical case study as the most appropriate research strategy for exploring the difference in practice for Enrolled Nurses who had undertaken education to upgrade their qualifications to become RNs. Critical case study was used to expose 'taken-for-granted' assumptions.

A specific aspect of this current research was "why did registered nurses choose this option?" Case study can focus on decisions. Schramm (cited in Yin, 2003, p. 12) comments

The essence of a case study, the central tendency among all types of case study, is that it tries to illuminate a decision or set of decisions: why they were taken, how they were implemented, and with what result. This definition thus cites the topic of "decisions" as the major focus of case studies.

de Vaus (2001) also contends that "a decision might be the unit of analysis for the case study" (p. 220). While the research question includes capturing the decision of the individual to undertake study, the wider decisions surrounding change in nursing education and change in professional standards made by the Nursing Council of New Zealand (NCNZ) were also significant. Case study can contribute to knowledge in many different situations where there is a need to understand complex social phenomena (Yin, 2003). Because case study "describes the total situation as a combination of different factors" (Lubbe, 2003, pp.12-13) the depth of the inquiry is greater than any other research method.

The perspectives of Stake $(1995,1998,2005)$ were used for this research as $\mathrm{RN}$ to $\mathrm{BN}$ programmes are a unique single case and because the philosophical stance of Stake was more suited to both the aims of the research and my personal stance as the researcher. While Yin (2003) promotes multiple-case design, he does identify five reasons for using a single-case design, the critical case, the extreme or unique case, the representative or typical case, the revelatory case and the longitudinal case. In contrast, Stake believes case study is primarily about capturing the complexity of a single case.

We study a case when it itself is of very special interest. We look for the detail of interaction with its contexts. Case study is the study of the particularity and 
complexity of a single case, coming to understand its activity within important circumstances. (1995, p. xi)

While Yin (2003) discusses a unit of analysis, Stake (1995) defines a case as a "bounded system ... it has a boundary and working parts ... the case is an integrated system" (p. 2). Stake's view is that case study is a poor basis for generalisation and case study designs are not chosen to optimise the production of generalisations. He states;

The real business of case study is particularisation, not generalisation. We take a particular case and come to know it well, not primarily as to how it is different from others but what it is, what it does. There is emphasis on uniqueness. (p. 8)

A valid modification of generalisation can occur in case study, described by Stake (1998) as naturalistic generalisations. While arguing that people can learn general things from single cases, he reinforces that case studies are undertaken to make the case understandable. Naturalistic generalisations are defined as "conclusions arrived at through personal engagement in life's affairs or by vicarious experience so well constructed that the person feels as if it happened to themselves" (p. 85).

Case study research can take one of three forms, according to Stake (1995), depending on the type of case. He identifies these as intrinsic case study, instrumental case study and collective case study. An intrinsic case focuses on that particular case, it has intrinsic interest. The instrumental case study is used to understand something else, it is instrumental to achieving something other than this case. Where more than one case is used in an instrumental way, the work is deemed to be a collective case study. Stake is very clear that "case study is not sampling research. We do not study a case primarily to understand other cases. Our first obligation is to understand this one case" (p. 4). This differs from the perspective of Yin (2003) who argues that multiple case studies fulfill the conceptual requirements of theoretical or literal replication as he sees case study as primarily about theoretical generalisation, rather than understanding one case. Hence, the perspectives of Stake were more valid for this research.

\section{Defining the case}

An intrinsic case study is perhaps the most fundamental of the three designs Stake (1995) proposes, where the case is in and of itself the focus of the study. It is the design used in this 
research because $\mathrm{RN}$ to $\mathrm{BN}$ programmes, while a response to change in nursing education, are unique. Stake $(1995,2005)$ argues that an intrinsic case study encapsulates rich, complex meaning and that this type of design describes the case with sufficient descriptive text and narrative to allow the reader to access the phenomenon of interest and the context. Hence, the case is $\mathrm{RN}$ to $\mathrm{BN}$ programmes, the phenomenon of interest is RNs gaining an undergraduate nursing degree and the context is NZ nursing education. It is important, asserts Ragin (1992), for the inquirer to define their meaning of the term case because the case is the object of study and there is a need to understand what a case is 'a case of'. He proposes four conceptualisations of 'a case', using a four cell, $2 \times 2$, framework that considers whether a case has empirical units or theoretical constructs and are these either general or specific. Cases are general empirical units, objects, that are ready to be analysed; or specific empirical units, found or recognised through research; or cases are general theoretical constructs, conventions, developed from theory or scholarly work; and specific theoretical cases are made, emerging via research. Luck et al. (2006) note that he also acknowledges the fourfold division as not mutually exclusive. Luck et al. argue that depending on the researcher's conceptualisation of the case, "concerns such as generalisability, the position of theory, causal vs. narrative analysis and authority vs. authenticity (Hammersley \& Gomm, 2000) need to be addressed" (p.105). They also suggest that there is a place for both qualitative and quantitative approaches depending on the theoretical construction of the case and that the particular theoretical position can be argued by the researcher within the logic of their epistemological, ontological and methodological approach.

The stance I relate to is the qualitative view taken by Stake (1995) rather than the quantitative position adopted by Yin (2003). This study's focus is on understanding the case of RN to BN programmes, their uniqueness and their context within NZ nursing education and professional practice. The focus is on particularisation, rather than generalisability. The case is considered intrinsically. How a case study researcher understands knowledge and reality is also considered important by Stake. The view I hold is both constructivist and relativist. The interpretive qualitative stance to research put forward by Stake matches this view. The distinction of qualitative research, Stake argues, is that it tries to promote understanding. He talks about empathetic understanding, the knowledge of another by experiencing it yourself, and explains that this occurs through thick description, which conveys to the reader what the experience itself would convey. "The qualitative case study researcher has tried to facilitate reader understanding, an understanding that important human actions are seldom simply caused and usually not caused in ways that can be discovered" (p. 39). 
Stake (2000) believes our understanding is attained and amended through our personal experience. It is our tacit knowledge which helps make connections and associations and hence, understanding.

Tacit knowledge is all that is remembered somehow, minus that which is remembered in the form of words, symbols or other rhetorical forms. It is that which permits us to recognise faces, to comprehend metaphors and to "know ourselves'. Tacit knowledge includes a multitude of unexpressible associations which give rise to new meanings, new ideas and new applications of the old. Polanyi recognised that each person, expert or novice, has great stores of tacit knowledge with which to build new understandings. (Stake, p. 20)

Naturalistic generalisations are arrived at when the reader recognises the similarities of objects and issues in and out of context. By presenting holistic and lifelike thick descriptions, the reader experiences the context vicariously. Naturalistic generalisations develop within a person as a product of experience, derived from tacit knowledge. It is readers who "recognise essential similarities to cases of interest to them, they establish the basis for naturalistic generalisation" (Stake, 1995, p. 23).

A qualitative design is emergent, with the details often not known ahead of time. Indeed, because case study fieldwork can take the research in unexpected directions, Stake (1995) advises that too much commitment in advance is problematic. He stresses deep thinking as the most important aspect. Aspects of the plan include "definition of case, list of research questions, identification of helpers, data sources, allocation of time, expenses, intended reporting" (p. 51). Because the case is "a complex entity operating within a number of contexts" (Stake, 1998, p. 91), the researcher must examine all aspects of its complexities to provide a holistic study. The focus is on understanding the case and making the case understandable for the reader. In essence, the researcher assists the reader in the construction of knowledge so both need conceptual structures and scaffolding to focus the attention of the case study. So "ideas are structured, highlighted, subordinated, connected, embedded in contexts, embedded with illustration, laced with favour and doubt....case researchers, as others, pass along to readers some of their personal meanings of events and relationships" (Stake, 1998, p. 95). Knowledge of the case passes from writer to reader in a potentially hazardous transmission so there needs to 
be ways to protect and validate this transfer of knowledge. He argues that to establish meaning we need to present a substantial body of uncontestable description.

Although the purpose of case study, and hence its design, is to optimise the understanding of the case, there is still the need for discipline and protocols. A number of researchers have noted that the methodological flexibility of case study can cause uncertainty regarding the appropriate procedural steps (Dale, 1995; Rosenberg \& Yates, 2007; Yin, 2003). Following the identification of the phenomenon of interest or the case, the basis of all research, Stake (1995) describes using issues as a conceptual structure. Issues questions are the primary research questions that "force attention to the complexity and contextuality" (p. 16) of the case. Some issues are problems and many issues are not simple, rather they are "intricately wired to political, social, historical, and especially personal contexts" (p. 17). Issues are chosen to help understand the complex life of the case. A data-gathering plan is useful but it needs to be rooted in the research questions. Always the focus is on understanding the case and making the case understandable for the reader.

\section{Methods}

The types of issues and questions that were raised in relation to this research included "how and why were RN to BN programmes established?" "Why did RNs choose this option?" "What numbers of RNs took up this option and nationally how many of these graduated?" "What was the personal and professional significance of obtaining an undergraduate nursing degree from a RN to BN programme?" "What factors encouraged or hindered individuals undertaking a RN to BN programme?" "Was it worth it?" "Did those RNs who obtained a nursing degree from these programmes impact on the national numbers of RNs with a degree qualification or higher?" "What, if any, professional impact has there been from these programmes?" These questions quickly identified the need to look at the case from different perspectives and that different data sources would be required. Luck et al. (2006) notes that methods refer to the "tools, procedures or techniques the researcher employs to gather and analyse data" (p. 105). There is no agreed set of methods for case study and the methods are selected in relation to the case and the research question. Stake (1995) identifies four methods of data collection as suitable with case study; observation, description of contexts, interview and document review. Although survey is not included as a method by Stake, it was used in this research to gain information on $\mathrm{RN}$ to $\mathrm{BN}$ programmes that was not available from any other source. 
The methods used in case study research are pragmatically, rather than paradigmatically, driven (Rosenberg \& Yates, 2007). By using mixed methods to capture the complexity of the case, the researcher does not dismiss or ignore epistemology or ontology, rather a pragmatic construction of the real world is more fitting with human experience of the world (Johnstone \& Onwuegbuzie, 2004). Luck et al. (2006) describe how "the 'paradigm of choices' offers a pragmatic pathway for nursing researchers to embrace methodological openness and paradigmatic freedom" (p. 107). This supports the use of methods which may be considered atypical for a particular research design. The use of multiple data collection methods to explore or understand the case is what enables a rich, detailed description and is one of the key strengths of case study.

The choice of methods in this research was driven by my desire to examine the case from different perspectives, particularly from the personal and the national professional perspective. I wanted to capture the significance of these programmes for individual RNs and to make their experience visible. There was also a desire to examine the national and professional implications of these programmes, to better understand their place and significance in nursing education and professional nursing and to begin to consider if the existence of these programmes was still warranted. To this end, three main methods were used to collect data for this research, with my own reflection and experience with $\mathrm{RN}$ to $\mathrm{BN}$ programmes becoming a fourth source of information to inform the understanding of the case. Interviews with graduates of a RN to BN programme, were used to inform the personal perspective, while document analysis contributed to the national, professional and institutional perspectives. A survey of all the Schools of Nursing was undertaken to provide information on the national, professional and institutional perspective, while my own experience contributed to these and the personal perspective. Stake (1995) argues that "the more the case is an intrinsic case study, the more attention needs to be paid to the contexts" (p. 64). This is supported by Merriam (1998) who also emphasises the importance of thick description and context. Mixed methods and viewing the case from different perspectives was considered the best way to fully capture the complexity and contexts of the case.

Interviews were undertaken with RNs who had completed a RN to BN degree. Both Stake (1995) and Merriam (1998) comment that interview is often the main (and sometimes only) source of data with case study. The 16 Schools of Nursing in NZ offering pre-registration programmes all have different curricula so those that offer an $\mathrm{RN}$ to $\mathrm{BN}$ option run essentially different programmes. To enable a focus on reasons and experience, to reduce variation and for 
pragmatic reasons, it was decided to use participants from one programme in the North Island. Eligible participants were those who had graduated in 2004 or 2005 (i.e. completed by December 2003 and 2004). The post-completion timeframe was so participants had time to be aware of the effects of the experience, yet it was not too distant for accurate recall.

Permission was granted from the institution for one of their administration staff to access the appropriate databases and mail a postage paid letter (supplied by the researcher) requesting research participants. For cost reasons only addresses within a $200 \mathrm{~km}$ radius were used. The secretary also excluded addresses she knew were no longer valid. Of the 40 graduates who met the initial criteria, 26 were sent the request. Nine responded. Unfortunately the ninth person made contact after data analysis was almost complete and the person was thanked but not included. Prospective participants were asked to contact the researcher either by phone or by email. Those who made contact were sent an information sheet (Appendix 1) and a copy of the consent form (Appendix 2) to enable them to consider these prior to meeting with me. The eight people who agreed to be part of the study were each interviewed at a mutually agreed time and place.

Documents analysed to inform the national, professional and institutional perspective included reports from NCNZ, the New Zealand Qualifications Authority (NZQA), and the New Zealand Health Information Service. Initially, I had hoped information from the NCNZ database would provide the numbers for RNs who had obtained a post-registration nursing degree. Since 2000 the NCNZ had been collecting information about post-registration qualifications of over six months duration, including Bachelor and post-graduate qualifications, as part of the workforce survey information that accompanied the renewal forms for annual practising certificates. However, gaining access to this information from NCNZ proved quite difficult. Eventually, a meeting with the Registrar of NCNZ revealed the complexities of the NCNZ database and that this information was not available in a valid or reliable form. There were many reasons for this, including that the qualifications were self reported and not verified unless specifically related to registration; any sort of qualifications were recorded, often in the form of initials without the country of origin noted; the database was 'live' in nature, meaning information changed daily; and the migratory nature of the nursing workforce. Although some information was obtained from the NCNZ database, it became apparent that a survey of each School of Nursing would be required to gain information on the numbers of RNs who had achieved their degree qualification from a RN to BN programme. 
Once ethical approval had been obtained, survey material (Appendix 3) was dispatched to all 16 Schools of Nursing. Information was sent in both hard copy (stamped addressed reply envelope supplied), and by e-mail, so participants could respond by whichever medium best suited them. All results were aggregated and no institution was specifically identified. Of the 16 institutions, nine responded to the survey. Additional to the survey, the website of each institution was searched and requests were made to for information about undertaking an undergraduate nursing degree as a RN. This was to ascertain the ease with which a $\mathrm{RN}$ could access information, as availability of information influences ability to make choices. This search for information on what was offered nationally for RNs also provided the cost of courses or programmes, something that had not been requested in the survey sent to the Schools of Nursing.

\section{Ethical considerations}

Prior to commencing this research ethical approval was obtained from VUW's Human Ethics Committee (Appendix 4). Upon meeting each participant they were asked if the information sheet had been read. This provided an opportunity for them to ask questions about the study. For seven of the eight I had been a lecturer involved in their RN to BN programme and they were asked if this was an issue or a concern. No one expressed concern. This point had been explicitly addressed in the information sheet. After outlining each point on the consent form, confirmation that they were happy to continue as a participant was sought. All consent forms were signed. Ensuring that research is undertaken in an ethical manner is an important aspect of reliability and validity (Merriam, 1998) as there are unique concerns related to qualitative research with regard to the researcher-participant relationship. Participants were also able to contact my thesis supervisors with any concerns or questions. All participants agreed to the interview being audio-taped and were aware that they could ask to have the tape turned off at any time.

Participants were asked to choose a pseudonym for future anonymity. It was explained that while the transcriber and my supervisors may be party to the transcript, I would be the only person who would know to whom the pseudonym referred. The transcriber was required to sign a confidentiality declaration (Appendix 5) and delete all copies of the files within five days of my collecting them. Confidentiality was maintained by limiting the raw data to the transcriber, my 
research supervisors and myself. All electronic versions of the transcripts were password protected and kept on my private computer. All written data were kept in a locked filing cabinet in my home.

One participant, who had not been in any of my classes and who was not known to me prior to the interview, did share negative sentiments about staff members and the institution during the interview. At one point I stopped the tape and acknowledged that her experience was not how it should have been. I expressed sadness that things had happened the way she described as they appeared to have been less than ideal. At that point I outlined options available to her to assist with either resolving the issues or discussing these further with a person more independent than myself. Her response was that she did not want to take up any of the options outlined as she now felt settled about what had occurred. Although I was aware of who these people were, this information was not shared with the participant or the people concerned. However, the fact that a participant had an experience where they felt unsupported is referred to briefly in the thesis.

\section{Data collection}

Data to inform the personal perspective were obtained through semi-structured in-depth interviews (Appendix 6) with eight $\mathrm{RN}$ to BN graduates. Merriam (1998) calls interviews a "conversation with a purpose" (p. 71) while Stake (1995) comments that "the interview is the main road to multiple realities" (p. 64). After reiterating the participant's rights and confirming the pseudonym, the interview began by asking each participant general information about when they registered, their nursing qualifications and their domestic and professional situation. The interview needed to unravel specifics of both their personal and their professional circumstances. The literature (Davey \& Robinson, 2002; Delaney \& Piscopo, 2004; Timmins \& Nicholl, 2005) identifies domestic and professional situation as factors that influence the success for RNs returning to study. This initial information indicated a diversity of participants. Respondents were mainly women, with one male; they registered between 1974 and 1995, with five being hospital trained Registered General and Obstetric Nurses (RGONs), while three were Registered Comprehensive Nurses (RCompN) who had gained their qualification through a polytechnic. Most worked full time and had families as outlined in Table 2. 
Table 2. Characteristics of participants

\begin{tabular}{|c|c|c|c|c|}
\hline & $\begin{array}{l}\text { Type of } \\
\text { registration }\end{array}$ & Domestic situation & Professional situation & $\begin{array}{l}\text { Full-time or } \\
\text { Part-time } \\
\text { (P/T) }\end{array}$ \\
\hline$A$ & RGON & $\begin{array}{l}\text { Mainly on own - had an } \\
\text { international student, \& adult } \\
\text { son staying for a while }\end{array}$ & $\begin{array}{l}\text { Public health nurse, became } \\
\text { a team leader part way } \\
\text { through }\end{array}$ & Full time \\
\hline B & RGON & $\begin{array}{l}\text { Married, with partner, } 2 \\
\text { children aged } 12 \& 15\end{array}$ & Staff nurse, coronary care & 0.8 \\
\hline C & $\mathrm{RCpN}$ & $\begin{array}{l}\text { Partner mainly overseas - } \\
\text { had } 3 \text { children while doing } \\
\text { degree }\end{array}$ & $\begin{array}{l}\text { Staff nurse, children's ward. } \\
\text { Then new town so part time } \\
\text { in various nursing roles }\end{array}$ & $\begin{array}{l}\text { Started full } \\
\text { time dropped } \\
\text { to } \mathrm{P} / \mathrm{T}\end{array}$ \\
\hline $\mathrm{D}$ & RGON & $\begin{array}{l}\text { Married with partner, } 2 \\
\text { children aged } 12 \& 14 \text { years }\end{array}$ & Staff nurse, emergency dept & Full time \\
\hline$E$ & $\mathrm{RCpN}$ & $\begin{array}{l}\text { Lived with parents. Assisted } \\
\text { with } 7 \mathrm{yr} \text { old grandchild }\end{array}$ & $\begin{array}{l}\text { Staff nurse, in a private } \\
\text { surgical hospital }\end{array}$ & Part time \\
\hline $\mathrm{F}$ & RGON & $\begin{array}{l}\text { Married with a very busy } \\
\text { partner, } 2 \text { children aged } 8 \text { \& } \\
10\end{array}$ & $\begin{array}{l}\text { Full-time across } 2 \text { positions } \\
\text { Part way through left one job } \\
\text { \& increased other to } 30 \mathrm{hrs}\end{array}$ & Full time to $\mathrm{P} / \mathrm{T}$ \\
\hline$G$ & $\mathrm{RCpN}$ & $\begin{array}{l}\text { House husband, and } 2 \\
\text { children } 5 \text { yrs \& } 6 \mathrm{mths}\end{array}$ & $\begin{array}{l}\text { Staff nurse, } 4 \text { days in } \\
\text { women's health. Then new } \\
\text { job as a practice nurse }+ \\
\text { some hospital pool staff work }\end{array}$ & $\begin{array}{l}\mathrm{P} / \mathrm{T} \text { to Full } \\
\text { time plus }\end{array}$ \\
\hline $\mathrm{H}$ & RGON & $\begin{array}{l}\text { Single parent with } 3 \\
\text { children, aged } 5,10, \& 15 \\
\text { vears }\end{array}$ & Staff nurse, coronary care & Full time \\
\hline
\end{tabular}

The participants were then asked to tell me about doing a $\mathrm{RN}$ to $\mathrm{BN}$ programme. The aim of qualitative research is to try to gain an understanding of the participant's viewpoint, to uncover their lived experience of an event or time (Kvale, 1996). The interview schedule (Appendix 6) ensured some consistency of questions while also providing enough flexibility to allow further discussion if the response appeared to warrant that. Questions covered why each person chose the RN to BN programme option, financial considerations, factors that encouraged and hindered them during the programme and the personal and professional benefits or disadvantages of having an undergraduate nursing degree. Participants were also asked their opinion on the worth of the experience and whether obtaining a degree should be mandatory for all RNs. During the interview some significant points were noted and further thoughts were documented after the interview. This was to capture initial impressions and details of note. The tapes were listened to again after the interview, with further considerations documented. The tapes, although transcribed by someone else, were checked by me against the audio tape for accuracy. The first transcript was received and checked prior to the second interview. The question relating to 
whether a degree qualification should be mandatory or not was one that arose in the first interview and was added to the schedule. No other changes were deemed necessary.

Data required to describe the national professional perspective of this case came from a combination of nursing literature and public access government and NCNZ documents. Archival material, such as copies of minutes from NCNZ meetings, were sourced by a NCNZ staff member based on my criteria, once all relevant permissions were obtained.

\section{Data analysis}

Data analysis in case study involves "giving meaning to first impressions as well as to final compilations" (Stake, 1995, p. 71). Most data analysis approaches share the feature of attempting to "tell a story from the data" (Hardy \& Bryman, 2004, p. 1). The goal of the data analysis strategy used in this study was to comprehensively understand the case of $\mathrm{RN}$ to $\mathrm{BN}$ programmes. Merriam (1998, p. 151) contends that

Data collection and analysis is a simultaneous activity in qualitative research. Analysis begins with the first interview, the first observation, the first document read ... It is an interactive process throughout that allows the investigator to produce believable and trustworthy findings.

To ensure methodological rigour, the data analysis methods must correspond to the chosen data collection methods (Rosenberg \& Yates, 2007). Therefore, the document and interview data were analysed thematically, while the survey data was analysed numerically. Qualitative data analysis is about description, re-presentation and synthesis of textual data (Hardy \& Bryman, 2004). Datasets of all the data obtained for each method were established. These datasets were initially analysed separately. Tables were used where possible to provide a picture of the data. The large amount of descriptive data of the context was examined to establish its relevance and importance to the case. Historical data were considered for their authenticity and reliability. The different perspectives being utilised and the holistic nature of the case were constant considerations. Survey data were initially organised into tables. Comparison of survey data with information obtained from websites and brochures took place. Where data required clarification or explanation the relevant School of Nursing was contacted. 
The interview transcripts were read repeatedly to gain a sense or picture of the data and these ideas were compared with the post-interview impressions. Initially analysis of these data provided some difficulty. I found Stake's (1995) description of how to undertake data analysis lacking in detail. His advice that "by reading and rereading the accounts, by deep thinking, then understanding creeps forward and your page is printed" (p. 73) did not seem to work. Having read a number of other opinions on data analysis (Burnard, 1991, 1995, 1996; Denzin \& Lincoln, 1998; Kvale, 1996) I began coding all the transcripts as demonstrated.

It was nice to, um, learn new, well, not learn new things but look into different things and keep my study up, keep my mind going and, other than just children.

Nice to learn

Look into different things

Keep my mind going

Codes were then grouped and listed. Dale (1995) notes that there is a large volume of data in case study which, while having advantages, has the potential disadvantage of overwhelming the researcher or leading to side-tracking. I developed tables from the data and codes, cut and pasted similar codes into categories, reread and reread. While the theme of diversity surfaced early on, and categories related to choice and experience became clear, I did not feel I was capturing the essence of the data. Having been immersed in data for what seemed too long, I reread (one of multiple times) Stake's key text. This time two statements 'rang bells'. 'With intrinsic case studies, our primary task is to come to understand the case" (Stake, 1995, p. 77) and "full coverage is impossible, equal attention to all data is not a civil right. The case and the key issues need to be kept in focus" (p. 84). Suddenly his concepts of categorical aggregation and direct interpretation made more sense. On rereading all the transcripts, the patterns emerged. The patterns were noted and explored. Interview data were placed into the categories to ensure that most were captured. The themes identified were repeatedly reviewed by rereading the data and the findings, and iteratively ascertaining consistency between what different participants said (Hardy \& Bryman, 2004). There was a close link between the data and the findings which is common in qualitative studies. This approach of repeatedly reviewing further enhanced the truthfulness of the participant meaning within the case.

The numeric data from the survey were tabulated and clear patterns emerged. These patterns were compared with the descriptive data from the survey and from the search of the websites. This "search for meaning often is a search for patterns, for consistency, for consistency within 
certain conditions, which we call "correspondence"'” (Stake, 1995, p. 78). These findings and patterns were also considered alongside the collated document data. Legitimisation of rigour in inquiry is dependent on the process of discovery as well as the product of inquiry. Stake argues that devoting too much time to formal aggregation of categorical data distracts attention from its various contexts, so for an intrinsic case, most of the time should be spent on direct interpretation as the primary task is to understand the case.

The findings from the different data sources were then considered holistically to gain an in-depth understanding of the case. Ayres, Kavanaugh and Knafl (2003) argue that some qualitative researchers fail to go beyond a list of themes or key categories, leaving them self-contained and unrelated. Until these themes are reintegrated to show how they work together in the case, the analysis is incomplete. By triangulating and integrating what the findings meant the different perspectives were converged to provide a comprehensive view of the case. The understanding of the case comes from the whole, from the synthesis of the different perspectives.

Stake (1995) argues that most qualitative researchers believe that there are multiple perspectives or views of the case that "need to be represented, but that there is no way to establish, beyond contention, the best view" (p. 108). Hence, discipline and protocols are required to meet the ethical obligation of minimising misrepresentation and misunderstanding. He advocates triangulation as one way to establish trustworthiness in case study. Triangulation derives from celestial navigation and involves the intersecting of points. The multiple methods and sources of data can be systematically triangulated and so strengthen the credibility of the interpretation. Multiple realities can be recognised and acknowledged through triangulation, as "the protocols of triangulation have come to be the search for additional interpretations more than the conformation of a single meaning" (Stake, p. 114). Yin (2003) describes four types of triangulation but particularly stresses data triangulation. As case study can use any of six sources of data collection, these essentially provide multiple measures of the same phenomenon, which Yin believes strengthens construct validity. Using multiple sources does not in itself equate to triangulation. Events or facts of the case study have to be supported by more than a single source of evidence. Yin claims that multiple sources are an invaluable advantage of case study. In this research the multiple data sources and triangulation were used to add depth and breadth to the study. While some findings were supported and triangulated by different data sources, such as interview data triangulating with my personal experience as a lecturer, the choice was 
made to focus on triangulating and integrating what the findings meant, rather than triangulating the findings.

\section{Rigour, trustworthiness and potential limitations.}

Rigour in research involves the process of discovery as well as the product of inquiry. Merriam (1998) notes that the theoretical debates on the appropriate criteria for assessing validity and reliability are unlikely to ever achieve consensus. Connelly and Clandinin (1990, cited in Merriam, p. 200) believe that "each inquirer must search for, and defend, the criteria that best apply to his or her work". Qualitative inquiry has replaced the terms reliability and validity with concepts such as generalisability, transferability, credibility, auditability, trustworthiness, triangulation and reflexivity (Koch, 1998; Schneider, Elliot, Beanland, LoBiondo-Wood, \& Haber, 2003).

A potential limitation and constant criticism of single case study has been that the results are not seen to be generalisable or transferable (Schofield, 2000; Yin, 1999, 2003). However, this view is now being challenged (Jones \& Lyons, 2004). Generalisation, while a crucial component of experimental research, does not apply to most qualitative approaches as the results are not widely applicable to large populations. Yin (2003) refutes the criticism of case study for its lack of generalisability by arguing that it is concerned with analytical generalisations and not statistical generalisation. His argument is

that case studies, like experiments, are generalisable to theoretical propositions and not to populations or universes. In this sense, the case study, like the experiment, does not represent a "sample," and in doing a case study, your goal will be to expand and generalise theories (analytic generalisation) and not to enumerate frequencies (statistical generalisation). (p. 10)

Yin (2003) asserts that theory development prior to the collection of any case study data is an essential step in doing case study, as a theoretical framework assists in defining the appropriate research design and data collection as well as becoming the main vehicle for generalising the results of the case study. He suggests that the concept of generalisation be reconceptualised and clarified. Stake (1995) refines the concept of generalisation in his own way, as naturalistic generalisation. He believes there are 'petite generalisations' that occur throughout a particular case, factors which lead to the refinement of a generalisation, and that these can lead to 'grand 
generalisations'. Jones and Lyons (2004, p. 75) believe "these offer more detailed theorisations and may include triangulation strategies as a validity enhancing technique, thereby making the link with transferability".

Transferability is achieved through meticulously describing the methodological aspects of the study and then it is up to the reader to decide whether the results of the research can be applied to different situations or groups of people (Jones \& Lyons, 2004; Lincoln \& Guba, 1985). The use of thick description allows the reader to confirm how the interpretation was constructed and to make their own judgements regarding the transferability of the findings. Based on the typicality of the case, the findings may be fitting or transferable to 'like' cases. Rich, thick description was provided in this study along with substantial amounts of raw data to allow readers to utilise their tacit knowledge and see for themselves if there were similarities. Naturalistic generalisations, as described by Stake $(1995,1998)$, were an aim of the research strategy.

Another constituent of rigour is credibility, where the truth of the findings are judged as credible by participants and others (Schneider et al., 2003). Strategies that demonstrated credibility in this research included the depth of engagement with the case, the coherence of the research strategy and methods to the aims of the study, triangulation and checking of interpretations with peers and participants. Sandelowski (1986) believes that a qualitative study "is credible when it presents such faithful descriptions or interpretations of a human experience that the people having the experience would immediately recognise it from those descriptions as their own" ( $p$. 30). This is supported by Koch (1998), who argues that how the interpretations were arrived at should also be shown. Credibility is one aspect of trustworthiness. According to Denzin and Lincoln (2000) trustworthiness has four components, credibility, transferability, dependability and confirmability and is about methodological adequacy. An identifiable and traceable decision trail has been provided to ensure auditability of the research, which can be used to determine dependability and confirmability (Lincoln \& Guba, 1985). A researcher is responsible not only for the results of research but also for explaining how the results were obtained. Hence, a detailed description has been provided of how data were collected, how categories were derived and how decisions were made. My theoretical perspectives have been outlined and linked to the decision trail as the descriptions and themes derived from data were my own interpretations. This transparency allows the reader to judge the trustworthiness of these explanations. As my personal experience with RN to BN programmes and RNs studying for a degree contributed to 
the study, my voice is visible, identifiable and subject to critique. The adherence to consistency in methods and research processes also reflects auditability and trustworthiness of the research.

Reflexivity, a concept strongly supported by Koch (1998), acknowledges that "interpretation exists in a complex matrix of alternative representations and derives its critical power and insight from this awareness" (p. 1188). She argues that when a reflexive approach is incorporated into research it sign-posts to readers what is going on in the research. It could be argued that reflexivity is an advanced form of a decision trail. Stake (1995) encourages deep thinking and reflection, which is similar to reflexivity. This study used a decision trail and reflection. A form of research journal was kept to promote reflexivity, and was particularly employed immediately after each interview. Impressions, key points and things of note were recorded from each aspect of data gathering for future consideration and reflection. Repeated consideration of the data, thinking and reflection were used almost excessively.

Ensuring internal validity, a positivist approach encouraged by Yin (2003), is also supported by Merriam (1998) who argues that internal validity is a strength of qualitative research. She asserts that internal validity is linked to the meaning of reality as it addresses the question of how research findings match reality. In qualitative research interpretations of reality are accessed directly through the researchers observations and interviews. Merriam believes that "it is important to understand the perspectives of those involved in the phenomenon of interest, to uncover the complexity of human behaviour in a contextual framework, and to present a holistic interpretation of what is happening" (p. 203). To this end she identifies strategies to enhance internal validity and most were used in this research. These included clarifying the researcher's biases, using peer examination, member checks and triangulation. Member checking is encouraged by Stake (1995) and involves returning transcripts and draft interpretations to at least some of the participants for verification. While believing this step is entirely necessary, Stake notes that you "typically get little back" (p. 116) as was the case with this research. Triangulation within the research design, as outlined earlier in the chapter, also contributes to the rigour and trustworthiness of this research. Schneider et al. (2003) confirm that triangulation is the expansion of research methods "to enhance diversity, enrich understanding and accomplish specific goals" (p. 31) and note that there are several perspectives about triangulation, each offering frameworks to enrich the understanding of human phenomena. 
There is no agreed method for ensuring rigour, so Koch (1998) argues for a rigorous approach during the entire process, including consideration of moral, political and ideological aspects. Throughout the process of research issues of representation and legitimation must be addressed. Having acknowledged that debate around the use of case study as a research approach exists, the suitability of the strategy to the aims of this study has been demonstrated. As this research utilised a design that allowed for different perspectives of the case to be explored, and incorporated mixed methods, a clear decision trail, thick description and reflexivity, the reader will be able to judge the legitimacy of the research for themselves. This research has used accepted qualitative strategies to ensure rigour but also notes the perspective of Morse, Barrett, Mayan, Olson and Spiers (2002), who argue that researchers should take the responsibility for "reliability and validity by implementing verification strategies integral and self-correcting during the conduct of inquiry" (p. 1) rather than relying on external reviewers' judgements. Verification is "the process of checking, confirming, making sure and being certain" (Morse et al., p. 9). If the principles of qualitative inquiry are followed, the analysis is self-correcting because the research is iterative rather than linear. They argue that the researcher should move back and forth between design and implementation to ensure congruence among question formulation, literature, recruitment, data collection strategies and analysis. This research has been iterative, with the data systematically checked, the focus maintained, and the fit of the data, the analysis and interpretation constantly confirmed. Hence, the rigour of this research has been ensured.

\section{Chapter review}

In this chapter the reasons for selecting case study as the preferred research strategy have been explained and defended. Case study has been shown to have exciting potential for use in nursing research, especially where different types of data information are required to provide a complete picture of complex issues, despite debate existing on some aspects of this approach. The research in this thesis focuses on an intrinsic single case, namely RN to BN programmes. A qualitative perspective, as described by Stake $(1995,1998)$ was followed and mixed methods including document analysis, interview, survey and the researcher's own experience and reflection were utilised for data collection. Justification was provided for how data were collected and analysed and how ethical considerations and questions of rigour were handled. 
In the next chapter national and professional perspectives of the case are considered and the NZ context in which the case is embedded is examined. This includes the nursing, educational and socio-political contexts. How and why $\mathrm{RN}$ to $\mathrm{BN}$ programmes were established is outlined along with the findings of a survey from the Schools of Nursing on these programmes. The place and significance of these programmes within the wider framework of nursing education and practice is considered. 


\section{CHAPTER FOUR}

\section{The National Professional Perspective}

\section{Introduction}

This chapter presents the findings from the national and professional perspective on registered nurse $(\mathrm{RN})$ to Bachelor of Nursing $(\mathrm{BN})$ programmes. Consideration has been given to those affected by change throughout the history of New Zealand (NZ) nursing education and some of these measures are described. There is also a long historical background of professional efforts to secure advanced educational qualifications for RNs, which assisted both the change to preregistration degree programmes and the establishment of arrangements for existing RNs. A chronological history of these endeavours using secondary sources, predominantly Burgess (1984), Hughes (1978), and Salmon (1983), demonstrates the complexity of nursing education. The change to pre-registration degree programmes occurred largely due to socio-political circumstances and educational reform. Nursing education and practice are embedded in these wider contexts which underwent major change bringing opportunities and challenges for the profession, and these influences are explored. How and why RN to BN programmes were established is then explained. Continuing change in professional nursing and education is relevant to the viability and place of these programmes. The results of a survey of all Schools of Nursing offering pre-registration programmes, and information obtained from websites and Nursing Council of New Zealand (NCNZ) data are used to report on the significance of these programmes and changes over time in the number of students completing $\mathrm{RN}$ to $\mathrm{BN}$ programmes. The potential influence of these programmes on the numbers of degree qualifications within the workforce is also considered.

\section{Consideration and professional efforts for RN education}

Since the Nurses Registration Act 1901 there has been consideration of those affected by new requirements in nursing education. Section 4 (1) of the Nurses Registration Act 1901 allowed existing qualified nurses to obtain registration. Midwifery registration in 1904 also included a clause allowing existing trained midwives to obtain registration. Provisions in the Midwives Act 1904 and the Nurses Registration Act 1901 were combined in the Nurses and Midwives Registration Act 1925. Papps and Kilpatrick (2002) argue that with the establishment of the Nurses and Midwives Registration Board this Act moved the control of nursing from medical to 
nursing hands. This Act also allowed for a new category of nurse, a maternity nurse, who could achieve registration after an 18-month programme. The maternity nurse was specifically to assist medical practitioners rather than have an independent function. Again consideration of those affected by this change saw women who were untrained but had been practising as maternity nurses prior to the Act, given the opportunity to gain registration within one year of the Act being passed. The 18-month course was not offered after 1970 and this option does not exist in the new scopes of practice.

The Social Security Act 1938 and the subsequent Social Security Amendment Act 1941 offered free medical care and resulted in increased numbers of people requiring care. The different types of registration established from the late 1930s to 1950s were, Papps (1997) contends, essentially to address staff shortages in hospitals and to have nurses with specialist knowledge and skills available to work within medically defined specialty institutions throughout NZ. The Registered Nursing Aid was created in 1939 to "be of value to the girl who could not pass the examination for a registered nurse" (Lambie, 1951, cited in Papps \& Kilpatrick, 2002, p. 5) and was the beginning of the 'second-level nurse'. Although psychiatric hospitals had formal training from 1905, their training programmes only came under the control of the Nurses and Midwives Board with the Nurses and Midwives Amendment Act 1944. A three-year psychopaedic programme commenced in psychopaedic hospitals in 1961, but along with psychiatric training, stayed the responsibility of the Department of Health while standard programmes were under the Hospital Boards. A two-year male nursing programme commenced in 1945 and was extended to a three-year programme in 1957. A revised general nursing curriculum in 1969 saw male and female programmes combined but it was not until the 1970s that male nurses could undertake the obstetric component. As each programme was established or a change in requirements occurred, consideration was given to those who were already experienced in that area.

Throughout NZ nursing history there has been a belief in the benefits of education and scholarship as demonstrated by RNs attending conferences and travelling overseas to observe, study or gain qualifications unavailable in NZ (Burgess, 1984; Salmon, 1983). Initially, most postregistration education available to RNs was offered by the Department of Health or Hospital Boards. According to Salmon (p. 60) "New Zealand universities and the nursing profession have had a long and tortuous history extending over all of this century and it is still in the making". She chronicles a history of interest in university education from 1910 when news was published in Kai Tiaki (NZ Nursing Journal) that the American University of Minnesota was establishing a Bachelor 
degree in nursing. A demand by nurses that university training should be available for nurses in NZ soon followed (Hughes, 1978). This was supported in 1912 when a Dr Pabst of Auckland Hospital urged the University of New Zealand to institute a degree in nursing as "trained nurses ought to be given full professional rank" (Salmon, p. 60).

From October 1922 discussions commenced with the University of Otago, encouraged by the Trained Nurses' Association, in an attempt to provide advanced training for nurses. Hughes (1978) describes this as the first attempt to provide instruction for nurses in NZ based on their educational requirements and not the service needs of hospitals. A five-year diploma course was proposed, with the fifth year available to nurses already registered. In 1924 a post-graduate course identical with the fifth year course in the Diploma of Nursing for specially selected RNs, such as sister-tutors, was proposed. This highlighted the need to employ someone from outside the existing University staff and began correspondence between the Department of Health and the University about sending a nurse to undergo the necessary training in London. Unfortunately "what precisely was being offered and accepted had not been made clear enough; as it turned out the University and the department had different views on the subject" (Hughes, p. 25).

Two nurses were sent abroad, Miss Moore to London and Miss Lambie to Toronto, and three students were enrolled in 1925 before the University belatedly attempted to settle the matter of salaries for Miss Moore and Miss Lambie. The Acting Director-General of Health informed the University that while the department had offered to send the two nurses overseas for training to help a course already established by the University, it could not consider becoming responsible for the salaries of the two lecturers. This response destroyed the assumption that the University could establish the Diploma at no cost to itself and put the Diploma of Nursing in jeopardy. Several attempts were made to save the course from collapse. The Trained Nurses' Association promised to raise money to support the course, begged the University to allow it to continue and gained support from the Medical Superintendent of Dunedin Hospital and others, resulting in proposals and resolutions by nursing and medical groups supporting the Diploma of Nursing, but to no avail. Despite four more students having been enrolled in 1926, a meeting in October that year deleted the Diploma of Nursing from the Calendar and no further students of nursing were accepted.

Following the collapse of the course in Otago, Miss Moore and Miss Lambie took a proposal to Victoria University College in Wellington, where they received support from a Professor Hunter. 
The swift and successful establishment of a more modest six-month post-graduate course saw a course begin in 1928, which was to be the beginnings of the New Zealand School of Advanced Nursing Studies (Hughes, 1978). This course started at Wellington Hospital, having received government approval and was under the joint supervision of the Department of Health, Victoria University College and the Hospital Boards Association. The School of Advanced Nursing Studies (SANS) provided education for senior RNs, in preparation for administration and tutoring. It ran until 1978 with a number of changes and developments that saw the programme expand from six months to an academic year and go through curriculum changes including offering short courses in public health and specialisation in areas such as occupational health nursing. Students from SANS attended courses at what became Victoria University of Wellington (VUW), but plans in the 1960s for a School of Nursing Studies at the University to teach a two-year diploma in nursing administration lapsed due to funding issues (Barrowman, 1999).

Interest in university education for nurses resurged in the 1960s (Burgess, 1984), supported by the efforts of the nursing team in the Department of Health and reports from international consultants, as described in Chapter One. The first report, from Canadian university Director of Nursing, Miss Reid, found 'firm grounds' for nursing in universities, while a later report, by fellow Canadian Dr Helen Carpenter, had clear recommendations for the transfer of nursing education to the university setting. Despite this encouragement, pre-registration education moved into the polytechnic sector, as previously described, but post-registration university courses did become a reality. Barrowman (1999) describes the complexity that surrounded nursing studies being established at VUW and the efforts to ensure previous financial problems did not impede the successful implementation of university programmes for nurses. In the wake of the Carpenter report and pressure from nurses for the status of a university degree, the Department of Health invited VUW to discuss the introduction of an undergraduate course for nurses and the government set up a committee. Massey University began planning for an undergraduate nursing course and Auckland University also showed interest in an area VUW had until then had to itself. This competition, along with support from within the nursing profession, encouraged VUW to plan for an undergraduate nursing course. The C. L. Bailey Nursing Education Trust was established and with the money it raised and a grant from the NZ Nursing Education and Research Foundation, a senior lecturer, Beatrice Salmon, was appointed in late 1972 to begin a stage-three nursing studies course for 1973. Massey University also commenced a nursing programme in 1973. 
Nursing studies papers were initially included as part of a Bachelor of Arts degree. Victoria University offered three nursing papers while Massey University introduced a two year diploma course, at baccalaureate level, and a nursing major for a Bachelor of Arts degree (Workforce Development Group, 1988). According to Salmon (1983), about the same number of nurses enrolled as internal students in Nursing Studies courses at both Massey and Victoria Universities. However, Massey University, the only extra-mural university in NZ at the time, was bolstered by extra-mural nursing student numbers and experienced progressive growth in their nursing programme. A Chair in Nursing was established along with a Department of Nursing Studies that increased nursing options to include a Diploma in Social Sciences, a Bachelor of Arts with Honours, a Master of Arts, a Master of Philosophy and a Doctor of Philosophy (Workforce Development Group). Meanwhile, VUW was surprised in the late 1970 s by the results of the Langer report, which recommended a greatly expanded undergraduate nursing programme at VUW and advice that if VUW was not willing, Auckland was. A combination of uncertainty, indecision, the imminent retirement of Beatrice Salmon and small numbers of enrolments resulted in a decision to suspend nursing studies at VUW after 1981 (Barrowman, 1999). Salmon, while lamenting the demise of the VUW programme, noted with pride that between the two universities at least 500 to 1000 nurses had enrolled in university study. Nursing studies did recommence at VUW in 1986 with three staff in the 'Fieldhouse Centre' but, after staffing issues and degree programmes being established in the polytechnic sector, the programme was disestablished in 1993 and a post-graduate programme was established in 1994 (Adams, 2003; Barrowman).

While opportunities to study nursing within universities has been problematic, developments for RNs within polytechnics occurred rapidly. Although the pilot programmes leading to registration only commenced in 1973, permanent post-basic courses were established in 1974 (Workforce Development Group, 1988). The first courses were six-week community health nursing courses, designed as orientation or refresher options. Three polytechnics were offering these and other short courses, such as gerontology and oncology nursing, and others quickly became available in response to local need. With the aim of rationalising post-basic options for RNs, a number of existing post-basic courses were phased out, including the SANS diploma, the six-month hospital-based midwifery programmes and the Plunket Infant Welfare Course.

A new Advanced Diploma in Nursing (ADN) was then introduced into polytechnics in 1979. This programme was one academic year in length and full-time. The programme consisted of a common core module in advanced nursing studies and a single specialty option, initially offered 
from different locations. For example, community health nursing was based at Auckland Technical Institute, maternal child nursing at Wellington Polytechnic and medical/surgical nursing at Christchurch Polytechnic (Burgess, 1984). Later, some institutions such as Wellington Polytechnic, offered all specialties. A comprehensive evaluation of these programmes (Kennedy \& Taylor, 1987) asked why nurses chose to enrol in an ADN post-basic course rather than a university post-basic course. This evaluation noted that a significant number of graduates had done some form of study in the three years prior to undertaking the ADN. One-third (32\%, $\mathrm{n}=182$ ) had done some university study, although $80 \%$ of those 182 had taken "non-nursing papers" (p. 32) and two had previously completed SANS programmes. The results showed that nurses most often undertook the ADN in order to improve their overall knowledge and skills and preferred this option over a university diploma because it was full-time, lasted one year and had sponsorship available. Nurses were also more confident that they could meet the demands of the ADN course more easily than those of university study.

By the late 1980s to early 1990s, post-registration education options in nursing included courses at Massey University and VUW and post-basic courses ranging from weeks to months, including the ADN, all offered by polytechnics. Additionally, hospitals provided clinically orientated postbasic options which were mainly considered in-service education. Although most of these choices required registration for admission, few if any gave academic credit for prior qualifications. The move of pre-registration programmes from hospitals to the tertiary sector corresponded with an increased emphasis on education and more post-registration educational opportunities for RNs. However, there was no formalised structure for post-registration education at this time.

\section{Socio-political and educational circumstances}

Following a declining economy in the 1970s, a comprehensive strategy of economic, social and political reform was enacted throughout NZ from the late 1980s to the 1990s to improve the country's economic performance. This was initiated from 1984 when the newly elected Labour government, the Minister of Finance Roger Douglas and economists from the Treasury used market based ideology to radically restructure NZ's economic and social institutions (McLaughlin, 2003) around smaller government, market forces, efficiency and increased competition, policies known as "Rogernomics". Central to this was a managerial doctrine of giving freedom to managers which became known as the New Public Management (French, 1998). It was 
considered that the public sector, including health and education, needed to model itself more on private sector principles of management including the discretion of managers to recruit, retain, train and motivate staff to achieve their organisation's objectives. State sector reform resulted in a separation of non commercial functions from trading functions, the requirement that trading organisations be run as businesses and make a return with practices in line with the private sector (French). Through statutory instruments, such as the State-Owned Enterprises Act 1986, and the development of policies laced with ideology and a legislative framework designed to facilitate and support these policies, the fourth Labour government, followed by the National Government (1990-1999) transformed the structure, staffing and culture of the NZ public sector.

The health sector underwent massive and continual restructuring over this time. Initially, Area Health Boards were established, the first major restructuring of the health sector since 1938. Then the National Government implemented more radical reforms, establishing a managed market that separated purchasers from providers by creating four Regional Health Authorities (RHAs) to purchase their population's health and disability services. The Health and Disability Services Act 1993 abolished Area Health Boards and replaced these with 23 Crown Health Enterprises (CHEs), limited liability companies that were required to competitively tender for services and make a profit. Barnett and Barnett (1999) contend that the cost-saving strategy of closing or downsizing services, particularly rural hospitals, was one of the more contentious features of CHE activity. Nursing services, along with nursing hierarchies and structures, were severely reduced during this time as generic managers took control (Papps, 1997). While modification of this model occurred with restructuring of the four RHAs to one transitional authority and then to the Health Funding Authority, and CHEs transformed into Health and Hospital Services (HHS), the concept of the funder provider split remained and the governance model showed a preference for private rather than public solutions and a business rather than a public service culture (Barnett \& Barnett; French, 1998). However, CHEs were unsuccessful, with all but two in financial deficit by 1996 .

Labour market reform, to support these changes, came with the Employment Contracts Act 1991. This provided the potential for labour flexibility but French (1998) argues it directly impacted on the control of nursing practice. National industrial awards were replaced by a series of worksite contracts linked to the policies and budgets of individual CHEs. National bargaining power was reduced and nursing practices became constrained by budgets, patient turnover and medical model costing categories. The profit concept also affected nursing education, with CHEs only 
providing clinical placements for students via a contract with payment for such access. The Hospitals Amendment Act 1996 attempted to gain greater flexibility in nurse staffing by allowing the substitution of different nursing professionals (Barnett \& Barnett, 1999). Managers used bench-marking data to monitor performance, improve productivity and reduce costs. Cost containment resulted in a reduction of nursing services, restrictions on the length and types of care available to patients and limits on in-service development or education available to staff.

Tertiary education, with the important role of ensuring a knowledge economy, was identified as key to improving the economic picture of NZ and hence became the focus of extensive reviews and reforms. In 1987, before the election, the Labour government began a tertiary education review that was completed in 1988 (McLaughlin, 2003). Treasury's post-election briefing papers dedicated an entire volume to education and envisaged the extension of the New Right, freemarket ideology to public education (Jacobs, 2005). Public submissions to the 1987-1988 review supported continued income support for all students and little change so, just a month later, the government appointed Professor Hawke to head a working group to advise on the possible role of tertiary education in social and economic life and to provide a policy action framework. In only four months the taskforce reported back with recommendations quite different to those suggested by the public (McLaughlin). The Labour government adopted many of the Hawke Report recommendations, introducing student fees, student loans, a bulk funding system applying the same rules to all institutions, devolved decision-making, and created polytechnics and colleges of education as corporate bodies with greater autonomy. The Education Act 1989 and subsequent amendments brought these to fruition. The Department of Education was broken up into six separate agencies, including a new, small, policy-orientated ministry. The Education Amendment Act 1990, which gave polytechnics the power to award degrees, opened up the possibility of a pre-registration degree for nursing.

In the 1990s the National government moved to a more competitive market-based approach with emphasis given to the private returns of education and the need for individuals to partly finance their own advancement, even through debt. Institutions were encouraged to be more innovative and responsive to the market, to increase student participation while constraining costs through efficiency and to remain competitive as the market was opened up to new private sector providers. The impact of market forces meant courses which did not attract sufficient enrolments to make a profit were no longer offered (French, 1998). Polytechnics took advantage of their new autonomy, creating degree programmes in subjects such as nursing, and embracing the 
entrepreneurial spirit, sometimes successfully and sometimes with disastrous financial consequences (McLaughlin, 2003).

Institutions responded to the changing circumstances and mergers and takeovers became common. One polytechnic, the Auckland Institute of Technology, was granted university status in 2000 to become NZ's newest and eighth university, Auckland University of Technology (AUT). Massey University merged with Wellington Polytechnic and so added a pre-registration programme to existing nursing studies courses. In this new corporate environment size and efficiency were important, so institutions competed for and offered programmes in different geographical locations nationally and internationally while smaller institutions struggled financially. UCOL, the 'rebranded' Manawatu Polytechnic, took over the fiscally troubled Wanganui and Wairarapa Polytechnics and ran nursing related programmes throughout NZ at different times, for example, in Christchurch, Northland and Gisborne and even went to India. Nursing appears to have been at the forefront of development in the polytechnic sector. The majority of the first degree programmes offered by polytechnic institutions were in nursing and some Schools of Nursing have gone on to offer post-graduate options, also new territory for these institutions.

This period of rapid change and public sector reform, along with the restructuring of health and education, created forces that radically altered dynamics and structures within the nursing profession. The government announced in 1987 that occupational licensing would be reviewed in the belief that professions were over-regulated and protectionist. With the review of the Nurses Act 1977 and pending omnibus legislation, professional moves for competence-based practising certificates started. French (1998) argues that monitoring ongoing competence and recognition of qualifications and professional development were aspects of assessing outcomes and appraising performance that fitted with New Public Management. Amidst this upheaval and change many nurses became cynical, disillusioned or left nursing (Papps, 1997). However, Jacobs (2005) contends that as old nursing structures and leadership platforms were swept away, new possibilities were created. Change in nursing education had a reciprocal influence on professional nursing over this time. 


\section{The establishment of RN to BN programmes}

Jacobs (2005) argues that the change in nursing education to pre-registration degrees occurred somewhat by chance and opportunity, as nurses as were not instrumental in the passage of the Education Amendment Act 1990. However, she identifies that nursing soon saw the opportunity the Act created and the debate about a degree as entry to practice was rekindled when a group of senior nurses discussed its implications at the New Zealand Nurses Association's (NZNA) annual conference in 1990 and raised the idea of a national forum. The Nursing Council of New Zealand (NCNZ) was asked to facilitate such a forum and the steering committee, with representatives from NZNA, the NZ College of Midwives, Nurse Educators in the Tertiary Sector (NETS), the Chief Nurses of NZ, NCNZ and the Department of Health, became known as the Vision 2000 Committee.

Before the two-day forum was held in March 1991, three institutions, Otago Polytechnic, Auckland Institute of Technology, and Wellington Polytechnic were already developing degree programmes (Jacobs, 2005). The forum in Auckland attracted approximately 260 participants from a cross-section of nursing and discussed a wide range of issues through presentations and workshops (Vision 2000 Committee, 1991). Jacobs states that the "participants seemed to be caught in a whirlpool" (p. 186) as the concerns raised did not focus on the opportunity at hand but covered many things from the issue of enrolled nurses, the development of advanced nursing knowledge and practice, fostering research, bicultural issues and autonomous Maori development, universities versus polytechnics and how a degree differed from a diploma. She argues that this was reflective of a profession divided by extensive financial, public sector and social change. Also, there had been no long exploratory lead-up to degree preparation for entryto-practice, as in some areas diploma programmes had only recently replaced hospital programmes. The lack of nursing hierarchies and central decision-making also meant opportunity for those feeling unrestrained and comfortable with competition (Jacobs).

The report from the forum was released in May 1991 and was followed by a discussion document (Allen, 1992) requesting submissions by March 1992. Submissions were analysed and the Vision 2000 Committee published A Framework for Nursing and Midwifery Education in New Zealand in December 1992 but events had already overtaken the recommendations, with three polytechnic pre-registration degree programmes commencing in early 1992. For example, the first of 22 recommendations in the discussion document was "That by the year 2005, the completion of a four year baccalaureate degree become the only criterion for entry to practice in both midwifery 
and nursing in NZ" (Allen, p. 4). The Vision 2000 Committee's December framework was silent on whether the degree should be a four-year or a three-year degree, and the timeframe for making all pre-registration programmes degree level had been brought forward to 1997 (Vision 2000 Committee, 1992).

In December 1991 Kai Tiaki (NZ Nursing Journal), ("Nursing by degrees", 1991/1992) described three polytechnic degree programmes due to commence in early 1992. Otago Polytechnic was offering a three-year $\mathrm{BN}$ whereby the graduate gained both a $\mathrm{BN}$ and registration as a Comprehensive Nurse, and it was also offering an experimental direct-entry three-year Bachelor of Midwifery. Auckland Institute of Technology (AIT) was offering a four-year Bachelor of Health Science, with the fourth year developed in conjunction with the Auckland Medical School and to be studied with other health professionals. Wellington Polytechnic's degree was also a four-year Bachelor of Health Science but this programme offered a common first year with the option to apply for either the three-year diploma programme or the four-year degree programme in the second semester.

Both AIT and Wellington Polytechnic were described as having approval and accreditation from the NZ Qualifications Authority (NZQA) subject to certain conditions, while it was written that Otago Polytechnic had received approval and accreditation but was awaiting the Otago Polytechnic Council's agreement to NZQA conditions. Otago Polytechnic's degree in nursing was approved as meeting the standards for registration of Comprehensive Nurses at the NCNZ meeting on 18 February 1992. At the same meeting Wellington Polytechnic's four-year degree had approval deferred until a legal opinion was received. This was because NCNZ was not sure if it was legally acceptable for registration to occur upon completion of the third year of a four-year course. At a later meeting (NCNZ, 5 May, 1992) it was accepted by NCNZ that

a person who undertakes a four-year degree course in comprehensive nursing will not be entitled to registration as a comprehensive nurses unless the four-year degree course comprises in part a three-year nursing course in comprehensive nursing which three-year course would itself entitle the student to registration as a comprehensive nurse.

Ultimately this debate was settled by the Ministry of Education who refused to fund a four-year degree programme. All programmes became three-year degrees (Papps \& Kilpatrick, 2002). 
From this first description of degree programmes leading to registration, arrangements for existing RNs to gain the same degree were outlined ("Nursing by degrees", 1991/1992). Alison Dixon (personal communication, November 16, 2006), then Head of the School of Nursing at Otago Polytechnic, explained that feedback from nurses during consultation on moving from diploma to degree level pre-registration programmes indicated they wanted the degree to be available to RNs. Both she and her staff were committed to opening the programme up to RNs once a course had been offered for the first time because they knew a $R N$ degree-prepared workforce was required to mentor students and to grow future practice development. While some difference existed (see Table 3), it appeared all three institutions expected RNs to complete the equivalent of one year of full-time study to gain an undergraduate degree. As this was new territory, no guidelines existed specifying the requirements for RNs. Dixon described the process of deciding how many papers or credits should be required as referring to the literature, deciding what was core to a degree, such as nursing knowledge and research threads, and then "basically making it up" (personal communication, November 16, 2006).

\section{Table 3: Description of degree programmes for RNs}

\begin{tabular}{|l|l|l|}
\hline Otago Polytechnic & AIT & Wellington Polytechnic \\
\hline $\begin{array}{l}\text { A RN may be able to } \\
\text { graduate with one year } \\
\text { of full-time study, } \\
\text { depending on } \\
\text { experience, after July } \\
1992 .\end{array}$ & $\begin{array}{l}\text { RNs without an } \\
\text { undergraduate degree } \\
\text { and with requisite nursing } \\
\text { experience and } \\
\text { qualifications may enter } \\
\text { at the fourth year of a } \\
\text { degree. }\end{array}$ & $\begin{array}{l}\text { Conversion programme: RNs will be able } \\
\text { to apply for the one-year conversion } \\
\text { programme which leads to the degree. } \\
\text { This programme has seven prerequisite } \\
\text { courses called the transition programme- } \\
\text { exemption for five of these may be given } \\
\text { on the basis of prior learning. The two } \\
\text { required courses can be completed in a } \\
\text { period of four weeks' full-time study, close } \\
\text { to entry to the conversion programme. }\end{array}$ \\
\hline
\end{tabular}

Source: “Nursing by degrees”, (1991/1992). NZ Nursing Journal, Kai Tiaki, 84(11), 25-26.

Despite the predictions (Horsburgh, 1991, p. 27) that not "every polytechnic will wish to offer a degree programme", by 1996 every polytechnic previously offering a diploma in nursing was providing a nursing degree. Jacobs (2005) argues that while conversations did occur at local and regional levels between nursing leaders, educational institutions, advisory committees and communities, it was the market that drove this development. Prospective students and their families preferred degree options and institutions offered what consumers wanted in order to 
survive. Not every institution offered a degree option for registered nurses. While I was unable to obtain data from all institutions to verify how many institutions did or did not offer this programme at some time, one institution responded that they had never offered the programme and it is fair to assume that in some areas market forces may have resulted in a decision that such a programme would not make a profit.

\section{A changing professional context}

By 1996 all existing 15 polytechnic nursing departments had been approved by NCNZ and NZQA "to offer the comprehensive nursing course as an undergraduate degree in either Nursing or Health Science (Nursing)" (NCNZ, 1996a, p. 8) and diploma programmes stopped taking new students. At the NCNZ meeting on 9 April 1998 it was resolved that entry to the register of comprehensive nurses would be by Bachelor degree only. Significant other developments occurred in the late 1990s both for professional nursing in NZ and for nursing education (Jacobs, 1998; Papps \& Kilpatrick, 2002). In February 1998 a Ministerial Taskforce was established to 'release the potential of nursing' (Ministerial Taskforce on Nursing, 1998) and then on 12 May, International Nurses' Day, an amendment to the Medicines Act 1981 was announced that would enable nurse-prescribing. Also in May, the NCNZ released the 'Framework, Guidelines and Competencies for Post-Registration Nursing Education' (NCNZ, 1998). This was updated to be the 'Framework for Post-Registration Nursing Education' in 1999 (NCNZ, 1999a). The framework was an attempt to rationalise post-registration education and qualifications and to provide a structure and process for approval and monitoring to ensure some national consistency, the lack of which had caused frustration for some time. Neither the 1998 nor the 1999 framework mentioned RNs obtaining a degree as part of post-registration education. RNs with and without a nursing Bachelor degree were considered the same with the emphasis for post-registration education on post-graduate study. The documents insisted that all providers have a NCNZ approved recognition of prior learning (RPL) policy to give "appropriate credit for learning that has occurred through precious experiences" (NCNZ, 1999b, p. 4).

By the late 1990s a significant number of post-graduate programmes were being developed, including post-graduate certificate, diploma and Masterate level programmes. These programmes were being established by both universities and polytechnics. Jacobs (1998, p. 5) noted that "it was anticipated that as degree studies became more accessible, previously qualified nurses would complete a first degree, and there would be a concomitant increase in 
numbers of nurses taking up post-graduate study". While acknowledging that to some extent that did appear to be happening, she claimed that there were still issues with programme accessibility and the balance between clinical components and an academic/research focus. Following an 'unbundling' exercise in 1994 funding earmarked for post-registration education of health professionals was identified and the Clinical Training Agency (CTA), a division of the Health Funding Authority, was established. Jacobs asserted that only a small proportion of this funding was committed to nursing and programmes were substantially clinical in nature and contracted yearly, on a contestable basis. However, the funding did make post-graduate nursing education more accessible than in the past. By this time nursing was developing a greater presence in the university setting. The University of Auckland established a new undergraduate degree in nursing in 1999 and Massey University, having merged with Wellington Polytechnic, also commenced an undergraduate nursing degree leading to registration on its Palmerston North campus, in competition with the local polytechnic provider. With AUT, there were now three universities providing undergraduate nursing degree programmes. These universities, along with VUW and a number of polytechnics offered a range of post-graduate study options for nurses.

While the Vision 2000 framework was never adopted, Papps and Kilpatrick (2002) argue that it provided a focus for future nursing education. One recommendation, that methods be implemented which ensured ongoing professional competence (Allen, 1992), resulted in criteria for competence being discussed in documents (NCNZ, 1996b, 2001a, 2001b) from the 1990s that included requirements for ongoing professional development and education. This finally came to fruition with the passing of the Health Practitioners Competence Assurance Act (2003), which came into force from September 2004. Criteria mandated by NCNZ for RNs to demonstrate competence and obtain an annual practising certificate included evidence of a minimum of 60 hours of professional development in a three-year period. Clinical career pathways (CCPs) had been introduced to NZ in the late 1980s as a mechanism to recognise and reward expertise in clinical practice and higher levels of practice. In 2003 representatives from the National Nursing Organisations established a working party to progress earlier work for a national framework and changed the term from CCP to professional development and recognition programmes (PDRPs) to better fit the NCNZ professional development requirements. The 2004 report of the working party identified four levels of practice and described how formal education could assist career and professional development (National PDRP Working Party, 2004). PDRP programmes support and assess RNs' development of a professional portfolio that provides evidence of their level of practice and competence. Nurses who complete a NCNZ approved 
PDRP programme meet the requirements for competence to obtain an annual practising certificate and are therefore not subject to the NCNZ audit requirements. These programmes are now offered by most secondary care and many primary care workplaces. They are also available through professional organisations such as the NZ Nurses Organisation (NZNO) and the College of Nurses, Aotearoa. The PDRP levels are now recognised in multi-employer collective agreements (MECA) with a payment for RNs achieving higher levels. This professional requirement and recognition of ongoing education confirmed for individual $\mathrm{RNs}$ and employers that post-registration education was a professional expectation.

In 2008 nursing education in NZ includes undergraduate degree programmes leading to registration, with these having been the standard for over 10 years, a range of post-graduate and post-registration education options available for RNs, and a professional expectation that RNs provide evidence of ongoing professional development and education. There are 16 Schools of Nursing across polytechnics and universities who offer undergraduate nursing degree programmes. Most of these offer a variety of post-registration nursing education options. As part of this research the websites and marketing material of these institutions were examined to see if they explicitly offered a degree option for existing RNs. Where a programme was advertised, their marketing material was requested. Although seven of the 16 Schools advertised a RN to BN programme, only six of these were still offered. The seventh had discontinued its programme and did not provide information other than that they now recommended RNs begin with a postgraduate certificate because it was no longer considered necessary for RNs to go back to Bachelor level study. The requirements for each of the six programmes, and the RPL given to RNs, varied between providers. Table 4 gives some examples of the different requirements

Table 4: Requirements and RPL given to RNs for an undergraduate nursing degree

\begin{tabular}{|c|c|c|c|c|}
\hline & Institution A & Institution B & Institution C & Institution D \\
\hline $\begin{array}{l}\text { Credits } \\
\text { needed to } \\
\text { complete } \\
\text { a degree }\end{array}$ & $\begin{array}{l}60 \text { credits } \\
=4 \times 15 \text { credit } \\
\text { papers }\end{array}$ & $\begin{array}{l}100 \text { credits to } \\
\text { complete } \\
-40 \text { credits } \\
\text { compulsory } \\
\text { - } 60 \text { credits optional }\end{array}$ & $\begin{array}{l}\text { Based on the year of } \\
\text { registration } \\
-1994+=60 \text { credits } \\
=4 \text { papers } \\
1974-1993=90 \\
\text { credits }=6 \text { papers } \\
\text { - Prior } 1973=120 \\
\text { credits }=8 \text { papers. }\end{array}$ & $\begin{array}{l}\text { Depends on before } \\
\text { or after } 1994 \\
+ \\
\text { other recognition } \\
\text { given for ADN } \\
\text { usually } 4 \text { to } 6 \text { papers } \\
\text { required. }\end{array}$ \\
\hline RPL & 300 credits & 260 credits & $240,270,300$ & Not specified. \\
\hline
\end{tabular}




\section{The significance of $\mathrm{RN}$ to $\mathrm{BN}$ programmes}

In an attempt to quantify the numbers of RNs who had completed a RN to BN programme and assess the significance of these programmes on the qualifications of the RN workforce, statistics on the numbers of RNs with degree qualifications were sought. However, NCNZ stopped recording post-registration qualifications in 1973 and it was not until 1999, when they surveyed all nurses applying for annual practising certificates about their initial qualification, subsequent nursing or midwifery qualifications and other tertiary qualifications held (NCNZ, 2000), that a decision was made to ask for this information on a regular basis. The information that is now obtained is self-reported, hence often incomplete and unverified, and NCNZ does not differentiate between nursing and non-nursing qualifications. Therefore, information on the numbers and types of qualifications held by nurses is potentially incomplete and unreliable. Additionally, it was explained by the Registrar of NCNZ (B. Ayling, personal communication, October 27, 2006) that the complex and mobile nature of the nursing workforce blurs the statistical picture. Nursing has a number of RNs going overseas, arriving from overseas and leaving and rejoining the workforce at any one time. For example, in the year 2004-2005 NCNZ registered 1,612 RNs from overseas. Of those, 263 had not entered the workforce here or had no APC and 253 were still overseas (B. Ayling, personal communication, October 27, 2006). Changes in reporting the data also influence its validity. In the 1999 survey of educational qualifications (NCNZ, 2000) midwives and enrolled nurses (ENs) were part of the sample, yet midwives and ENs were not included in the 2006 information obtained. From 2004 midwives were registered by their own Midwifery Council and no longer came under the jurisdiction of NCNZ. However, some midwives, who were also nurses, were included. Previously NCNZ received all APC information, and hence data, by 31 March of each year. This has now changed to four times per year meaning a snapshot of the whole profession at one particular time is no longer possible.

This complexity was acknowledged in the NCNZ 1999 survey (NCNZ, 2000). The survey, noting that 1,306 nurses were overseas, had a $71 \%$ response rate from nurses and midwives practising at that time. The survey asked for information on education and training programmes undertaken that were formal and of at least six months' duration, including non-nursing tertiary qualifications. The report remarked on the confusion that surrounds post-registration and post-graduate qualifications, with some respondents reporting they possessed post-graduate qualifications when these were clearly post-registration qualifications. Post-graduate qualifications must be 
completed with a recognised tertiary educational institution at Masters level or level eight on the NZQA framework. The changing nature of post-registration qualifications also warranted comment, with a large increase in qualifications completed in the previous five years. Hospitalbased post-registration qualifications reached a plateau during the period 1980-1994 and from 1995 to 1999 the "number of Bachelor degrees increased by $542 \%$, with increases noted across all post-graduate qualifications" (NCNZ, p. 8).

The 1999 survey (NCNZ, 2000) showed 18.2\% of the respondents had a Bachelor degree, of which $7.2 \%(2,287)$ received this as their initial qualification. Approximately $1,100-1,200 \mathrm{NZ}$ nursing students pass the NCNZ state final examination to become RNs each year (NCNZ, 2006). Given that the graduates from the first three degree programmes leading to registration would have only sat the state final exam in 1994, by 1999 the percentage of RNs with initial degree qualifications amongst the 31,801 respondents would be low. The report stated that $4 \%$ of those who responded held Bachelor degrees in non-nursing fields. A significant number of the remaining $7 \%$ of nurses with Bachelor degrees may have obtained these from an $\mathrm{RN}$ to $\mathrm{BN}$ programme but this could not be confirmed from the data provided. Some data presented did relate specifically to post-registration Bachelor degrees. One table of data reported postregistration qualifications by educational institutions. This identified that 687 or $19.5 \%$ of the 3,509 total post-registration Bachelor degrees came from institutions outside NZ and 587 or $16.7 \%$ came from Massey University, the institution that had offered extramural options and postregistration nursing programmes since 1973. Another table of data demonstrated that 2,706 or $77.1 \%$ of the 3509 obtained their Bachelor degree between 1995 and 1999, with only 803 or 22\% of the respondents with Bachelor degrees obtaining these prior to 1995 (NCNZ, 2000).

Qualifications statistics were also reported from data collected by NCNZ from workforce survey information collected 1 April 2002 - 31 October 2002 (NCNZ, 2002). Again this was self-reported rather than verified data that included RNs, midwives and ENs. The report noted that $15 \%$ of the workforce was from overseas and that while the majority still came from the United Kingdom/Ireland, more were now immigrating from Asia and South Africa. There were a total of 47,696 respondents to the survey, including RNs, ENs and midwives. In $2002,26.4 \%$ of nurses and midwives had an initial registration (13.4\%), a post-registration $(8.4 \%)$ or a non-nursing (4.6\%) Bachelor degree (see Table 5), an 8.2\% increase since 1999. 
Table 5: Nurses with degree qualifications, 2002

\begin{tabular}{|l|c|c|c|c|}
\hline \multicolumn{1}{|c|}{ Qualification } & $\begin{array}{c}\text { Registered } \\
\text { nurse/ } \\
\text { midwife }\end{array}$ & $\begin{array}{c}\text { Enrolled } \\
\text { nurse }\end{array}$ & $\begin{array}{c}\text { Numbers of } \\
\text { active nurses } \\
\text { /midwives }\end{array}$ & $\begin{array}{c}\text { Percentage of } \\
\text { total with APC }\end{array}$ \\
\hline $\begin{array}{l}\text { Bachelor Degree in } \\
\text { nursing (registration) }\end{array}$ & 6,070 & & 2,181 & 12.7 \\
\hline $\begin{array}{l}\text { Bachelor Degree in } \\
\text { nursing (post-registration) }\end{array}$ & 4,016 & 8 & 4,024 & 8.4 \\
\hline $\begin{array}{l}\text { Bachelor Degree (non- } \\
\text { nursing) }\end{array}$ & 2,152 & 29 & 6,060 & 4.6 \\
\hline $\begin{array}{l}\text { Bachelor Degree in } \\
\text { midwifery (registration) }\end{array}$ & 353 & & 353 & 0.7 \\
\hline Total & $\mathbf{1 2 , 5 9 1}$ & & & $\mathbf{2 6 . 4}$ \\
\hline
\end{tabular}

Source: Nursing Council of New Zealand. (2002). New Zealand registered nurses, midwives and enrolled nurses: Workforce statistics. Wellington: Author

A further $5.5 \%$ held post-graduate qualifications, which meant $68.1 \%$ of nurses were not at degree level. Also, 11.3\% were studying for further qualifications (see Table 6). Of these, $4.2 \%$ were studying towards a Bachelor degree. However, the combined total of those studying at post-graduate level was higher than those studying at Bachelor level. The statistics on RNs only showed that 30,920 were actively practising and that between them they had 26,584 postregistration qualifications, with some people holding more than one of these. This confirms the comments by the Registrar (B. Ayling, personal communication, October 27, 2006) that the majority of RNs were engaged in ongoing professional development and education. Of the 26,584 post-registration qualifications, 6614 were listed as post-registration Bachelor degrees in nursing, 3216 as non-nursing Bachelor degrees and 5177 as post-graduate qualifications. The report noted that the highest cohorts of nurses holding post-registration Bachelors degree were aged between $40-49$ years of age. 
Table 6: Nurses and midwives studying for further qualifications, 2002*

\begin{tabular}{|l|c|c|}
\hline \multicolumn{1}{|c|}{ Qualification to be gained } & Number & $\begin{array}{c}\text { Percentage of } \\
\text { total }\end{array}$ \\
\hline Bachelors Degree & 2,002 & 4.2 \\
\hline Post-graduate studies at Masters level & 2,294 & 4.9 \\
\hline Other & 1,109 & 2.3 \\
\hline Subtotal studying & $\mathbf{5 , 4 0 5}$ & $\mathbf{1 1 . 3}$ \\
\hline Not studying & 41,077 & 86.1 \\
\hline Not stated & 1,214 & 2.5 \\
\hline Total & $\mathbf{4 7 , 6 9 6}$ & $\mathbf{1 0 0}$ \\
\hline
\end{tabular}

* Source: Nursing Council of New Zealand. (2002). New Zealand registered nurses, midwives and enrolled nurses: Workforce statistics. Wellington: Author

Data were obtained from NCNZ on the tertiary qualifications of RNs as at 31 March 2006. This information only related to those registered in the $\mathrm{RN}$ scope of practice and again was selfdeclared, unverified data except where the qualification led to registration. The data and the format in which these were given provided limited details specific to RNs who may have undertaken an RN to BN programme. The data showed that 20,105 RNs had declared they held one or more of 25,838 tertiary qualifications. At this time NCNZ issued 43,583 APCs to RNs, enrolled nurses and nurse assistants (NCNZ, 2006). The type and origin of qualifications revealed the diversity of the data, with four Bachelors of Music, 10 dental certificates and many unknown abbreviations such as BTM and BTR, with many obtained in 59 countries other than NZ, including Botswana, Egypt and Peru.

What was evident from the statistics was that while there are increasing numbers of RNs with initial and post-registration degree qualifications, the majority gained since 1995 , over $50 \%$ of the NZ nursing profession still does not have a degree or higher qualification. While the percentage of RNs without a degree is reducing as degree qualified graduates enter the profession, NZ now registers more nurses annually from overseas than from within NZ (see Table 7) and the majority of countries do not have degree-level registration requirements. This means that the numbers of graduates from pre-registration degree programmes are effectively balanced by the numbers registered from overseas, resulting in little increase in the percentage of degree-qualified RNs within the workforce. Nurses from overseas are significant within the workforce, although many that gain NZ registration never actually practise here (B. Ayling, personal communication, October 27, 2006). There were increasing numbers of overseas RNs within the RN to BN 
programme used for this research. However, none responded as participants. As the 2002 (NCNZ, 2002) statistics show that more RNs held post-registration degrees than RNs held initial registration degrees, it can be surmised that $\mathrm{RN}$ to $\mathrm{BN}$ programmes have had some contribution to those figures. However, it was not possible from the information available to quantify either the numbers of graduates from $\mathrm{RN}$ to $\mathrm{BN}$ programmes or the significance of these programmes on the qualifications of the RN workforce.

Table 7: Registrations per year form NZ and overseas

\begin{tabular}{|l|c|c|c|}
\hline Date & NZ & O/seas & Total \\
\hline 1999 & 1,214 & 1,040 & 2,254 \\
\hline 2000 & 1,309 & 1,114 & 2,423 \\
\hline 2001 & 1,237 & 1,060 & 2,297 \\
\hline 2002 & 1,199 & 1,311 & 2,510 \\
\hline 2003 & 1,169 & 1,515 & 2,684 \\
\hline 2004 & 1,310 & 1,720 & 3,030 \\
\hline 2005 & 1,224 & 1,574 & 2,798 \\
\hline 2006 & 1,313 & 1,560 & 2,873 \\
\hline
\end{tabular}

Source: NCNZ annual reports 2003 \& 2006 (NCNZ, 2003; 2006).

Nine of the 16 Schools of Nursing surveyed for information on programmes for RNs to obtain an undergraduate nursing degree (see Appendix 3) responded, with only one having never offered a programme for RNs. The findings of the survey are summarised in Table 8. 
Table 8: Numbers of graduates, by year, from institutions offering RN to BN programmes.

\begin{tabular}{|c|c|c|c|c|c|c|c|c|c|}
\hline & A & B & C & D & $E$ & $F$ & $\mathbf{G}$ & $\mathrm{H}$ & Total \\
\hline $\begin{array}{l}1^{\text {st }} \text { year } \\
\text { offered }\end{array}$ & 1995 & 1996 & 1995 & 1997 & 1992 & 1995 & 1995 & 1998 & \\
\hline 1994 & & & & & 22 & & & & 22 \\
\hline 1995 & & & ${ }^{\star} \mathrm{NNA}$ & & 38 & ${ }^{\star} \mathrm{NNA}$ & 19 & & 57 \\
\hline 1996 & 42 & 8 & ${ }^{\star} \mathrm{NNA}$ & & 38 & ${ }^{\star} \mathrm{NNA}$ & 24 & & 112 \\
\hline 1997 & 32 & 21 & ${ }^{*} \mathrm{NNA}$ & 8 & 31 & ${ }^{*} \mathrm{NNA}$ & 44 & & 136 \\
\hline 1998 & 34 & 45 & ${ }^{*} \mathrm{NNA}$ & 44 & 59 & ${ }^{\star}$ NNA & 10 & 0 & 192 \\
\hline 1999 & 36 & 41 & ${ }^{*} \mathrm{NNA}$ & 46 & 33 & 18 & 53 & 18 & 245 \\
\hline 2000 & 34 & 30 & ${ }^{*} \mathrm{NNA}$ & 16 & 45 & 22 & 42 & 31 & 220 \\
\hline 2001 & 34 & 32 & ${ }^{*} \mathrm{NNA}$ & 27 & 27 & 15 & 37 & 27 & 199 \\
\hline 2002 & 19 & 25 & 16 & 3 & 10 & 14 & 35 & 23 & 145 \\
\hline 2003 & 25 & 30 & 20 & & 3 & 5 & 28 & 21 & 132 \\
\hline 2004 & 10 & 14 & 11 & & 1 & 4 & 9 & 5 & 54 \\
\hline 2005 & 6 & 11 & 2 & & 1 & 1 & 15 & 5 & 41 \\
\hline 2006 & 3 & 16 & 3 & & 1 & & & 3 & 26 \\
\hline Total & 275 & 273 & $\begin{array}{c}52+ \\
7 \text { yrs } \\
\text { of NNA }\end{array}$ & 144 & 309 & $\begin{array}{c}79+ \\
4 \text { yrs } \\
\text { of NNA }\end{array}$ & 316 & 133 & 1581 \\
\hline
\end{tabular}

${ }^{*} \mathrm{NNA}=$ numbers of students not available despite the programme being offered at that time

Schools commenced programmes for RNs between 1992 and 1998, with 1995 being the most common start date for programmes. Some institutions were unable to supply the student numbers from early years of the programme and one respondent noted that the numbers may not have been completely accurate as the information was not available in a ready format. While the data are acknowledged as incomplete, a pattern is clearly discernable. What is immediately evident is that these programmes had their peak numbers between 1996 and 2003. Since 2004 there has been a marked decline in the numbers of graduates, with four of the eight programmes no longer offered. Of the four institutions still offering this option, one stated that because of dwindling numbers, separate teaching was no longer run so RNs attended the same classes as pre-registration students but that they were counselling applicants to apply for post-graduate options. It makes sense that with low numbers such programmes are no longer economically viable, but it is unclear whether this is because fewer RNs are interested in this option or because more are being counselled into post-graduate options. While it is not possible to quantify the 
numbers of graduates from these programmes, it is clear that some institutions had around 300 RNs qualify with a degree over a 10 year period.

\section{Chapter review}

The focus of this research, $\mathrm{RN}$ to $\mathrm{BN}$ programmes, was the product of a history of interest in degree programmes being available for nurses. Individuals and professional groups even donated money to ensure the survival of university-based post-registration education after early attempts to secure these had failed. The establishment of RN to BN programmes occurred as a result of the introduction of pre-registration degree programmes, which occurred following the socio-political and economic restructuring of the 1980s and 1990s. The passing of the Education Amendment Act 1990, which allowed polytechnics to award degrees, provided the opportunity for degree-level pre-registration education and this opening was quickly seized, even before professional consensus on the issue. Transition arrangements, or RN to BN programmes, were envisaged from the inception of pre-registration degree programmes. While not all institutions offered this option to RNs, the majority did, although the requirements and RPL given varied between institutions. Quantifying the numbers of graduates from these programmes has not been possible, but it is appears that numbers peaked between 1996 and 2003 and now many such programmes are ending. While the exact number of graduates or the impact on qualifications could not be determined, the evidence shows that significant numbers of RNs took the opportunity these programmes provided to obtain an undergraduate degree.

The following chapter is the first of two chapters that discusses the findings from the personal perspective of this study. Data were obtained from interviews with eight RNs who undertook a $\mathrm{RN}$ to $\mathrm{BN}$ programme and provide insights related to their decision and experience of completing the programme. 


\section{CHAPTER FIVE}

\section{The Personal Perspective: Climbing Mountains}

\section{Introduction}

I mean, you don't get anywhere if you don't try, you don't climb a mountain unless you take the first step up the hill, but you also make sure that it's a mountain that you can climb and going on from there, you know, it's having the tools to reach the top of the mountain that you're climbing I guess. (Phillip, p. 12)

This is the first of two chapters that consider the perspectives of eight Registered Nurses (RNs) who had completed a RN to Bachelor of Nursing (BN) programme. As the participants of this study explained their reasons for and experience of undertaking a $\mathrm{RN}$ to $\mathrm{BN}$ degree, rich data were collected that highlighted personal aspects of this case. Undertaking a BN degree was described as a challenge by all the participants. Metaphorically, it was akin to climbing a mountain. In this chapter the findings related to the decision and experience of undertaking a RN to BN programme are presented, including the participants' perceptions as to the worth of the programme. While not conventional within case study, in places literature is provided to strengthen and support the experiences and comments made by the participants. Where possible this was New Zealand (NZ) evidence, such as Seaton (1998) or Blackie (2001), but these were the only NZ studies that considered the experience of RNs studying for an undergraduate nursing degree.

In making their decision to complete a degree via a $\mathrm{RN}$ to $\mathrm{BN}$ programme most considered other options but what was important was that it was the right time and the belief that it was achievable. Completing a degree was hard work, as assignments were time-consuming and demanding which affected family and other responsibilities. Specific skills, support and sustenance were required. However, the participants also described enjoyment and a sense of personal satisfaction from succeeding in the programme. Achieving their goal was like reaching the top of a mountain.

\section{Deciding which mountain to climb}

As there is no formal requirement for $\mathrm{RNs}$ to obtain a degree and controversy surrounds the need for such a qualification, the participants were asked about their reasons for undertaking such a 
programme. As they discussed their considerations and reasons, most seemed aware that they were taking on a large climb. Professional impetus was a factor for each of those interviewed.

I knew that I had to do something, I couldn't just sit where I was ... there were lots of things really going on in the profession, there was this responsibility that we've got to upskill ourselves and although, if you looked at my CV ... I was doing bits and pieces there was nothing ... that would've counted towards up-skilling myself but I thought the RN to $B N$ was a way of really bringing my nursing into the $21^{\text {st }}$ century if you like ... really bringing myself up to what was happening in the profession at that time. (Millie, p. 5)

Professional motivation included prospects for career promotion and employment mobility.

When I first went into it I would've only been about 26 and I felt that it was important for me to keep up my education if I was going to carry on with nursing which I intended to and still do and I feel, as a registered nurse, you do need to have a Bachelor degree in nursing to be able to have more opportunities open up to you ... it just opens the doors. If the opportunity arises then I want to be able to take that opportunity without having to work towards it at the time. (Kate, p. 3)

Career prospects were more commonly combined with professional interest in changes within the profession.

I realised things were happening in nursing that maybe I wasn't aware of and I was curious about those ... there was also that selfish motive too that I could work for [School of Nursing] which I was interested in doing but I had to have a higher qualification than the one I would be teaching so I needed to get a degree ... it was that opportunity maybe to turn it into more of a career than just, you know, a job that paid the mortgage.

(Bessy, p. 5-6)

All the participants linked undertaking their degree with the professional responsibility of being up-to-date and a number commented on the career implications. Blackie (2001) and Seaton (1998) each found that RNs who had returned to study had an awareness of qualification escalation resulting in the need to 'keep up' or they could be 'left behind'. Participants in this study expressed similar sentiments. 
What was coming through and it was a time of great change and a lot of opportunities so it's like, you know, you've got to go for those opportunities or you'll be left behind ... I thought, well, I should really get on the bandwagon and not be left behind. (Bolivia, p. 5-6)

Changing requirements contributed to both fear and motivation. Despite there having been no compulsory requirements to achieve the new standard from previous changes in nursing education, one participant in this study believed qualification escalation would result in RNs being required to upgrade their qualifications.

Because I was an RGON-trained nurse and I could see from the literature coming out from the Nursing Council that we were going to have to up-skill our basic training, well, that was where I thought that it was all going to go so I thought all RGONs would have to do some kind of programme or six months' update to become comp trained. (Emily, p. 3)

However, when asked if new graduates entering the profession with a degree had influenced their decision, many of the participants discussed their own specific area of practice rather than the bigger picture of the profession. They generally described their own level of exposure to new graduates and whether they were employed in their area. For example, Millie had this to say:

Not really a consideration because ... we didn't usually get new grads, so that wasn't such an influence with me ... I think the biggest influence was knowing that I wanted to do something and then my manager really encouraging me. (Millie, p. 5)

Professional extrinsic motivation was not the only force behind the decision to undertake a degree. For all the participants the personal motivation to achieve, to meet the challenge and to succeed for their own sense of accomplishment appeared to be a significant factor in deciding to undertake a degree that had uncertain professional recognition.

While Bolivia (p. 5) "thought it would be good for [her] soul to get back and do some learning", for Bridie it was much more about the personal challenge.

I just thought l'd really like to see if I could do it, it was like a personal achievement ... it was all about proving to myself that I could [do] that academic work really, I always thought that I wasn't clever enough, so that, there was more sort of pressure from myself really, wanting that self-satisfaction. (Bridie, p. 3) 
For Phillip it was a combination of the personal and professional factors

The other thing is to actually be relevant with the fact of having students coming through, being up to date and just about succeeding at the challenge, I think ... you know, it's a self goal ... nothing wasn't really an option as far as I could see myself, I like to be able to do my best and to be able to do my best I needed to advance myself and so it also provided impetus for that. (Phillip, p. 4-5)

The decision to commence an undergraduate $\mathrm{BN}$ degree was a conscious choice influenced by more than just professional and personal motivation. Amongst the factors that influenced this choice, two aspects emerged from the interviews. These were that it had to be 'the right time' and that the mountain they chose, or the type of study, had to be 'do-able'.

\section{The right time}

Timing was significant with domestic influences a factor in whether or not it was the right time for each participant to begin their study. As noted in Chapter Two, domestic responsibilities, and in particular child care requirements, influence the uptake of education (Dowswell, Bradshaw, \& Hewison, 2000; Price, 2003). While the majority of nurses are women, the bulk of the literature either assumed nurses were women, and hence had domestic responsibilities, or found domestic influences less important for male RNs. The one male participant in this study considered domestic responsibilities significant. He identified that time spent studying was time away from his family so the stage of his family was integral to his decision to undertake the RN to BN programme. Also, the expected length of time the programme would take was a consideration as he was aware that his actions would affect his family.

Time and family commitment because it's not just when one person studies in the house, it's not just that one person that studies, the whole house is involved. (Phillip, p. 3)

Millie had been interested in study for a while but had been prevented from undertaking anything earlier because of her parental and financial situation.

I had wanted to up-skill myself for a number of years, I was all ready to really probably do it back in 1990 but then my husband left me and so I had two teenage boys to bring up and I just felt that I couldn't do it at that time so it was actually the right time for me.

(Millie, p. 4) 
Like Millie, Bessy said she had talked about doing her degree for years but that she "never quite got there". Then she started having a family and "got a bit distracted" (p. 3). She went on to describe how the domestic situation can crowd out the opportunity for nurses to take on extra study.

My other life I would say was my passion and took my energy so nursing was nice and easy and convenient and I was working in an area that l'd worked in for a long time and I knew very well so, working was fun, it wasn't stressful. The other parts of my life were, so l'd done a lot of doing nothing within nursing really so it was, it wasn't an option to do nothing, I was ready to do it I suppose. (Bessy, p. 8)

For one participant her difficult domestic situation was a positive impetus for her to take on degree studies. She was coping with a recent separation and family health issues but was encouraged by a lecturer to "do something positive with your year" (Margaret, p. 5). She described how study towards a degree was positive for her during a difficult time.

Being able to do something worthwhile in a year where I could have been a victim kind of situation instead of that I had the degree to focus on and so did they so it was quite good for my parents, I can still hear my father saying, oh, you know, [name] had to separate but she's finishing her degree this year so it was really good for them too, they could focus on that, good for my adult children too, yeah. (Margaret, p. 17)

Timing was also a factor because of programme requirements and professional or employment situations. For Margaret, who was an RN through a diploma level EN to RN programme, timing was particularly significant as her access to the degree path was about to expire.

So I rung [School of Nursing] to see about doing a paper and the Dean of Nursing rung me back and said, look, your five years is up at the end of this time, for your window to get your cross credit for your previous papers that you'd done ... so I decided to stay for the year and complete my BN. (Margaret, pp. 3-4)

Professional developments and progress also contributed to timing. The introduction of nurse prescribing opened professional opportunities for which the degree was a stepping stone and that provided an impetus for Millie. 
Because it would have been so good to have nurses prescribing with the [name] service, so he [manager] was pushing me to do my Masters but I was saying, I haven't studied, you know ... I hadn't actually really studied at all for years so, he was saying, do your Masters and I was saying, no, no, [laughter] let me get my degree first so I took on this challenge. (Millie, p. 2)

\section{“Do-able"}

The choice to do a polytechnic-based undergraduate RN to BN degree was based mainly on a belief that it was an achievable qualification. As Phillip (p. 2) said "it was a challenge, it was pretty hectic as far as timeframes went with working full time, supporting family etc, but [it was] do-able".

Millie, and most other participants, chose to do a RN to BN programme because they had been away from formal academic study for some time.

I had a diploma, only a diploma. I hadn't done any other academic ... thought about postgraduate and I thought, no, that was not what I wanted to do straight off. By having such a long time away from study I thought l'd start at the undergraduate level and then if I decided to go on then I could go on ... I had a lot of life experience and I had a lot of practical skills and, and skill base practically, however, in the academic world I didn't have that experience, I thought it was best to start doing undergraduate. (Bolivia, pp. 5-6)

For both Millie and Bolivia the degree was seen as a stepping stone rather than an end in itself. The RNs in Seaton's (1998) study had a similar concept but described their polytechnic baccalaureate degree as a building block, a point that enabled them to move into something else that they may have set their sights on. For Margaret, doing a degree was just a progression.

I was really encouraged to do the degree as that was the next step, I thought it was a linear thing and I didn't even think about going into it in any other way. (Margaret, p. 14)

Most participants had considered whether to do a Masters degree rather than an undergraduate $\mathrm{BN}$ degree, but the former was seen as a tough mountain that they may not conquer. 
[Masters] that was mentioned at the time but at the time it was quite a big commitment to make and I wasn't sure that l'd be able to complete it ... just the length of time, I think, ... and that is the reason I carried on and did the $R N$ to $B N$, it was do-able.

(Phillip, pp. 2 \& 3)

For Emily, who had already been caught in changing requirements with two programmes that had changed, it was that fear that she would be caught yet again and left with no qualification.

I didn't want to go straight on into the Masters and then have that programme change and not finish it and at the end still only have the qualification of an RGON. I wanted to, I thought, this is achievable ... I [can] get my degree and I can still have something, you know, I can have that recognition on, for that secular learning on paper. (Emily, p. 8)

Phillip also wanted to complete a qualification.

I felt it was better to almost take a step backwards and complete something than to start something and then not, you know, sort of burn out halfway through ... I think it was just the fact of having something cold and hard in your hand. (Phillip, p. 5)

Millie has done four papers towards her Masters degree after completing her degree, and shared her belief about what is "do-able".

I knew that I couldn't go straight to Masters and I think I would've actually, having done four papers now, if I had've gone straight into those I think I would've given up, you know, at least I had some skills, some assignment writing skills, essay writing, I had some research skills and that, but if I had've just gone and done a Masters, in hindsight, I think I would've just, probably given up. (Millie, p. 4)

For Bridie a Masters degree was a mountain she would not even have attempted. While not an option she had considered prior to commencing her BN degree, when asked if she felt nurses should just go straight into Masters study, she responded that while that may suit some, for her "I wouldn't have done my Masters, I wouldn't, I would not have done anything" (p. 12).

The decision to enter into an undergraduate BN degree was interwoven with the student's choice of institution and type of programme. As institutions usually offer just one type of programme, these aspects are linked. Most participants chose the institution because of either some previous 
association, such as Millie (p. 4) who stated "I probably chose the $R N$ to BN because of my involvement in that preceptorship course" or because they believed it would best suit their needs.

I also hadn't written assignments for nearly 20 years so I knew going to [institution] I would be supported through that process rather than perhaps being thrown into academia as such and not being able to do it. (Bessy, p. 7)

Other participants expressed sentiments similar to the findings of Seaton's (1998) research, where RNs considered how they wanted to learn. Participants in this study stated they wanted some class-based sessions and lectures. Emily (p. 8) said she was "looking for the support ... and looking for the networking with other staff', based on her previous experience.

I did them extramurally and there just wasn't that support there and a ton of work to do, a ton of reading whereas, and it's all about being, it's working smarter not harder, it's a lot easier to rock up onto a lecture, sit down for an hour and get everything given to you and hints about what exactly that the lecturer requires in the assignments or even in the exam than what it is extramurally and kind of fuddling in the dark and thinking, you know, ... have I interpreted this the right way or am I going the right way with this? (Emily, p. 6)

Kate, who had three small children, a husband overseas much of the time and who lived two and a half hours driving time away from the institution, talked about how "it definitely was an option for me to do it online and I did consider it" (p. 8) but she, like Emily, believed there were more benefits from attending classes.

It was just easier to come up and have that support of meeting with all the other nurses, to discuss things at the study day and that so, I quite enjoyed that ... it was good to come down to the study days. (Kate, p. 8)

A lack of computer literacy was a significant factor in rejecting the notion of online options, with some participants identifying that they were totally computer illiterate. Bessy (p. 7) described how she "didn't even own a computer when I started doing my degree, I hand wrote all my assignments" while other participants were clear on how they wanted to learn.

I wouldn't have considered an online, I'm not really, I'm sort of a technophobe so I probably wouldn't consider doing an online course. I really liked this, you know, the communication, face to face. (Bridie, p. 12) 
When asked about extramural and online options Phillip identified that he wanted an educational approach that was consistent with nursing.

Yes I did consider those but I found that actually being able to meet with the tutors and people who were running the programmes, they then knew you as well and I don't know, it just seemed to make it just that little bit easier, it's probably, a bit like in my work, you know, putting the face to the person is always, you know, the human aspect, you're not looking at conditions, you're looking at people and I think, I looked at the degree programme the same really. (Phillip, p. 10)

Having classroom-based sessions met a variety of learning and professional needs. Millie (p. 12) talked about the importance of "deep and meaningful conversations" and that classroom sessions were a "really good way for me of doing it ... for my style of learning". Participants commented that classroom contact provided encouragement and allowed for clarification and reinforcement that contributed to the programme being "do-able".

The study days, they were very beneficial cause you could ask, I mean l'm quite a verbal person so you could actually ask a lot of the questions to get what you wanted to know ... and that just backed up what you'd read. (Bolivia, p. 5)

\section{Surviving the climb}

To be successful climbing any mountain, even one you consider "do-able", requires mastery of specific skills along with support and sustenance. For those who had been away from formal study for a long time, assignment writing was a major skill they had to become confident with.

I think after being away for nearly 20 years without having done ... very little in the academic side of things, it was that assignment writing, it was going right back to basics, having to do the assignments, having to do a lot of reading, learning how to reference ... After the first two or three assignments then it got a lot easier. (Bolivia, p. 5)

It took time to learn the skills required to achieve academically and this was often more of a challenge than the content.

Learning things like how to research a topic and how to write assignments, I don't know whether my first few attempts were really that good but that was the hard thing, it wasn't 
so much the actual doing of the papers but it was actually getting the assignments right, ... knowing where to go for research and things like that. (Millie, p. 3)

One challenge was learning to use technology, an essential academic skill that some RNs had to learn.

Not being able to type very well, I was helped by my wife initially who typed my first assignments but after that I sort of sped up a little bit, even if it was just two-fingered and my grammar and things improved each time. (Phillip, p. 7)

As RNs became competent with new skills and were able to successfully complete coursework they gained a sense of accomplishment and a boost in self-confidence which Rusin (1993) says is an often unanticipated intrinsic reward and this provides an impetus to continue.

The best part was when I got the results from my assignments, the fact that l'd done so well, much better than what l'd ever thought that I would do and it was the self-satisfaction ... reading back over my assignments and thinking, had I actually written that, you know, that was just fantastic ... and knowing that I could actually write an academic essay it was a really good feeling, it was a really good sort of sense of self-satisfaction.

(Bridie, pp. 3-4)

RNs returning to study tend to be goal-focused achievers who wish to succeed. Results and feedback gave both encouragement and direction.

It gave you a little boost ... it almost recharged your batteries ready for the next one ... and every time that assignments came back you tried to better the one previously ... the mark was always important but the feedback was always very constructive to help you with your next one, it helped, sort of like a rudder of a ship guide you more so you knew where you could improve on ... like the icing on the cake, you'd spent all this time preparing the cake, putting the mixture together and it looked pretty good when you sent it off ... then once you'd got it back with the comments and, and the mark, then you actually digested it. (Phillip, pp. 6-7)

A number of participants described the hard work of doing assignments but Millie (p. 3) explained that this was balanced by the achievement of completing each one and a sense of progress "the pure enjoyment of getting an assignment finished and in and then back and a reasonably good 
mark ... it was painful to get to that point but ... knowing that I was taking steps towards that goal". Assessments and results were not the only positive and sustaining aspects of the programme. Emily talked about how "the networking, with the other students, the growth in knowledge" (p. 12) were the best parts of the experience. Others also commented positively on the networking and interaction with class colleagues, what Millie (p. 12) called the "deep and meaningful conversations".

I thoroughly enjoyed it ... I think just the stimulation and talking with other nurses from all walks of life and all walks of nursing, it was really, really stimulating, ... it was actually really good listening and hearing and being able to discuss a wide range of nursing topics.

(Millie, pp. 2-3)

Millie talked about "the thirst for knowledge" (p. 4), about looking at her practice differently, how she enjoyed the listening and talking with other nurses. She described what she called the "wow" factor of the experience.

l'd come away from times together over at [institution] and just be bubbling and thinking whoa (laughter) you know. (Millie, p. 7)

Critical to successful mountain climbing is the support received from friends and family. Such support reduced the feelings of stress experienced by RNs while studying. The support was also felt through acknowledgement and pride in their efforts, assistance and acceptance of the lack of availability of time. The support, both practical and emotional, was sustaining and encouraging. Bessy (p. 13) said "my family and friends were ... huge, they were really supportive, they were all very proud of me" and described these personal factors as "one of my big encouragements". She described herself as "very lucky" because at the time she had a "house husband" who was "wonderful" (p. 3). Kate's husband was away a lot of the time, but still she described how "he encouraged me to do it and helped look after the children so I could" (p. 5). Supportive partners certainly helped.

My husband was incredibly supportive and he took over a lot of the cooking of meals when I was having to do an assignment, he took over a lot of that, the cooking and like being there for the boys. (Bridie, p. 5)

Family and friends took on a range of practical duties both to provide time for study and to assist the study. 
My parents have always been really good for babysitting and my partner was good at the time too as well, he was like my critical friend where l'd give him my assignments and he would have no idea what I was talking about but he'd just look at the content of them.

(Emily, p. 2)

Colleagues were an additional support to family and friends, particularly colleagues who were also studying or who had completed a similar programme.

The biggest encouragement ... was my supportive wife, she was behind me $100 \%$ even when l'd ... talked about doing the RN to BN and basically she said, "why not?" and supported me all the way through there and also with taking on more higher responsibility, ... my family supported me and also the colleagues that were studying at the same time, we would often talk about what we'd been doing and if we were having a hard time at the time, would just encourage each other a bit ... when they're down you're usually up and when you're down they're usually up so, it really helps balance you. (Phillip, pp. 7-8)

The beneficial influence of classroom sessions and networking with other RNs has already been identified. Participants talked positively about the support and encouragement they received from lecturers, particularly in difficult times. Margaret, who studied largely on her own, found other support.

Two of the librarians were amazing, they got me through the year basically, every time I got a bit frustrated, l'd go and they helped me with CINAHL and all my research.

(Margaret, p. 6)

\section{Reaching the top}

Conquering the mountain and completing the degree provided a great sense of achievement and pride. It had been hard work, taking between one and five years to finish. All the participants described great satisfaction in obtaining a degree. Obtaining a degree was predominantly a personal achievement.

I think doing something l'd always wanted to do, actually doing it, finishing it, getting it done, I did it well, got mainly A's so, for me, that's, you know, I'm very proud of that, that would probably be it, that sense of achievement, personally, of achieving that, of every 
now and then thinking, ooh, you sort of forget you've got one and you think, ooh, l've got a degree. (Bessy, p. 14)

Some participants described the professional significance of having a degree.

Knowing that I was actually able to keep up there with my other colleagues, and just that real sense of achievement. Professionally, I think knowing that l'd actually completed, that l'd actually up-skilled myself. I wasn't sort of back in the (laughter) dark ages of nursing but I had actually worked to bring myself up to speed with my colleagues and with the new nurses that were coming out, also that I could say l've actually completed my degree. (Millie, p. 8)

Both Millie and Bridie expressed a sense of 'being equal' with other degree qualified RNs as an outcome of attaining their degree. Although few participants had identified being motivated by newly qualified RNs having a degree, clearly there was a sense of being 'less than' by not having a degree.

I've achieved, I know I can do academic work, that was a great sense of satisfaction ... I feel like, in inverted commas, a better nurse, I feel more on an equal footing with those other registered nurses who have got their degree, like there's no difference now between them and myself. (Bridie, pp. 8-9)

Obtaining a degree had professional outcomes for some participants. Bessy, describes how achieving her degree reconnected her with nursing.

That achievement feeling, understanding what people were talking about, ... research especially, understanding that and seeing its relevance to nursing and I think regaining being proud of being a nurse again ... being able to read all this evidence and research that backed up what we were doing and made it valid and I think, seeing nursing probably as a profession. (p. 11)

Apart from the personal sense of achievement, there was another personal aspect to achieving a degree for Bessy.

On a personal note, I think it's being such a role model for my daughters. My oldest daughter tells me that she won't be silly like me and not get a degree till she's had 
children, she's going to leave school, get a degree, do her Masters and then she might have a family before she does her PhD. (p. 12)

Amongst comments like "succeeding at the challenge" (Phillip, p. 4), the participants repeatedly mentioned that they, and those that had supported them, were proud of their achievement. Most talked about graduation as the culmination of this achievement. For Millie (p. 7) it was "a really big high ... it was a great day, I was so proud of myself". Stanley (2003) identified that finishing the degree, the journey's end, was a key feature of the experience of undertaking a postregistration degree. Within my employing institution some newly graduating RNs choose not to attend the traditional rite of passage, the graduation ceremony. All the participants of this research enjoyed their graduation.

It was a great celebration when I graduated, that was fantastic and my family was very very proud of me so that was great, you know and I think it, it does give me something, I would really encourage [any] RGON to go and do more academic work. (Bridie, p. 9)

Graduation day was described as special for many reasons. For Emily, who had set out to achieve something, this was the confirmation that despite the difficulties, she had succeeded.

It was really neat, the atmosphere was really good, walking up on stage, yay, l've done it, you know, l've got more than what I needed but l've got it, l've done it, yeah, and I was really proud of myself and my parents were really proud of me, you know, my father came up to me and said your grandfather would have been really proud of you and ... the discussions with other nurses, you're wasting your time doing a degree, that didn't take away any of that feeling, it didn't take away any of that polish at all, l've got it. (Emily, p. 9)

Graduation day was also an acknowledgement of those that had supported you.

Just also the fact that my family were there also, and the children and my wife was there and also my mother and you know, we all shared in the day because we'd all given commitment to it, as I said, if one studies then everybody studies in the house almost.

(Phillip, pp. 5- 6)

Some participants noted that their achievement was also acknowledged within their workplace. Bridie said a luncheon was put on for them and Margaret (p. 16) described how the management was "very positive and my graduation was really celebrated by them and I was given gifts by the manager". For Bessy, the recognition was more subtle. 
I think it important professionally, I think that people take more notice of you. I think, as you get to know people they judge you and value you what you say but when people first meet you, having that degree, maybe it makes you feel a bit more certain of yourself ... you realise that your opinion can be as valid as anyone else and that if you can back it up through research and things then it becomes even more valid. (Bessy, p. 14)

\section{Was it worth it?}

Achieving qualifications cost individuals and their families time, money and effort. Assessing the worth of such activity is always complex. The participants in this study were unanimous in believing that gaining an undergraduate nursing degree was both worth the cost and was right for them. They talked about how it changed their nursing practice, how they gained confidence and indirectly, how they influenced others.

When asked about the worth of doing an undergraduate degree comments included "absolutely worth it" (Emily 19); "hundred percent worth it, I'm so pleased that I did it" (Millie, p. 12) and "for me [it] felt the right way to do it and I have no regrets in doing it that way" (Phillip, p. 9). Such comments are in line with other researchers' findings that RNs gain personal and professional benefits from attaining a degree (Blackie, 2001; Davey \& Robinson, 2002; Lillibridge \& Fox, 2005). What is less clear is why RNs perceive an undergraduate degree being worth the cost when there is no formal financial or professional recognition.

It was worth it. I feel like l'm really quite a different nurse now that l've done that work than I was before and it's given me an openness about further studies. (Bridie, p. 10)

Some participants identified the difference it made in their practice.

I probably practise differently, it's more of a partnership with my patients now after doing my Professional Nursing Practice than what it was before ... I think by changing my practice in that way it's broadened how I practise generally, I have no problems now professionally in dealing with disgruntled clients. (Emily, p. 18)

In contrast, Kate, who was the youngest participant and who had qualified in the last diploma level class, said

On a personal level I do feel more fulfilled, it's my career and feel like l've achieved a degree and I'm pleased I have done it but ... I don't think it's changed the way I work from 
a day to day basis, I don't think it's affected my practice but it has made me a bit more maybe open minded. (Kate, p. 6)

She was the only one who felt it hadn't changed her practice but she did acknowledge that it enabled her to "learn new, well, not learn new things but look into different things and keep my study up, keep my mind going" (p. 3).

Those who had been in nursing longer appeared to gain greater benefit from undertaking the degree.

For me, it was just that journey I needed to go through, you know, being very institutionalised, stuck in a hospital for, well ... I suppose it was nearly 20 years, and I think it made me more global in that sense I saw the rest of the world and the rest of the world in nursing and it's very easy to just think that you're the be all and end all of everything when you work in a hospital, you don't see that bigger perspective.

(Bessy, p. 16)

Others echoed the idea that undertaking the degree gave them a chance to lift their head from day to day practice and consider wider aspects of nursing.

I think my degree, it gave me a better perspective on the changing political environments in nursing because we're very insulated when you work in a hospital and you stay in clinical ... it's very difficult now to work clinically and keep abreast of all the changes, there'd be a new policy coming up every single week, you're short-staffed ... the political environment's always changing as well, it's incredibly difficult for someone who works fulltime. (Emily, p. 16)

An increase in knowledge seems an obvious outcome from study toward an undergraduate degree. As these were all knowledgeable, practising $\mathrm{RNs}$, it was significant that most commented on knowledge when discussing the worth of the programme. Like others, Bolivia specified particular papers when identifying increased knowledge for practice. However, her general comments about the value of the programme, "it was very beneficial because it enhanced my knowledge on what I did on a day to day basis" (p. 18), encapsulated what other participants discussed.

For me, it's put everything in perspective, it's why you do what you do. It gives you that extra knowledge. It probably underpins the clinical skills that I already had and the 
knowledge, it sort of all strengthens it, it brings it together, makes you look at the bigger picture more. (Bolivia, p. 12)

Lillibridge and Fox (2005) found most RNs who gained a degree attained more than they expected and were amazed that they did change their perspectives and see a bigger picture. Confirming the findings of other studies, they also noted that RNs increased their confidence and ability to interact more equally with other health professionals. Bessy described some of these changes.

It's like a growing up within nursing and you realise ... things that have formed your practice ... theorists have identified that and there's a common thread throughout nursing ... I have a bit more confidence ... I think it gives you that grounding and that validation of yourself as a nurse, that you are proud to be a nurse, you're a professional and that your opinions will count and you can perhaps negotiate with the rest of the team from a different perspective as a result. (Bessy, p. 15)

Increased self confidence, identified as an outcome for RNs who gain a post-registration degree, (Davey \& Robinson, 2002; Hardwick \& Jordan, 2002; Lillibridge \& Fox, 2005) has both personal and professional implications as well as indirect benefits for practice and patient outcomes. Aspects of this are confidence to seek career advancements and further study.

It's given me a huge boost in my confidence, in self confidence ... it's certainly encouraged me to go and do some Masters papers too ... it also gave me the self confidence to apply for another position ... it gave me the self confidence that I actually can cut it out there in the real world of nursing. (Millie, p. 9)

Achieving a degree creates opportunities for the future. The participants of this study described how the very process of completing a degree gave them more confidence in the workplace and Margaret (p. 19) stated "I feel more career-orientated, I can see a pathway to being a Nurse Practitioner if that's what I chose to do". Bessy identified that a degree brought increased opportunities as "without a degree a lot of nursing positions wouldn't be available to me" (p. 15). It also increased academic options.

It's the entrance way to a lot of the other academic things, I could choose to go in different directions now and use my degree as the basis of that. (Margaret, p. 20) 
Millie was the only participant to have commenced study towards a Masters degree. However, other participants commented that having successfully completed the undergraduate degree, they now had confidence for other climbs as they knew they could manage study.

It's given me an openness about further studies, not Masters but because I know that I can achieve it, I could do post-grad studies. (Bridie, p. 10)

\section{The influence of climbers}

While achieving a degree had positive personal outcomes for the participants, I was also interested in wider professional impacts. The literature was inconclusive on the effects of RNs obtaining a degree on practice and patient outcomes although there was research evidence of perspective transformation, change in professional practice. While Kate felt there had been no change in her practice, others gave examples that showed their patient care had altered. Like Emily (p. 18) who identified that she "practise[d] differently, it's more of a partnership with my patients now", and Bridie, described a more patient-centred approach to practice.

I really got a greater insight or level of understanding, especially about things like cultural safety so, professionally it really did help me within my working, I felt like l'd elevated myself and also, increased the level of my understanding or how I would be treating the patients, I felt like it's given me an extra depth to my nursing ... I felt like l'd evolved.

(Bridie, p. 4)

Participants described professional change and perspective transformation. Bolivia (p. 11) described the change as "you grow in your profession". Some participants had been in nursing a number of years but identified that it was studying for a degree that changed their perspective.

I was 17 and a half when I went nursing and, you've had this, you're gonna save people's lives and you went through your training, you learnt all the skills but you didn't really actually think about what is nursing ... I have a greater awareness for a lot of things, a greater awareness of research that's going on out there, greater awareness of what the newer nurses coming on are actually learning as opposed to what we learnt way, way back when, yes. It really opened my eyes, I think to my role as a nurse. (Millie, p. 11)

The professional impact of the degree occurred not just because the RNs see more possibilities in their practice, what Phillip (p. 9) describes as how he would "look at things with different eyes 
... and see if there's other ways or better ways of doing things" after completing his degree. It also occurred because of the influence of these RNs on their colleagues.

The knowledge that you learn and pass on isn't just to your students or to yourself, you're also spreading your knowledge to your colleagues as well so they're actually changing their practice with the evidence that you're providing. (Phillip, p. 11)

Some participants were aware that gaining their degree had wider professional implications. They described these as being more relevant to and better able to assist students, being role models and being up to date in their practice.

It would affect the wider profession in the fact that you've got more people who are looking at research, looking at why things are being done in the way they're being done, and trying to make a difference, trying to expand the professional bridge ... reaching out further. (Phillip, p. 12)

Rather (1993) called RNs with degrees "harbingers", birds that carried the message, either positive or negative, about degree study. Participants in this study talked about encouraging their colleagues to do further study, and about assisting them. Phillip (p. 10) noted that "I'll be able to support them and know what they're going through", while Bolivia was mindful that encouragement needed to be subtle rather than forceful.

You want to see where people sit and then you can suggest it, you can invite them or offer this, offer that it's available ... you can't tell people to do it, it's about change management and it's about baby steps and you can, you can offer it to them and say, well, this is available, have you thought about this course. (Bolivia, p. 17)

\section{Chapter review}

The examination of the participants' perspectives and experiences has revealed that undertaking an undergraduate degree was akin to climbing a mountain, it was challenging and hard work. While professional considerations were a factor, most RNs were intrinsically motivated to undertake their degree. As mature learners lacking currency with academic study, they wanted classroom time to enable guidance from lecturers and networking with other RNs. This influenced which programme they chose. Timing was significant as studying had to fit into already full lives. Of central importance was a belief that the programme was achievable or "do- 
able". What was important in encouraging their progress was gaining the skills they required around assignment writing, along with passing assessments and positive feedback. The lay support of family and friends was critical to RNs getting study time and succeeding. Attaining their degree was a great achievement that the RNs were proud of and this was celebrated on their graduation day with those that had supported them. All the participants believed completing an undergraduate nursing degree was worth the cost, despite mixed professional recognition. The interview data revealed that the participants' thinking, perceptions and practice were transformed as a result of completing their studies.

The following chapter provides further insights from the participants related to their experience of completing a $\mathrm{RN}$ to $\mathrm{BN}$ programme. Examination and discussion of the findings highlights the diversity and difference that surround the case of this study. Change in nursing education results in moving goal posts for RNs and divided opinions related to the value of a degree. Variable employer support and unforeseen hurdles combine to create difficulties that RNs must overcome to achieve a degree. 


\section{CHAPTER SIX}

\section{Diversity and Difference}

\section{Introduction}

The Registered Nurses (RNs) interviewed each had different personal and professional situations. The effects of these and other influences on their experience of completing a Bachelor of Nursing (BN) programme are presented in this chapter. In the previous chapter, participants described personal and professional reasons for undertaking a $R N$ to $B N$ programme, with timing and a belief that obtaining a degree was achievable identified as important. The course was a challenge and hard work, but they all perceived that it was worth the cost and effort. However, the data revealed that there were differing financial and personal costs, related to personal and professional factors.

Despite graduating from the same institution in one of two cohorts, the participants' experiences were incredibly varied. The diversity amongst and surrounding the participants surprised me. Change in New Zealand (NZ) nursing education, differing opinions about the value of an undergraduate nursing degree for $\mathrm{RNs}$ and varying levels of employer support influence educational aspirations and create confusion, frustration and disparity. This landscape of professional diversity combined with complex personal and domestic situations had real impacts on RNs undertaking a $\mathrm{RN}$ to $\mathrm{BN}$ programme. The findings related to diversity and difference are discussed in this chapter and focus on moving goal posts, divided opinions, unnecessary hurdles and personal trials.

\section{Moving goal posts}

Diversity is a hallmark of nursing. RNs practise in many different settings, with differing types of and ages of clients, to meet a variety of needs using a range of expertise and knowledge. This diversity is reflected in the Nursing Council of New Zealand's (NCNZ) scope of practice for RNs, which acknowledges that RNs "practise in a variety of clinical contexts depending on their educational preparation and practice experience. Registered Nurses may also use this expertise to manage, teach, evaluate and research nursing practice" (NCNZ, 2006, pp. 1-2). The professional histories of the participants included acute care, community contexts, education, staff nurse, senior nurse and management roles. 
As discussed in Chapter One, changes in nursing education and registration requirements have resulted in different $\mathrm{RN}$ qualifications within the NZ nursing workforce. This difference was reflected in the participants of this study (Table 9). The five hospital trained Registered General and Obstetric Nurses (RGONs) registered between 1974 and 1985 while the three Registered Comprehensive Nurses (RCpNs) qualified between 1981 and 1995. Collectively they had 181 years of nursing experience. These RNs had lived through changes in nursing education.

Table 9: Qualifications and employment of participants

\begin{tabular}{|c|c|c|c|}
\hline & Year of qualification & Type of registration & Full time or part time \\
\hline A & 1974 & RGON & Full time \\
\hline B & 1981 & RGON & 0.8 \\
\hline C & 1994 & RCpN & Part time \\
\hline D & 1982 & RGON & Full time \\
\hline E & 1995 & RCpN & Full time to part time \\
\hline F & 1983 & RGON & Part time to full time plus \\
\hline G & 1981 & RCpN & Full time \\
\hline H & 1985 & RGON & \\
\hline
\end{tabular}

One of the RCpN participants was in the final diploma level class as degree programmes leading to registration were introduced. Having been on the cusp of change, she felt she was disadvantaged by the moving goal posts.

I was the last of the diploma course and I felt that the nurses coming out after me had all just done three years and I was having to pay, you know, a few thousand to finish my degree ... I sort of had a grudge, I guess, that maybe we should have been financed for some of it because having to do more study right when the others had already started to do their degree and in three years we were finishing our diploma. (Kate, p. 4)

In contrast, another of the RCpN participants had been one of the first Comprehensive Nurses and as such her experience of change in nursing education was animosity from other nurses. She used these recollections to understand how some RNs reacted to the more recent change of RNs being degree qualified.

It's probably how hospital trained nurses felt when polytech nurses came out, that suddenly your knowledge and experience is less valuable 'cause you can't back that up 
with an academic qualification ... Oh, they hated us with a vengeance (laughter). We were polypads ... they used to tell us not to waste their time with that fuzzy wuzzy stuff and they used to time me doing the drug round and I wasn't allowed to hold the drug keys until I could do the drug round in less than 30 minutes ... I think, looking back, probably they felt a bit threatened like we did, when the degree nurses came out.

(Bessy, pp. 10-11)

The other RCpN had previously been qualified as an Enrolled Nurse (EN). Having originally qualified through a hospital system, she then completed an EN to RCpN diploma level programme that gave her up to five years to complete the additional papers required for a degree. She lived overseas for some years and in her absence the institution's RN to BN programme changed in line with a new BN curriculum. This meant that classes were no longer offered for the papers she was required to complete, effectively prohibiting her from joining other RNs working toward their degree. This in turn made her experience quite different from the other participants.

As well as different professional histories and registration qualifications, the participants had varying amounts of post-registration education. Post-registration education includes a diversity of terms and meanings that have changed historically and cover a wide spectrum of activities including clinically specific updates, attending speakers on general topics, reading literature and formal academic study. A variety of providers offer these options and historically there have been few formal requirements regarding level, length of programmes or attendance/assessment expectations. Because of this, it was often difficult to gain credit from such study towards an undergraduate degree.

All participants had attended in-service and up-dating courses, what Millie (p. 2) called "bits and pieces", while six had completed formal study and qualifications. This included papers toward the Advanced Diploma of Nursing (ADN) more than ten years ago, a certificate in tropical diseases obtained in London, polytechnic-based short courses and year-long specialist practice courses, a recent preceptorship programme and tertiary level papers. Most received little or no credit towards their BN for this formal study. One participant seemed to have been continually involved in study, only to regularly find that because of the moving goal posts what she had done did not meet the changing requirements. 
I've always done ongoing education right throughout the time that l've been registered because I think that's important, you need to up-skill and be current with things .... I did Human Development 1, 2 and 3. I did a Psychology paper ... I did Sociology papers and I think that was about all, I think l'd done about seven papers .... [on her return from overseas she], talked to two lecturers about what I was going to do and where I was gonna go and some of those papers that l'd done were now included in cross credits for RGONs so that seemed to be a waste of time. (Emily, pp. 3, 4 \& 5)

Indeed Emily described being repeatedly affected by changes in nursing education. She had done seven undergraduate nursing-related university papers, a post-registration certificate in Community Health from one polytechnic and a paper on coronary care from another polytechnic when transition arrangements came into being for RNs to obtain an undergraduate nursing degree. She discovered that most of her previous study would not count toward a BN degree, or that she would have to pay to see if she was eligible for any credit under the recognition of prior learning (RPL) process. Moving goal posts affected Emily again when a change in the institution's curriculum required her to do more than the 100 credits she required to obtain a degree.

I started and did some papers and the curriculum changed and I went and did the Critical Care course and then from there I went on and did the core papers to finish my degree. I ended up with 150 credits. (Emily, p. 2)

Pennington et al. (1993, p. 170) identify that "nothing ever stands still, and certainly not nursing curricula". RN to BN programmes are based on undergraduate degree programmes, which on average modify their curricula every four to seven years to stay dynamic and current. These adjustments ultimately prompt changes in $\mathrm{RN}$ to $\mathrm{BN}$ programmes. Two participants were affected by curriculum change, demonstrating that alterations within programmes are another aspect of the moving goal posts that RNs face.

Although adult education seeks to acknowledge and incorporate the experience of students returning to study, there is difficulty in terms of recognition, validation and giving credit for previous experience. Consistent with the findings in international literature (Davidhizar \& Vance, 1999; Gould, Smith, Payne, \& Aird, 1999; Rendon, 1988), the participants had extremely variable educational and employment histories, including their length of experience and diverse clinical and non clinical areas of employment. The length of time participants had been registered 
ranged from 12 to 33 years. This variation is typical of what is found throughout adult education (Lavelle, Patterson, \& Iphofen, 1997). The credit given by $\mathrm{RN}$ to $\mathrm{BN}$ programmes for registration usually did not distinguish between hospital-based and comprehensive forms of registration. However, as shown by these findings, obtaining formal credit for other post-registration education was difficult and it also appeared to the participants that their nursing experience did not have the same value as academic qualifications.

I was really angry that nurses were coming out with a degree and were seen to be, I guess it was my perception, more qualified than me as a nurse and I had some, nearly 20 years experience by then and I felt my experience wasn't valued because I didn't have a formal qualification beyond the diploma. (Bessy, p. 5)

As discussed in Chapter Two, there is an ongoing debate within nursing about the value of experience versus the value of qualifications (Lowe, 2003). In acknowledging this tension, Bessy shared her thoughts on how experience could be recognised in nursing.

There's lots of times I used to think Alison Holst got an honorary degree for being such a good cook [laughter] I should get one for being such a good nurse [laughter].

(Bessy, p. 5)

Acknowledging that doing a degree was a journey through which she grew and developed, Bessy stated she did not really believe that nurses should automatically receive a degree. She did, however, think she should have had more credit for her experience than she was given. While curricula varied across institutions, generally RNs gained around $250-280$ of the 360 credits required to obtain a degree as recognition for their registration and experience. The debate regarding the amount of work and credits $\mathrm{RNs}$ should be required to do to gain an undergraduate nursing degree, which occurs internationally and professionally within NZ, was reflected by the participants.

I don't think they should've been given a degree but I think that maybe less of those first and second year papers, to achieve a degree ... [l] did 10 papers .... I think probably four or six papers would have done it, rather than the 10. (Bessy, p.10)

Initially, as discussed in Chapter One, polytechnic-based RN to BN programmes offered more credits and recognition for professional nursing knowledge and registration than universities and Seaton's (1998), findings showed RNs chose the polytechnic system "as a fast-track way to gain 
a degree" (pp. 90-91). As RNs had the options to apply for direct entry into post-graduate studies, some RNs who commenced RN to BN programmes did not complete the BN degree but moved straight into post-graduate education. What number of students did this and whether it was because they thought they were expected to do too much to obtain a degree or whether it was because they saw $\mathrm{RN}$ to $\mathrm{BN}$ programmes as a stepping stone, is not known. The participants acknowledged this. "Quite a few of the people I started doing the degree with did a couple of papers then stopped that and went straight to post-grad studies" (Bessy, p. 7), but these RNs are not captured in this study and are an area for further research.

Changes in nursing education and qualification escalation were acknowledged by these participants. It was within this context of change that these RNs chose the option of a RN to BN programme.

When I started with the RGON that was the goal to finish there, but as time goes on the goal posts move and, with the Masters programme ... 'cause things are sort of, certainly more leaning towards that direction, but all I can say is I'm on the paddock and that's the big thing. (Phillip, p. 10)

\section{Divided opinions}

As discussed in Chapter Two, there are deep divisions and differing opinions about educational preparation within the nursing profession. The participants discussed their experience of these different attitudes.

There was a lot of talk amongst nursing at the time with us older nurses as such that it was almost like we were being made redundant or, you know, we would be the care assistants of the future 'cause the nurses with the degrees would be doing all the real work as such. (Bessy, p. 7)

Along with fear, there appeared to be a belief by some staff that nurses were studying to benefit themselves and not the wider nursing community. Participants described reactions from their colleagues.

There were some ... I can't really use the word "assassination", "character assassination", but they certainly made you feel like you were sort of getting ahead at their expense almost or just trying to be one better than them but after a while that died a natural death.

(Phillip, p. 9) 
Participants described reactions as negative.

There was a little bit of negative culture towards, through a few staff members towards the fact that I was doing a Bachelor and I could feel that ... they felt quite threatened in the workplace. (Margaret, p. 17)

While it is clear there was tension in workplaces from colleagues there was also reports of managers, those with power, feeling threatened and creating difficulty for RNs undertaking study. Two participants talked about managers whose attitudes and behaviours hindered their study efforts.

Unfortunately the manager that had supported me left ... I did one year ... and then he left at the beginning of the next year, and then we got a manager who was a registered nurse but hadn't done anything to upskill herself but she'd got into a managerial position and wasn't intending to do anything to upskill herself and was in some ways a bit negative towards, [me] you know like, for instance, not giving me the, all the days off that I needed, only being allowed a certain number and then the rest annual leave. (Millie, p. 8)

Colleagues appeared not to understand why RNs took on study when there were no financial rewards. The participants in this study reflected the lack of value attributed to an undergraduate nursing degree.

I was always really clear that whether I had a degree or not it was never going to impact on my salary scale, like it wasn't going to mean anything really apart from a widened sort of point of view. (Bridie, p. 3)

There was a sense that a degree really did not mean much, so why do it? Participants often described the reaction of their colleagues in a way that showed neither they, nor their colleagues meant to denigrate each other; it was just differing points of view.

The discussions with other people... the other nurses, you're wasting your time doing a degree ... I thought that's your opinion ... I understand what they were saying and where they were coming from and it was true but at the end of the day I still wanted something that was achievable for me. (Emily, p. 9)

At other times participants were just aware of the indifference of colleagues. 
I don't really feel that there was any sign of appreciation from my work colleagues ... I don't think they sort of even really thought it was a big deal. (Bridie, p. 7)

The participants in this study acknowledged negative attitudes and behaviours in the workplace but also talked overwhelmingly of the positive attitudes and support they received, especially from those who had already done a degree and those who were also studying.

My colleagues encouraged me and it was also encouraged through the Director of Nursing, [who] was very keen for people to be more qualified ... your colleagues who have actually done the same degree programme, knew the work that you were going through and so every so often they'd all, you know, they'd come up to you and ask how things were going and you knew that they were thinking of what was going on, how they'd got through it as well. (Phillip, pp. 5 \& 8)

Divided opinions occurred not only amongst colleagues and managers; they were also evident amongst the participants. Each person was asked whether there should be a mandatory requirement for existing $\mathrm{RNs}$ to obtain a degree. The participant responses reflected both their experience of obtaining a degree and aspects of the professional debate on RNs gaining a degree. Only one participant was adamant that it should not be compulsory. Bridie had identified that she found doing the degree quite stressful and hard, juggling work, study and family commitments. She believed options should be available for nurses and that funding should accompany those options, but "absolutely not" (p. 10) a mandatory requirement to complete a whole degree. Two others who did not believe it should be compulsory qualified their comments. One considered older colleagues and felt mandatory requirements should not apply to them, but that for those with a number of years left in the profession, it would be good. The other commented,

I don't think it should be mandatory but I think that it would be nice to have recognition be it financially perhaps for the effort, it would certainly provide an impetus for people to partake in it but that shouldn't be the reason that they do it, they should want to do it because they want to do it not because there's a financial gain at the end. (Phillip, p. 11)

Another participant, who supported the idea of a mandatory degree, also felt that there was not enough recognition. "I don't think the effort and the commitment is recognised professionally, for an RGON to up-skill” (Emily, p. 15). The majority of the participants did think it was a good idea 
but qualified their responses. Margaret (p. 13) thought "it would be best for them and for the system" but acknowledged,

Seeing the stress involved in that, where some people have had to undertake things outside their comfort zone, is the lack of support. I feel that every nurse would benefit, has got the capacity to do it but it's providing the right circumstances because if the circumstances aren't correct then people fail and they're fabulous nurses and they shouldn't fail. (Margaret, p. 13)

Doing a degree was acknowledged as an extra stress to place on an already stressed workforce.

They're a long term commitment, time and a lot of nurses out there at the moment are very stressed, they are, the work-force issue is huge, average age of a practice nurse is 48 , there's a lot that are working well over 50 , the time, the changing environment.

(Bolivia, p. 17)

While participants were divided and considerate on the issues for RNs to obtain a degree, most seemed to believe that nursing as a profession now required degree level preparation.

I think that if we want to be taken seriously as a professional then that should be the minimum qualification nurses have. I think that the knowledge you gain within your degree is the minimum knowledge that you require now as a nurse. I mean with the HPCA Act now and all sorts of things that really govern our practice we've been taken seriously as professionals, we're paid as professionals, the scientific knowledge now is just incredible compared to when I trained, where it was very basic anatomy and physiology, that scientific knowledge now is huge and I think that you want critical thinkers within nurses, you want, you need that practical common sense side but you need people who are informed and knowledgeable to ensure safe patient outcomes ... that's it now, it's ... moved up another level. (Bessy, p. 17)

\section{Unnecessary hurdles}

Tertiary level study is expensive, costing the participants in this study on average $\$ 3,000-$ $\$ 3,500$ in fees alone to complete their BN degree. Most of the participants received some support, either from their employer or from a scholarship scheme offered by the institution. This differed from the findings of Seaton's (1998) study where all participants undertook study initially without employer support, although some did receive financial or time assistance as they 
progressed. This may indicate a change that has occurred over time. For two of the participants in this study, the financial cost was not a major consideration. For Bolivia this was because she believed "you have to pay for things. The user pays" (p. 8), while for Margaret, who had to pay for fewer papers because she had completed the EN to RN programme, her personal and financial circumstances were supportive, "I was able to live fairly cheaply for that year and because of my personal circumstances, financially, I didn't really have any restrictions"(Margaret, p. 15).

However, for other participants, the financial cost and amount of support available were major influences on their decision to undertake a degree and their experience of study. Lack of financial assistance caused stress and hardship for one participant.

I did six days a week quite often because, in those days you weren't funded to do your BN .... My husband lost his job and I was back when [child] was six months old working full time ... I took a student loan to start my degree which was another financial consideration but I needed money to, I couldn't afford the money to pay my fees so I took a student loan to pay my fees and buy a computer and used to quite often work a sixth or seventh day to pay for the time l'd had off so, yeah, it was quite a financial consideration .... There was no thought that they would pay your fees, that was a given, you paid those. (Bessy, p. 9)

Employer support clearly made a difference.

After about, probably be about the third year I was doing it, they started to pay study days, you'd notice that people wouldn't be at work 'cause they were at a study day at [institution] and it was a paid day, so there was quite a shift then. When I did my last year all my study days were paid, my fees were paid, if they weren't on scholarship so it was a huge change but I was in a different role because l'd started as a nurse educator then and part of the deal of that job was l'd finish my degree so there was that commitment there from my employers I suppose ... they were hugely supportive. My colleagues would take my pager and tell me to go and sit in a room and finish an assignment. Yeah, that was hugely supportive. I had paid study leave, I could take time in lieu, I could work from home, that was amazing, my fees were paid, my study days were paid, I had access to computers too, you know, at work so, I could do stuff at work, quite different from my first experience with it. (Bessy, pp. 9 \& 13) 
Participants that had financial assistance seemed appreciative of this support. Even with contributions to fees, there were still additional financial costs, such as travel, with three participants traveling approximately one to three hours each way to study days.

I got half the papers paid for in the first year and because of a mistake I got all of my papers paid for in the second year [laughter], And then my last papers I got the scholarship from [institution] So, I was actually really lucky but there was also the coming back and forth and using annual leave because we were only allowed a certain amount of study days ... so there was those financial considerations I suppose, indirect financial [considerations]. (Millie, p. 6)

While assistance with fees or time off was commented on positively by the participants, congruent with the literature, there were comments about how more employer assistance was needed "when you look at career structures and continuing education for nurses, I still feel it's unsupported" (Margaret, p. 21). The RNs clearly saw employer support as tangible acknowledgement of their efforts.

They paid for study days for us, when I say "us" it was because I wasn't the only person from the area that was doing the degree and I think it was their way of showing commitment to supporting the degree programme as well. (Phillip, p. 6)

\section{Personal trials}

Although the study participants had uniquely different personal and domestic circumstances some similarities and patterns were detectable. Three participants worked full-time, three worked part-time and the other two varied between full-time and part-time paid employment. All the participants of this study were parents, although two no longer had children at home. One participant identified as a single parent with three children, while the partner of another person with three children was overseas a significant amount of time and another participant with two children described her partner as "extremely busy". Seven of the eight participants were female.

In response to questions about what was the best and worst part of the experience of undertaking an RN to BN programme, most participants included the personal impacts of less time for family, social and leisure activities when discussing the worst aspect. 
The worst part was the time away from my family and my family was really very, very tolerant, my boys were very tolerant of me being otherwise occupied and not available to them. Not able to go away with my friends, for weekends ... the worst experience was the fact that I sort of had to withdraw from my previous life in order to achieve and hand in those assignments on time. (Bridie, p. 4)

Family was also identified as a factor that hindered RNs in the course.

Sometimes my family did hinder me because there would be things I had to do and I also knew I had [to have] an assignment ready. I remember [name] coming home from school one day, she had a book and I was sitting at the computer and she came and jumped on my lap and read me her school book and I was going, that's nice, dear and still typing my assignment and feeling quite annoyed with her because I had this assignment to do so, yeah, that sounds a bit awful but that was a factor. (Bessy, p. 13)

Adding the role of student to already busy, complex lives has impact in terms of time and energy. For participants with families there were often multiple factors that impacted on their study.

You know what family life's like, you tend to do your best assignments between 12 and 3 in the morning. It's just the way it is, it's just the way it is ... And it's where our computer sits as well. It's in a main room so it was really hard to have some peace and quiet.

(Bolivia, p. 10)

Blackie (2001) argues that most women in paid work complete a 'second shift' as they undertake the domestic tasks related to families and complete their study during their scarce leisure time. Clearly for some of these participants, spare time occurs mainly in the middle of the night. Emily, who worked full-time and was on her own with three children, described how she managed family and study.

It was really busy, my boys are good boys and though they were really helpful, we'd all sit in the kitchen at the dining room table and they'd do their homework and l'd be doing my study at the same time. My computer was set up in my eldest boy's room and he'd just go to bed and l'd be up till two, three in the morning and do my assignments and things on the computer and he'd just be sleeping there. (Emily, p. 2) 
Personal family events also affect the experience of undertaking a $\mathrm{RN}$ to $\mathrm{BN}$ programme. As RNs returning to study tend to be older, they often face added issues related to their developmental stage of dealing with teenagers or aging family members. Three of the participants in this study were influenced by unexpected family related significant events, although for the youngest participant, it perhaps should not have been totally unexpected.

My husband had just gone to East Timor and then I found out I was pregnant during my first paper with my oldest child so that changed things dramatically 'cause l'd gone in thinking I was childless and intended to do the course quite quickly but then I found out I was pregnant and l've had two more since doing my papers and so I had to cut down on the papers I did per semester. (Kate, p. 2)

Age and life stage impacted on participants in different ways. While Kate, as the youngest participant, was dealing with unexpected pregnancies, the oldest participant found having grown children who had left home gave her time and freedom to pursue study. The majority of the participants were however, middle-aged.

I think also the age of the nurses who are doing all that academic studies, I think, in some ways, it doesn't come at the most easiest time for them, you know like in their 40s or especially heading off into menopause, I think all that sort of things that makes it even more, makes it difficult to cope, where we are in our lives really, children, where I found myself at that time of life I think it didn't make it any easier. (Bridie, p. 12)

For two participants, the unforseen events were the illness and death of the older generation. Such events have a significant effect on progress in an academic course.

I also had an interesting time while I was studying as well. [Partner's] mother came to live with us for six months who had a terminal illness and died here so I did all those nursing cares. I actually did one assignment over the telephone. (Bolivia, p. 4)

Bolivia also discussed that over those six months her house was often besieged with family and friends visiting and staying. As the computer was in the main room, she faced the double difficulty of lack of time and lack of access to work on her assignments. It was evident from the literature (Lillibridge \& Fox, 2005) that RNs believed they should be treated differently from preregistration students, that there should be regard for their knowledge and their circumstances. Being treated regardful of your difference and circumstances, an aspect of the concept of cultural safety, seems applicable to NZ RNs undertaking a RN to BN programme. Boliva was accorded 
this regard as she was almost finished her degree, and allowed to present an assignment verbally. This was not an easy option.

Because I'd done all the reading I just did not physically have the time to do it so I did, I was on the phone for an hour ... I'd rather write one any day ... Luckily l'd done all the readings cause I could actually say who they all referred to ... She questioned me on everything. So, when I explained that I would do my summary I wouldn't introduce anything new, da da da da da, conclusion ... that was just fitting into it because I was so close and I just physically could not do it. (Bolivia, p. 4)

Phillip also commented that talking to his lecturers helped him get through, as they not only gave him allowances for his circumstances, but encouragement to continue.

Personally, one of the biggest hindrances I had from, part-way through was the loss of my father, that was a big ... it sort of put things aside for a short time ... which made it very hard, they found him with cancer so he had to have surgery and then not too long after that he passed away so that was a bit of a trial. (Phillip, p. 7)

Taking on degree level study clearly added stress to the lives of the participants. The connection between stress and health issues is well known so it seems unsurprising that participants in this research experienced health effects. Phillip faced more than one personal trial during his programme. After his father's death, he himself became ill.

Also illness to myself ... that wasn't planned for I ended up getting a DVT from studying, just in the fact of sitting down for too long, possibly while being on the computer and things like that ... it was during study that I found that I had one. (Phillip, p. 8)

Phillip had previously described long and late nights as he mastered not only the content of the programme but also using a computer. He actually counted himself as lucky, because the Deep Vein Thrombosis (DVT) actually exposed an underlying condition. However, the DVT was directly attributable to his degree studies. Bessy also became unwell as a direct result of her study.

I did three years and then I literally stopped from exhaustion, I think, I got quite unwell, I got pneumonia and got really unwell so I took a year off, stopped smoking, got healthy and got really bored again so went back and finished my degree. (Bessy, p. 5) 
As she had described working often seven days a week due to financial pressures, studying and having small children at home, it does not seem surprising Bessy became unwell. While the literature discusses the stress of adding study to already busy lives, little quantifiable evidence was found about how RNs were affected. This clearly shows the personal cost. All health events impact on the experience of RNs undertaking a BN. Another participant faced a serious health issue.

My personal circumstances were quite challenging as well so it was a really hard year for me, and when I did my research paper l'd just luckily done all my research and injured my back at work, a patient fell on me and I was off work for several weeks and I did my research paper sort of lying flat on my back kind of thing but luckily I had the stuff and I phoned the library girls when I got stuck and they got stuff for me which was really good ... when my back pain didn't resolve I had a scan and they discovered I had a mass in my abdomen and it was too large to operate so I had some three months of chemotherapy to shrink the mass before they operated and that was near the end of my time.

(Margaret, p. 7-8)

\section{Chapter review}

This chapter has highlighted the diversity and difference that surrounds RNs undertaking a RN to BN programme. As students had quite varied personal and professional circumstances different considerations were required. Having regard for this difference requires flexibility from and within programmes, in terms of RPL, the type and amount of requirements to achieve a degree and consideration for professional and personal circumstances. However, the experience of these participants was that this does not always occur. The divided opinions that exist within the profession regarding whether a degree is necessary for existing RNs were reflected in workplace cultures and these impacted on the RNs who were studying. Employer support with funding and time makes a difference to and is appreciated by RNs undertaking a degree, yet this was experienced as variable and inconsistent. The findings confirmed that there were significant personal and family costs for RNs involved in degree study, with concerning impacts on health. Opinions remain divided over whether all RNs should be required to achieve a costly and largely unrecognised undergraduate degree, given the workplace stress and age of the RN workforce. 
Within an environment of change, despite differing personal and professional circumstances, these participants made a choice to obtain a degree qualification through a $R N$ to $B N$ programme. Their experiences during and after completion of degree study has highlighted different levels of support and different views on whether such programmes should be compulsory but a common belief that there has been a change to their practice. What have emerged through the preceding chapters are core themes of change, difference and choice.

Chapter Seven includes examination and discussion of these three core themes and the findings of this study. The place and future of $\mathrm{RN}$ to $\mathrm{BN}$ programmes within nursing education is considered. The limitations of this study are discussed and suggestions are made for further research in this area. 


\section{CHAPTER SEVEN}

\section{Discussion and Conclusions}

\section{Introduction}

Case study has been shown to be a useful research strategy for understanding complex social phenomena (Luck, Jackson, \& Usher, 2006; Stake, 1995; Yin, 2003). This study has used mixed methods and a case study approach to examine the personal and professional significance of registered nurse $(\mathrm{RN})$ to Bachelor of Nursing $(\mathrm{BN})$ programmes. By considering findings from both the personal and the national professional perspectives in an integrated way as they informed an understanding of the case as a whole, the core themes of change, choice and difference emerged. These themes are connected and interlinked. The findings show that RN to BN programmes were the result of change; change in nursing education that saw pre-registration courses and entry to the profession move to degree level, change in the socio-economic and educational context of New Zealand (NZ) and change in professional nursing practice. There were choices in how both individuals and the profession reacted to this change. Difference and debate surrounds programmes for RNs to obtain an undergraduate nursing degree, both within NZ and internationally. The purpose of this chapter is to provide a discussion of the findings and to relate this to current practice and consider the place and future of $R N$ to $B N$ programmes in nursing education. Also included are the implications of the findings and recommendations for future research.

\section{Discussion}

The theme of change was central to this study. Change in nursing education is an international phenomenon, with the move to an undergraduate degree as the level of entry to the profession occurring in many countries. Australia was the first country in the world to establish all preregistration education and entry to the profession at the level of an undergraduate degree. This change occurred quickly, it was assisted by change in the wider tertiary education sector and was achieved by 1994 . The move to pre-registration degree programmes in NZ happened in a similar way, relatively quickly and encouraged by change in the tertiary education sector. In the United Kingdom (UK) and the United States of America (USA), where pre-registration degree programmes have existed for much longer, diploma level programmes are still the main route to a $\mathrm{RN}$ qualification. Each country has responded to the move to degree-level entry to the profession 
in a different ways, but all have established arrangements that allow existing RNs to gain an undergraduate degree. Hence, the phenomenon of RNs gaining an undergraduate degree is international. Due the different circumstances, history and professional nursing contexts of each country, programmes and requirements for RNs to gain an undergraduate degree vary. The NZ response to change, the establishment of $\mathrm{RN}$ to $\mathrm{BN}$ programmes, is therefore unique.

Throughout NZ nursing history changes in pre-registration education has resulted in national and professional consideration being given to individuals affected by the change to enable them to meet the new standards if they chose. Usually these arrangements have been for a finite time. A profession is a collection of individuals, so the changes that occur within nursing education and the provisions made for those affected by change are usually encouraged and/or requested by individual nurses. The creation of $\mathrm{RN}$ to $\mathrm{BN}$ programmes was the direct result of the requests of RNs during consultation on the establishment of pre-registration degree programmes. Nurse educators, philosophically supportive of the concept of assisting RNs to gain a degree qualification and the knowledge required to assist pre-registration students, heeded these calls for such a programme and then acted to make it a reality. The personal responses of RNs to changes in nursing education encourage the professional responses to such change.

Changing requirements can result in either fear or motivation within existing RNs and these different responses, while ultimately a feature of the individual, can also become attitudes of the profession. The participants in this research experienced changing requirements as moving goal posts that occurred both nationally and locally within programmes. While clearly motivated by the changing requirements, some participants also expressed frustration or annoyance that escalating qualifications appeared to value academic attainment over the experience of practise. Change at the institutional level, with alterations in programme requirements and new curricula, also impacted on RNs, contributing to confusion, frustration and for one participant in this study, the need to complete more papers than originally required. Participants in this study, congruent with the findings from the literature and other NZ research, described the fear that their existing qualifications may count for little in the future, or that they would be 'left behind' but acknowledged that this fear also acted as a motivator.

This concurrence of fear and motivation related to change was also evident at a national professional level, with nursing not wanting to be left behind as other health professionals increased their entry requirements to degree-level. The arguments supporting the move to 
degree-level pre-registration programmes for nurses and RNs obtaining a degree, included changes in healthcare and the need for a different type of nurse, one who can think critically, use evidence-based practice and respond to the new diseases and technologies that are being developed. However, the desire by nurses for the status and rewards of being considered a true profession cannot be ignored as a motivating factor. At an individual level, some participants were motivated by the hopes of promotion and advancement within the profession.

A change has occurred in the way education is viewed by nurses. This has resulted from shifts in nursing education and professional requirements which in turn supports and encourages further educational change. Attitudes towards education influence RNs considering undertaking an undergraduate degree and influence the perceptions of colleagues, contributing to the workplace environment surrounding those RNs who are studying. Again this change has occurred at both the individual and the national professional level. The actions and dreams of nurses since 1910 who worked to achieve degree-level education for nurses has been underpinned by a faith in individual nurses to take advantage of such opportunities and a belief in the positive benefits of education and scholarship. There were no formal expectations for RNs to continue with any form of education until recent times, and no clear pathways for education existed. The development of post-registration education frameworks and requirements (Nursing Council of New Zealand [NCNZ], 1998, 1999a, 1999b), along with the establishment of Professional Development Recognition Programmes (PDRP) (National PDRP Working Party, 2004) and requirements by NCNZ for nurses to provide evidence of ongoing education as a requirement of demonstrating competence, has meant post-registration education of some level is now an expectation.

These more recent changes in nursing education have been influenced by the socio-political environment in which nursing education and practise are embedded. Change in society has regularly influenced nursing and nursing education. The introduction of degree-level preregistration nursing programmes occurred more by opportunity than by planning. While ultimately the culmination of earlier professional endeavours to advance nursing and nursing education, this change occurred as a result of wider socio-political and economic changes and came at a time when the profession was in some disarray (Jacobs, 2005). The introduction of pre-registration degree programmes occurred amidst a lack of professional consensus and in an environment of competition and entrepreneurialism. The change was led by nurse educators and educational institutions rather than by the NCNZ or the wider profession. Consensus has not often been a feature of change in nursing education (Adams, 2003; Burgess, 1984; Papps, 1997) and there 
appears to be little national or professional consensus on the place and continued existence of $\mathrm{RN}$ to BN programmes. Currently, they appear to exist depending on the desire of the educational institution and the economic viability of the programme.

The history of change in nursing education was responsible for the different qualifications amongst the participants. However, change, although constant, has also happened slowly, with the last hospital-based pre-registration graduates only completing in 1990. It was evident from the interviews that those on the cusp of change in nursing education had different experiences. So for Kate, who was in the last class to graduate at diploma-level as the pre-registration programmes moved to degree-level, her experience of the outcomes of obtaining an undergraduate nursing degree was different than participants who registered earlier. Although pre-registration degree programmes commenced in 1992, diploma-level programmes were still being phased out in 1998 when the NCNZ made the formal decision that entry to the register would only be by degree. Hence, the majority of RNs currently practising qualified prior to the introduction of pre-registration degree programmes. The findings of this research have demonstrated that $\mathrm{RN}$ to $\mathrm{BN}$ programmes have made a significant contribution to the numbers of RNs with a degree qualification. Despite this, the bulk of the workforce still does not have a degree qualification or higher. Yet, the number of $\mathrm{RN}$ to $\mathrm{BN}$ programmes offered and the numbers of RNs taking up this option have markedly reduced. Corresponding with the decline in RNs choosing the $\mathrm{RN}$ to $\mathrm{BN}$ option, there has been a marked increase in the number and type of post-graduate education options available.

A major finding of this research was the change in thinking and practise, perspective transformation, that occurred for the participants of this study. Consistent with international literature (Hardwick \& Jordan, 2002; Stanley, 2003) achieving their degree was a great source of achievement and pride for the participants. The degree had been hard work, akin to climbing a mountain, but attaining a degree bought more benefits than a qualification. Participants described increased self confidence, a sense of being "up there with my other colleagues" (Millie, p. 8), a sense of satisfaction. Only Kate, who was the youngest and most recently registered of the participants, did not identify a change in her practice. She did describe feeling "more fulfilled" and "more maybe open minded" (p. 6), but others talked enthusiastically about "I'm really quite a different nurse now" (Bridie, p. 10) and how they "practise differently, it's more of a partnership with my patients now" (Emily, p. 18). All the participants stated their belief that completing the RN to BN programme 'was worth it'. While it can be argued that most people benefit from education, 
and believe their efforts have been worthwhile, the findings showed that the $R N$ to $B N$ degree changed the thinking and practise of existing RNs, which must benefit the wider profession and patient outcomes.

Throughout the history of change in pre-registration standards, there has never been a requirement on existing $\mathrm{RNs}$ to meet the new requirements; this has always been a matter of choice. However, as the findings of this research show, choice is often influenced by the personal and professional situation of the person. The cost of studying, both financially and in terms of time away from other priorities, was an important consideration in deciding if it was 'the right time'. Timing was significant for the participants. This is consistent with literature (Thompson, 1992) where many RNs expressed interest in study but just needed to find the right time. The age and stage of family members, and the participants themselves, influenced both the choice of doing degree study and their experience of it. As most returning RNs tend to be middle-aged, they face not only the pressures of their own children and aging parents, but often career expectations and their own health issues. From my experience, there appears to be a (mis)perception that older RNs choose not to undertake study because of their age. Yet these findings showed that Millie, the oldest of the participants, with the longest time registered, was the only person to have gone on to Masterate study. Being older, and less restricted by family pressures may make choosing further education easier. A concerning result from this research was the personal cost to participants from the choice of degree-level study. Participants described doing the majority of their assignment work in the middle of the night and four of the eight participants described significant health issues, most directly attributable to the added stress of degree study. Of note here is that many pre-registration nursing students are now mature adults. It would seem likely therefore, that mature pre-registration students may face similar considerations in choosing to study nursing, comparable pressures from their programme and possible deleterious health consequences.

The choice of an $\mathrm{RN}$ to $\mathrm{BN}$ programme from the range of post-registration education options available for RNs was influenced, according to the participants, by the belief that it was 'do-able'. In discussing how this factor contributed to their decision, 'do-able' was described as a mountain that they believed they could climb. In contrast, post-graduate study was envisaged a much higher and more difficult climb, one they were unlikely to succeed with. Succeeding was the equivalent of reaching the top of the mountain, it was finishing the programme and gaining the qualification. This study revealed that the length of the programme and achieving a degree 
qualification were considered important by the RNs interviewed. These findings echo the results of the evaluation of the Advanced Diploma of Nursing (ADN) programmes (Kennedy \& Taylor, 1987). In that research nurses were asked why they enrolled in an ADN post-basic course rather than a university post-basic course and reasons given included that the course lasted one year and that nurses were more confident they could manage the ADN course than university study.

Another consideration in the choice of an $\mathrm{RN}$ to $\mathrm{BN}$ programme was how the programme was delivered. The participants, like those in the study by Seaton (1998), all wanted some classroom time and lecturer guidance. Networking with other RNs was considered a valuable component of the course that they chose. Online and distance modes of delivery were considered unattractive options because of a lack of confidence with technology and because personal interaction was more congruent with the practise of nursing. Academic insecurity (Horne, 1993) was another factor contributing to the choice of an RN to BN programme. The findings showed that some participants initially lacked the skills related to research and assignment writing. Becoming competent with academic skills and being successful with assessments resulted in a boost in self-confidence and the impetus to continue.

Choice occurred at the national professional level also. Not all institutions offered an RN to BN option and while most delivered the $\mathrm{RN}$ to $\mathrm{BN}$ programme through delivery streams separate from those offered to pre-registration students, in some places, particularly as numbers of RNs dropped, this was not an option. It was clear from the literature that RNs want to be treated differently to pre-registration students and, as Lillibridge and Fox (2005) describe, have integration and academic socialisation with their peers and not novices. While this is the ideal, cost and timing, as significant for institutions as they are for individuals, influence what is able to be provided. Institutions need to be economically viable, so any professional desire of educators to provide a specific option for RNs, must comply with the time availability of staff and the course must be financially feasible.

The decision to undertake degree-level study through a $\mathrm{RN}$ to $\mathrm{BN}$ programme was a choice made for personal and professional reasons. While the participants all described professional reasons such as 'keeping up' and being 'up-to-date', they also talked about personal satisfaction and attaining the qualification to prove something for themselves. As identified in Chapter Two, debate exists within the profession on whether RNs studying for a degree are benefiting themselves or the profession. The findings show that there is personal and professional benefit 
for individuals. At a national level, a similar question can be asked, are institutions providing these programmes for individual institution profit or for professional good? The absence of professional consensus relating to these programmes means that choice for individuals, and the choice for institutions, may be removed as market forces are the only controlling influence. Phasing out programmes and advising individuals to consider post-graduate study, which seems to be happening in a defacto way, may be the choice of the profession. If so, there needs to be transparency and consensus around such decisions as the evidence from this research demonstrates some RNs prefer a choice that they perceive as 'do-able'.

The different opinions on the place and value of $\mathrm{RN}$ to $\mathrm{BN}$ programmes are problematic for individuals, managers and institutions. Obtaining an undergraduate nursing degree as an RN does not even feature as a possibility on the NCNZ framework for post-registration education (NCNZ, 1999a, 1999b). Hence, some nurses do not see any value in experienced RNs obtaining this qualification. Additionally, this lack of national professional recognition results in a lack of personal recognition for the efforts of those who have obtained a BN degree. This contributes to a lack of financial recognition, differing amounts of employer and collegial support and a lack of clarity around the choices that are available for $\mathrm{RN}$ considering further education. The findings showed mixed reactions from colleagues, different levels of financial and time assistance and little financial reward. However, the results also demonstrated, consistent with the literature findings, that when recognition and assistance were provided, the participants were very appreciative. The tension between the merits of education and the value of practical experience were also evident in these different opinions.

Difference clearly surrounded $\mathrm{RN}$ to $\mathrm{BN}$ programmes. When or if programmes started, what format they took, how much credit they gave for existing registration, how long programmes ran for and the numbers of RNs successfully completing these programmes, all varied across the country. This is further evidence of the lack of consensus and variation related to this educational option. An issue identified in the literature and highlighted by this research is the difference and difficulty of awarding recognition for prior learning (RPL). At the personal level some RNs appeared to frame this as the tension between academic knowledge and qualifications, and the value of practical experience. Bessy described feeling really angry and "I felt my experience wasn't valued because I didn't have a formal qualification" (p. 5). Somewhat jokingly, she raised the issue of the honorary degree, but she was also clear that RNs were being asked to do too much to gain an undergraduate degree. The differing amount of credit awarded by institutions for 
registration further highlights the difference that exists. To obtain RPL students usually have to demonstrate that they have met the level required, the amount of work or weighting expected and that they have also covered the majority of the content. Emily had done seven university papers prior to commencing her $\mathrm{RN}$ to $\mathrm{BN}$ programme but received no additional credit for these. Horne (1993) calls the denial of credit to students "institutional chauvinism" (p. 63) while Rather (1994) says it denigrates previous nursing education. As RNs in NZ can apply for direct entry into postgraduate study, and with this becoming increasingly common and a recommended option, steps need to be taken to have greater clarity and consistency around awarding RPL to RNs, both for their registration and experience, and for any formal study that they have completed.

The characteristics of RNs choosing to study for a degree through an $\mathrm{RN}$ to BN programme also differ. This was reflected in the participants who had different types of registration, length of nursing experience and areas of nursing employment. What was not reflected in these participants was the significant number of RNs within the workforce who gained their initial registration outside of NZ. Indeed, $\operatorname{NCNZ}(2003,2006)$ notes that more people register annually who are existing RNs from overseas than register from NZ pre-registration programmes. As the majority of RNs from overseas have registered without a degree-level qualification, they provide a pool of potential students for $\mathrm{RN}$ to BN programmes. Most of these nurses need to undertake a Competency-Based Assessment Programme, predominantly supervised practise, to obtain NZ registration. Consideration could be given to combining the requirements of a $R N$ to $B N$ programme with the requirements of the competency programme. Likewise, there are now also Return to Nursing programmes being offered by undergraduate education providers, and these may be able to be combined with an $\mathrm{RN}$ to $\mathrm{BN}$ programme for those who are interested in this option. Of note is that both the competency programme for international RNs, and the programme for returning RNs must be approved by NCNZ, because they have a practise component and lead to registration. The $\mathrm{RN}$ to $\mathrm{BN}$ programme, because it is purely academic in nature, receives no such NCNZ attention. In my employing institution, the majority of RN to BN students now have first registered overseas. These RNs also contribute to slow rate of change in the percentage of RNs who hold a degree-level qualification or higher. Currently there appears to be more than $50 \%$ of existing RNs who still do not have a degree or higher qualification.

Despite the bulk of RNs not having an undergraduate degree or higher qualification, the findings show that the number of $\mathrm{RNs}$ entering $\mathrm{RN}$ to $\mathrm{BN}$ programmes has reduced dramatically, fewer institutions are offering these programmes, and that while the numbers of graduates has been 
significant, these total a few thousand out of an active RN workforce of approximately 40,000 (NCNZ, 2006). The last available workforce statistics (NCNZ, 2002) showed more RNs studying at post-graduate level or higher, than were studying at degree-level. This statistical trend evident in 2002 is likely to have continued. Since the late 1990s there has been increasing emphasis on advancing and advanced nursing practice in NZ (Jacobs, 1998, 2005). To progress this, importance has been placed on post-graduate education, with a greater availability of courses at post-graduate level including a growing choice of clinically focused papers. Other factors influencing the uptake of degree programmes by RNs include the many demands on an RNs time, with high acuity levels in the practice environment, continuing resource constraints and requirements for $\mathrm{RNs}$ to provide evidence of their competence and ongoing professional development. Additionally, RNs now have a financial incentive to demonstrate higher levels of practice and education through Professional Development Recognition Programmes (PDRPs) and higher education. Hence, the choices available to RNs have changed considerably in the last few years. Rather $(1993,1994)$ argues that returning RNs have an understanding of what shapes and guides practice so seek the advanced content that post-graduate study is designed to provide.

The question therefore, needs to be asked about whether $\mathrm{RN}$ to $\mathrm{BN}$ programmes should continue. The evidence from this research is that at the personal level, individuals saw obtaining an undergraduate nursing degree as an achievable qualification, especially as many of the participants had been away from formal study for a long time and lacked academic confidence. All those interviewed found the programme worthwhile, with most reporting a change in practice and thinking, although some believed that the amount of work required for an experienced $\mathrm{RN}$ to obtain a degree was too high. At the national professional level it is clear that change has continued in nursing education and that more options are now available for RNs seeking postregistration education and higher qualifications. The increasing availability of post-graduate study, combined with the ability to achieve a qualification at post-graduate certificate and postgraduate diploma level has seen a corresponding decrease in the uptake and availability of RN to BN programmes. RNs are being encouraged to seek post-graduate rather than undergraduate education, while some RNs just do not wish to commit to a course of study when they already have full and busy lives (Thompson, 1992). 


\section{Recommendations}

What is needed around this issue is professional consensus. There is a need to provide greater consistency and direction to individuals and institutions on degree education for RNs and this requires agreement on the place and future of $\mathrm{RN}$ to $\mathrm{BN}$ programmes. Agreement needs to occur at a national professional level and ideally should come from NCNZ. Although previous history highlights a lack of professional consensus in some areas, one way to progress this would be a review of the post-registration education framework (NCNZ, 1999). This would be timely, considering the changes to other areas of professional nursing and practice requirements that have occurred since 1999. If $\mathrm{RN}$ to $\mathrm{BN}$ programmes are to be retained there needs to be more consistency in the credit given for registration and the requirements to achieve a degree qualification. The literature (Delaney \& Piscopo, 2004; Horne, 1993; Thompson, 1992) supports reducing institutional barriers and excessive requirements on $\mathrm{RN}$ students. Consideration of the complex and busy lives of RNs, along with their desire to interact with peers rather than preregistration students, should be acknowledged in the way programmes are offered.

Individual RNs sacrifice personal time, money and energy to gain educational qualifications in the belief that their efforts will enhance practise and improve patient outcomes. Professional reasons dominated the findings on why the participants chose to undertake an RN to BN programme. Professional consensus is required in order to assist RNs with their educational choices or there is a risk that nurses will become confused or frustrated with an unclear palette of choices, and opt to do nothing. A clear, inclusive post-registration framework is required that identifies the personal and professional outcomes of programmes. All pathways should be included with information that clarifies any financial or professional acknowledgement resulting from a programme or pathway. This would better assist RNs with their choices. Further research into post-registration education and the active dissemination of the findings of such research is required.

The risks as well as the benefits of education need to be known by RNs so that they can make appropriate choices regarding support, employment requirements and personal domestic responsibilities. This study revealed concerning health consequences for RNs who were undertaking study to obtain a degree qualification. Partners and families, the main support for RNs undertaking study, also need to be aware of their important role during this time. 


\section{Implications for managers, employers and educational institutions}

All RNs who choose to study should be supported by managers and employers. They require support financially and with time release, as it has been shown that without this assistance RNs can become unwell. Greater consistency and transparency around what support is available is required as these findings showed that the amount and type of support participants received varied greatly. Managers need to be aware of the positive benefits of providing support as the RNs in this study clearly valued and appreciated the assistance they received from their employers. An awareness of the value RNs place on employer support may encourage the greater provision of such support. Ultimately, employers require evidence that support for RN education at degree-level results in useful outcomes. The findings of this research showed that perspective transformation (Harrington, 1996; Maltby \& Andrusyszyn, 1997; Morris \& Faulk, 2007; White \& Gomez, 2002), a change in thinking and practise, along with greater self confidence, were major outcomes for RNs completing degree-level education.

At a national professional level, agreement around the place and future of $\mathrm{RN}$ to $\mathrm{BN}$ programmes is required to provide clear guidance to managers and employers. If $\mathrm{RN}$ to $\mathrm{BN}$ programmes are to continue, they need to be visible on a post-registration education framework. This would assist managers and employers and would demonstrate a valuing of all post-registration education.

Educational institutions also need a consensus statement on the place and future of $\mathrm{RN}$ to $\mathrm{BN}$ programmes to enable them to plan to continue or to discontinue programmes. As many of the participants identified academic insecurity as an issue, education providers need to offer assistance with assignment writing and academic skills for returning RNs. Greater clarity and assistance surrounding RPL needs to be instituted, to ensure RNs receive the recognition they are entitled to. Maintaining delivery options for RNs that allow networking and interaction were identified by RNs as important. Further research to ascertain if RNs are more comfortable with online options is also required. Educational institutions need systems that easily provide data related to grandaunts of $\mathrm{RN}$ programmes. A number of Schools of Nursing commented on the lack of ease in retrieving data.

\section{Professional implications}

Professional leadership is required on the issue of RN to BN programmes. These programmes were established because of the entrepreneurial leadership of nurse educators who not only saw 
the gap in the market, but who were philosophically committed to meet the educational needs of existing RNs. The unregulated way in which these programmes were developed, combined with ongoing change in professional practice and in the socio-political environment in which nursing and education are embedded, has resulted in differing programme requirements and variable recognition of the programmes and their graduates. Leadership is once again required to ensure a consensus position and some certainty on the future of $\mathrm{RN}$ to BN programmes.

Better systems are required to collect, record and monitor the educational qualifications of RNs. A lack of statistical information on the educational position of RNs impedes planning. Replacing assumptions with facts may also reduce the tension between experience and academic qualifications. The registrar of NCNZ stated a belief that the majority of RNs are involved in education (B. Ayling, personal communication, October 27, 2006), yet there is little understanding of how this relates to qualifications.

Recognition is needed within nursing education of the place and significance of $R N$ to $B N$ programmes and the RNs that were students on them. Rather (1993, p. 111) argues that "the whole community of nursing benefits from the advanced learning of one of its members". The findings of this study has shown that RNs who complete a degree provide a positive influence, in their practise, supporting and encouraging other RNs, and in their work with pre-registration students.

\section{Limitations of the research}

This research used mixed methods and two perspectives to uncover data about RN to BN programmes. One factor that may be considered a limitation of this study was the number, location and type of participants interviewed. The sample of participants was taken from one institution and only nurses who had completed an $\mathrm{RN}$ to BN programme were considered. These were purposeful decisions that deliberately shaped the research. However, this did impact on the number and range of RNs recruited, who were all Pakeha, with no overseas RNs represented in the participants. The RNs who contributed to this research did provide rich data and diversity. Because of the size of this study, those nurses who did not complete, or did not undertake an RN to BN programme were also not included. Again, this was a conscious decision related to the nature of the study. The stories of these eight participants cannot be generalised to all $\mathrm{RN}$ to $\mathrm{BN}$ students or to RNs in other programmes. Despite this I believe the findings of this study provide 
valuable insight into the decisions and experience of RNs studying for an undergraduate degree through a $\mathrm{RN}$ to $\mathrm{BN}$ programme.

My background as a lecturer within the $\mathrm{RN}$ to $\mathrm{BN}$ programme that the participant sample was drawn from was addressed as an ethical issue and did not appear to be an influence to the participants. This was dealt with in the information sheet, by my raising this with the participants who knew me prior to them agreeing to be part of the study, reiterating it at the beginning of the interview and reminding the participants that they did not have to answer any questions and that the recorder could be turned off at any time. I do not believe it was an issue in any of the interviews.

A further limitation of the study was the response rate of the survey. As only $56 \%$ of institutions replied, some with incomplete figures, the numbers of graduates were unable to be quantified. However, a pattern was discernable from the data provided. Other statistics related to RN qualifications were used to support the statistical impression.

\section{Recommendations for future research}

This study examined the personal and professional significance of $\mathrm{RN}$ to $\mathrm{BN}$ programmes. However, there were other aspects of the case that were not able to be explored. In particular, the numbers and experience of those who started but did not complete a $\mathrm{RN}$ to BN programme and those who chose not to undertake such a programme. This information would provide a more holistic view of the motivations, decisions and experience of RNs regarding post-registration education. Also, research needs to capture overseas RNs who make a significant contribution to the NZ nursing workforce. Therefore, the recommendations for future research include exploring and investigating:

- The experience of those who started but did not complete an undergraduate degree and who did not return to such education.

- The numbers and decisions of those who used this programme as a stepping stone to go onto post-graduate education.

- RNs who went straight into post-graduate study, without attempting any degree level study to consider their experience of this.

- The reasons NZ RNs without a degree chose not to attempt this type of education. 
- Overseas RNs who have undertaken a RN to BN programme to ascertain their reasons for and experience of such study.

- RNs responses to different educational delivery modes.

- The perspectives of managers or employers on RNs completing an undergraduate degree.

A larger study which considers and triangulates the perspectives of institutions, managers/employers and RNs would be useful. However, as many of these programmes no longer run, a retrospective evaluative study that considers what types of programmes should be offered in response to changes in nursing education may also provide important information.

\section{Summary and conclusion}

A detailed description of $\mathrm{RN}$ to $\mathrm{BN}$ programmes revealed the themes of change, choice and difference and provided insights about their significance for individuals, institutions and the profession. The findings showed that several thousand RNs sacrificed personal time, energy and finances and used $\mathrm{RN}$ to $\mathrm{BN}$ programmes to advance their educational attainment and gain a degree qualification. They did this to be professionally up-to-date, to enhance their career prospects, and for the personal satisfaction of obtaining a degree qualification. There were significant personal and financial costs to undertaking degree-level study and worrying effects on the participants' health. Despite these, all the participants considered completing a degree through a $\mathrm{RN}$ to $\mathrm{BN}$ programme was worth it. Even with this personal affirmation, numbers graduating from these programmes have declined rapidly and fewer institutions are now offering $\mathrm{RN}$ to $\mathrm{BN}$ programmes. This has occurred even though less than $50 \%$ of the nursing profession has a degree or higher-level qualification. Nurses are now encouraged to undertake programmes at post-graduate rather than undergraduate level. The RNs in this study all described the RN to BN programme as a challenge and hard work, yet it was considered an achievable mountain to climb, whereas post-graduate study was a mountain some would not attempt.

The professional nursing environment has changed since the introduction of $\mathrm{RN}$ to $\mathrm{BN}$ programmes. More choice is available at post-graduate level, including new clinically-based papers. Professional requirements related to continuing competence, advancing levels of practise and the recognition of professional development have now been developed. With these changes, the declining numbers of $\mathrm{RNs}$ entering $\mathrm{RN}$ to $\mathrm{BN}$ programmes and an increasing 
percentage of pre-registration degree qualified RNs, it appears there is no longer a need for undergraduate degree programmes for registered nurses. However, this research has found that $\mathrm{RN}$ to $\mathrm{BN}$ programmes do have positive personal and professional outcomes. Professional consensus on the future of these programmes is required. Retaining a small number of flexibly offered RN to BN programmes would provide continued choice to RNs. There would need to be more national consistency and easier recognition of prior learning in the requirements of such programmes. It is recommended that there is a specific end date to such programmes. This would provide clear messages to RNs, their employers and educational institutions. Without some professional consensus and direction, these programmes will be retained or ended solely on the grounds of economic viability.

The introduction of pre-registration degree programmes required consideration of existing RNs and a mechanism to enable them to achieve this new standard. The establishment of RN to BN programmes was both a product of and a reaction to change. These programmes have had significance within nursing education and positive personal and professional outcomes. Better recognition for those RNs who have achieved an undergraduate degree is required. Although there were limitations to this case study, the results give useful insights into the personal meaning and professional place of $\mathrm{RN}$ to $\mathrm{BN}$ programmes. It raises further questions about undergraduate degree programmes for RNs and change within nursing education, so more research is still required. 


\section{APPENDICES}

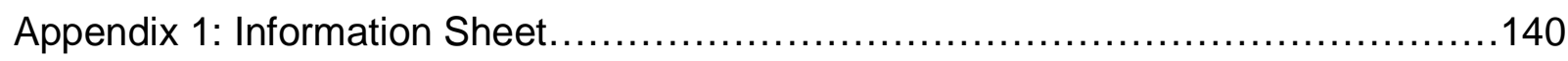

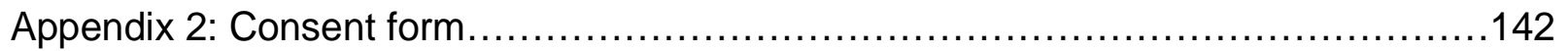

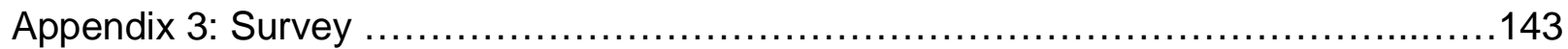

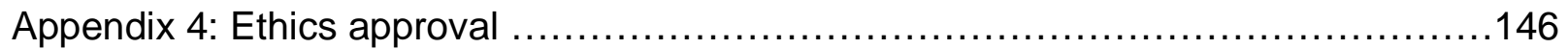

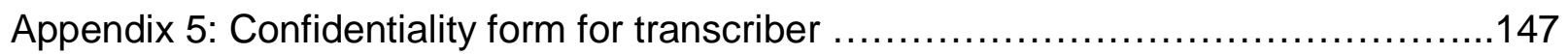

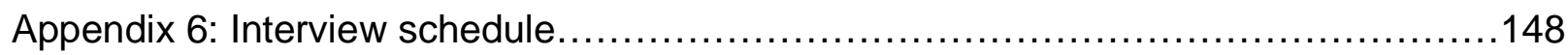




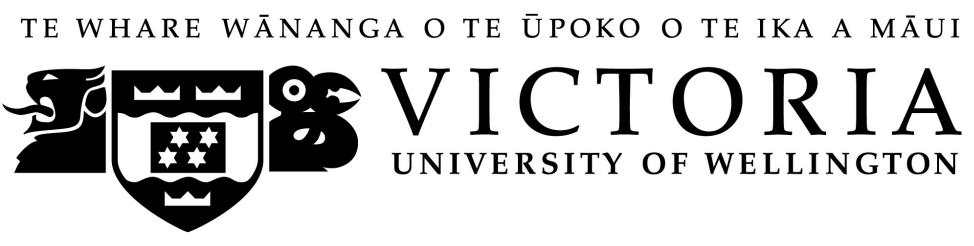

Appendix 1

\section{Information for Intending Participants}

\section{'Completing a Bachelor of Nursing as a Registered Nurse'.}

My name is Tina Smith and I am a Registered Nurse, a lecturer in nursing at UCOL and I am currently enrolled in the Master of Nursing programme at the Graduate School of Nursing, Midwifery and Health from Victoria University of Wellington. As a nurse educator and a lecturer in the Registered Nurse to Bachelor of Nursing (RN to BN) programme I am interested in why nurses chose to do an undergraduate nursing degree when it was not required by the Nursing Council of New Zealand and when they also had the option to apply for entry straight into postgraduate level study. I am also interested in what effects completing the programme have had on them personally and professionally. Knowing the registered nurses' perspective will add to our understanding of why nurses choose differing options of study or qualifications, and what effects a degree qualification has had on them personally and professionally. This may provide useful information for other nurses contemplating undertaking a degree, for managers deciding what types of nursing study to support and for educators and education providers.

This research has received ethical approval from the Human Ethics Committee of Victoria University of Wellington.

My intention is to meet with you for a semi-structured interview of approximately one hour, at a time and place convenient to you. During this time I will ask for some basic information, for example, relating to your nursing qualifications and experience and your situation at the time of undertaking the course. You will then be asked about your experience of undertaking and completing an undergraduate nursing degree. Included in this conversation will be questions around why you chose this option, what factors hindered or encouraged you, as well as what you see as the personal and professional outcomes of this experience.

With your permission the interviews will be taped and then transcribed. You have the right to decline to answer a particular question or to have the tape-recorder turned off at any time. You will be asked to read your transcript to comment on its accuracy. You can delete any part of the taped or transcribed recording that you do not want to be included in the research, for whatever reason, either during the interview or later after reflection. Selected excerpts, using your own words, may be printed in the final reports of the research, such as my thesis, conference reports or journal articles. You have the right to withdraw from the study at any time during the research until I begin analysing the data. I will tell you at the time of the interview when data analysis is likely to start. Should you decide at any time to withdraw from the study, your tapes and transcripts will be destroyed. Every attempt will be made to protect your confidentiality. Pseudonyms will be used on the tapes, all printed material and in the final reports. Because New Zealand is a small place and the location of the programme may be recognisable to some people, 
it is up to you as to what level of detail is included. Ideally any detail that may identify you will be excluded. However, if you wish certain detail to be included which might identify you, I will discuss this with you, and if you have considered the potential for identification and still wish the detail to be included, then this can occur.

During the course of the research all tapes, discs, transcripts, signed consent forms and any other research material will be kept in a secure place. The tapes and transcripts will be seen by myself, the transcriber, (who will have signed a confidentiality form), and my supervisors at Victoria University of Wellington. No person other than myself will see the signed consent forms, thus protecting your identity.

At the conclusion of the research the tapes will be erased and destroyed, but the transcripts will be retained in a secure place for three years. At the end of three years these will be destroyed also.

The findings of this study will be offered to you, either as a summary of the research or as a copy of the thesis. I plan to share the results at education seminars, conferences and through publications, such as journal articles. I will let you know about any publications if you would like this information.

When considering your involvement with this research you need to consider that it is likely that I was one of your lecturers during your ' $R N$ to BN' programme. It is important that you feel totally free to offer honest comment and that my involvement with you and the programme will not inhibit your remarks. Also, should we meet in the practicum setting at any time I will not mention or discuss the research so as not to identify you as being involved in this project.

My supervisors are: Dr Pamela Wood, Associate Professor \& Dr Kathy Nelson, Lecturer Contact details: $\quad \mathrm{Ph}(04) 463-6650$ or (04) 463-6138

Graduate School of Nursing, Midwifery and Health, P.O. Box 600, Wellington

E-mail: $\quad$ Pamela.Wood@vuw.ac.nz Kathy.Nelson@vuw.ac.nz

I am available for clarification of any aspect of the study by phone or in person.

In summary - you have the right to

- Accept or decline participation

- Withdraw from the study at any time until I begin the analysis

- Have your privacy and confidentiality protected

- Ask questions at any time

- Not answer questions or turn off the tape-recorder at any time

- Comment on or amend the transcripts

- Receive information about the progress and outcomes of the study

Tina Smith

$\mathrm{Hm}: \quad 063566366$

Wk: 069527001 Ext 70426

E-mail: T.Smith@UCOL.ac.nz 


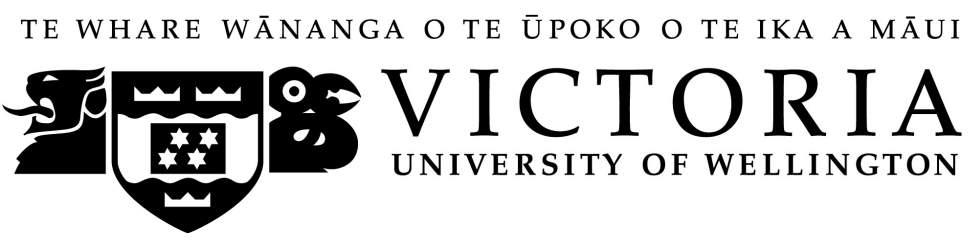

Appendix 2

\section{Consent Form}

\section{'Completing a Bachelor of Nursing as a Registered Nurse'}

I have read the information sheet for this study and have had the details of the study explained to me. My questions about the study have been answered to my satisfaction, and I understand that I may ask further questions at any time.

I also understand that I have the right to withdraw from the study at any time until data analysis begins. I agree to the use of a tape-recorder but I have the right to ask at any time to have it turned off or to have any or all of the tape deleted. I agree to provide information to the researcher on the grounds that my name will not be used, and that I have complete control over the level of detail concerning me that is used. The means of protecting my confidentiality has been explained to me.

I therefore give my informed and voluntarily consent to participate in this study under the conditions as set out in the Information Sheet.

Signed:

Name:

Date:

I would like to be informed of any subsequent publications arising from this research.

The address I would like information sent to is: 


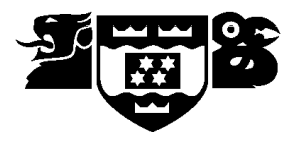

\section{Appendix 3}

November 2006.

Head of School

School of Nursing

\section{Dear}

My name is Tina Smith and I am a Registered Nurse currently enrolled in the Master of Nursing programme at the Graduate School of Nursing, Midwifery and Health from Victoria University of Wellington. My research focuses on transition programmes for registered nurses to obtain an undergraduate nursing degree. As part of this research I am seeking information from providers, such as you, who may have offered degree transition programmes for registered nurses. An information sheet about the study is attached.

I would be extremely grateful if you, or a staff member, would take a few minutes to complete the attached questionnaire and return to me in the stamped, addressed envelope supplied. Both a hard copy and an electronic copy of this letter and questionnaire will be sent to you so you may reply in which ever medium you find most convenient.

If the programme still runs, I would appreciate a copy of the information available to prospective registered nurse students.

No Schools of Nursing will be individually identified in the research. All statistics given will be aggregated.

Please respond by $\mathbf{1}^{\text {st }}$ December 2006. If you wish to discuss this further please contact me on t-moore@xtra.co.nz or on 0272227166.

Yours sincerely

Tina Smith 
VICTORIA UNIVERSITY OF WELLINGTON

Te Whare Wananga o te Upoko o te Ika a Maui

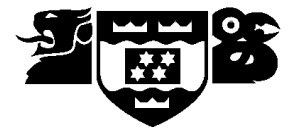

\section{Information Sheet}

\section{'Completing a Bachelor of Nursing as a Registered Nurse'.}

My name is Tina Smith and I am a Registered Nurse currently enrolled in the Master of Nursing programme at the Graduate School of Nursing, Midwifery and Health from Victoria University of Wellington. I am interested in registered nurses who chose to do an undergraduate nursing degree. This may provide useful information for other nurses contemplating undertaking a degree, for managers deciding what types of nursing study to support and for educators and education providers.

This research has received ethical approval from the Human Ethics Committee of Victoria University of Wellington.

As part of this research I am seeking information from providers who may have offered degree transition programmes for registered nurses. The enclosed questionnaire seeks information on if, when and for how long you offered a programme for registered nurses. It also asks about the name of the programme and the numbers who have graduated from the programme.

Your completion of the questionnaire will be taken as consent to use the data in this research. No Schools of Nursing will be individually identified in the research. All statistics given will be aggregated. No person other than me and my supervisors will see the information provided. The material will be kept in a secure place and destroyed at the end of the research. .

If the programme still runs, I would appreciate a copy of the information available to prospective registered nurse students.

I plan to share the results at education seminars, conferences and through publications, such as journal articles. On the questionnaire you can indicate if you wish to receive a summary of the research results.

My supervisors are: Dr Pamela Wood, Associate Professor \& Dr Kathy Nelson, Lecturer Contact details: $\quad \mathrm{Ph}(04) 463-6650$ or (04) 463-6138

Graduate School of Nursing, Midwifery and Health, P.O. Box 600, Wellington

E-mail: $\quad$ Pamela.Wood@vuw.ac.nz $\quad$ Kathy.Nelson@vuw.ac.nz

I am available for clarification of any aspect of the study by phone or e-mail

Tina Smith

Phone: 0272227166

E-mail: t-moore@xtra.co.nz 
VICTORIA UNIVERSITY OF WELLINGTON

Te Whare Wananga o te Upoko o te Ika a Maui

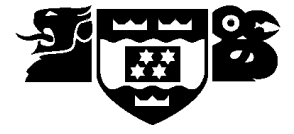

\section{Completing a Bachelor of Nursing as a Registered Nurse}

Name of Institution

What year did your institution first offer a degree in nursing leading to registration?

At the end of what year did your first degree graduates finish?

What was the name of your degree? Eg. Bachelor of Nursing, Bachelor of Health Science.

What year did you first offer a programme for Registered Nurses to obtain a degree?

What years did this programme run?

What do you call this programme?

Please provide the numbers of graduates, by year, for each year that the programme for Registered Nurses ran.

\begin{tabular}{|l|l|}
\hline Year & Number of RN Graduates \\
\hline & \\
\hline & \\
\hline & \\
\hline & \\
\hline & \\
\hline & \\
\hline & \\
\hline & \\
\hline & \\
\hline
\end{tabular}

We are interested in receiving a summary of the research results Yes / No (circle)

If your programme still runs I would appreciate you posting or e-mailing the information available to prospective Registered Nurse students.

Thank you in anticipation for completing this form. 


\begin{tabular}{|c|c|c|c|}
\hline & & Phone & $0-4-4635676$ \\
\hline & & Fax & $0-4-4635209$ \\
\hline & & Email & Allison.kirkman@vuw.ac.nz \\
\hline $\mathrm{TO}$ & Tina Smith & & \\
\hline COPY TO & Kathy Nelson, Janeen Batchelor & & \\
\hline FROM & Dr Jenny Neale, Acting Convener & an Eth & s Committee \\
\hline DATE & 14 September 2006 & & \\
\hline PAGES & 1 & & \\
\hline SUBJECT & $\begin{array}{l}\text { Ethics Approval: No109/2006, } \\
\text { Nursing as a Registered Nurse }\end{array}$ & eting & Bachelor of \\
\hline
\end{tabular}

Thank you for your application for ethical approval, which has now been considered by the Standing Committee of the Human Ethics Committee.

Your application has been approved and this approval continues until March 2007. If your data collection is not completed by this date you should apply to the Human Ethics Committee for an extension to this approval.

Best wishes with the research.

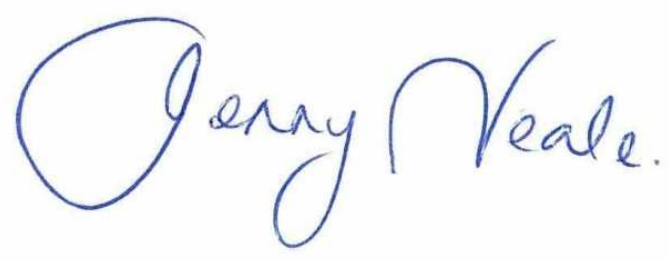

Jenny Neale pp Allison Kirkman Convener 


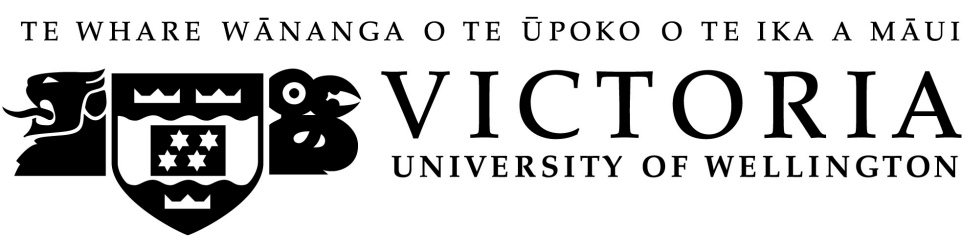

\section{Confidentiality Form for Transcriber}

\section{Appendix 5 \\ 'Completing a Bachelor of Nursing as a Registered Nurse'}

\section{Confidentiality Agreement}

I understand that the material I have agreed to transcribe for Tina Smith is confidential and must remain so. I agree to only discuss this material with Tina and that I will not, at any time, directly or indirectly share or discuss the content with anyone else.

I will maintain confidentiality throughout the transcribing process by ensuring that no other person will have access to the tapes, the computer files or the transcript material except for myself and Tina.

I will ensure that all computer files related to this information are password protected and that, once transcribed, all copies (tapes, computer discs or CDs and hard copies) are returned to Tina Smith and the computer file deleted.

Full Name:

Signature:

Date: 


\section{Interview Schedule}

\section{Appendix 6}

Introduction, with a reminder that participants can refuse to answer any questions at any time, that they can ask for the tape recorder to be turned off and that they are encouraged to say what they believe, even if it is critical in nature.

To start I will ask some general information.

- How long you have been a Registered Nurse?

- What nursing qualifications did you have prior to commencing the $\mathrm{RN}$ to $\mathrm{BN}$ programme?

- Could you outline your domestic situation at the time of doing the RN to BN programme.

- What was your professional situation at the time of undertaking the $\mathrm{RN}$ to $\mathrm{BN}$ programme?

Tell me about doing the $\mathrm{RN}$ to $\mathrm{BN}$ programme.

What were your reasons for undertaking this programme?

Which, if any, other options did you consider and how did you make your choice?

What were the best parts of the experience?

What were the worst parts of the experience?

What factors, personal and professional, encouraged you while on this programme?

What factors, personal and professional, hindered you while on this programme?

How has completing this degree affected you on a personal level?

How has completing this degree affected you on a professional level?

What do you perceive were the benefits of completing this programme?

What do you perceive were the disadvantages of doing this programme?

Do you believe that gaining a degree qualification should be a mandatory requirement for RNs?

In your perception, weighing everything up, was it worth it and why, or why not?

Are there any additional comments you wish to make about this experience?

Thank you for giving your time and sharing your thoughts on this programme. Your input is greatly appreciated. 


\section{REFERENCES}

Adams, K. F. (2003). A postmodern/poststructural exploration of the discursive formation of professional nursing in New Zealand 1840-2000. Unpublished doctoral dissertation, Victoria University of Wellington, Wellington, New Zealand.

Adamson, M. J. (1997). Action research: The journey from enrolled nurse to registration and beyond. Discovering a process to promote self-efficacy and professional development. Unpublished master's thesis, Victoria University of Wellington, Wellington, New Zealand.

Aiken, L. H., Clarke, S. P., Cheung, R. B., Sloane, D. M., \& Silber, J. H. (2003). Educational levels of hospital nurses and surgical patient mortality. JAMA, 290(12), 1617-1623.

Aitcheson, L. (2002). A case study of PACT Otago's journey in establishing and providing community mental health services, 1990-1999. Unpublished master's thesis, Victoria University of Wellington, Wellington, New Zealand.

Akinsanya, J. A. (1990). Nursing links with higher education: A prescription for change in the 21 st century. Journal of Advanced Nursing, 15(6), 744-754.

Allen, N. (1992). A framework for nursing and midwifery education in New Zealand. A discussion paper prepared for the Vision 2000 Committee. Wellington: Vision 2000 Committee.

Ashworth, P. D., Gerrish, K., Hargreaves, J., \& McManus, M. (1999). "Levels" of attainment in nursing practice: Reality or illusion? Journal of Advanced Nursing, 30(1), 159-168.

Ayres, L., Kavanaugh, K., \& Knafl, K. A. (2003). Within-case and across-cse approaches to qualitative data analysis. Qualitative Health Research, 13(6), 871-883.

Azuine, R. (2003). Diploma education makes nursing seem pre-historic... making nursing a degree entry profession in England. Nursing Standard, 17(37), 31.

Baj, P. (1985). Demographic characteristics of $\mathrm{RN}$ and generic students: Implications for curriculum. Journal of Nursing Education, 24, 230-236.

Barnett, P., \& Barnett, R. (1999). Reform and change in health service provision. In P. Davis \& K. Dew (Eds.), Health and society in Aotearoa New Zealand (pp. 219 - 234). Auckland: Oxford University Press.

Barrowman, R. (1999). Victoria University of Wellington 1899-1999: A history. Wellington: Victoria University Press.

Beeman, P. B. (1988). RNs' perceptions of their baccalaureate programs: Meeting their adult learning needs. Journal of Nursing Education, 27(8), 364-370.

Beeman, P. B. (1990). Brief: RN students in baccalaureate programs - Faculty's role and responsibility. Journal of Continuing Education in Nursing, 21(1), 42-45. 
Benipal, J. S. (1999). An audit of the educational needs in management and clinical practice of registered nurses/midwives at Auckland Healthcare. Unpublished master's thesis, Massey University, Palmerston North, New Zealand.

Benjamin-Coleman, R., Smith, M., Alexy, B., \& Palmer, K. (2001). Distance education: A decade of distance education: RN to BSN. Nurse Educator, 26(1), 9-12.

Bentley, G. W., Cook, P. P., Davis, K., Murphy, M. J., \& Berding, C. B. (2003). RN to BSN program: Transition from traditional to online delivery. Nurse Educator, 28(3), 121-126.

Blackie, S. A. H. (2001). Women, work, study and health: The experience of nurses engaged in paid work and further education. Unpublished master's thesis. Massey University, Palmerston North, New Zealand.

Bircumshaw, D. (1989). How can we compare graduate and non-graduate nurses? A review of the literature. Journal of Advanced Nursing, 14(6), 438-443.

Brownson, K. (1997). A guide to armchair education: How to pursue a bachelor's degree without leaving home (almost). Nursing97, 27(2), 70.

Brownson, K. (2005). Online degrees for nurses: A flexible alternative. Journal of Nurses in Staff Development, 21(1), 26-30.

Bryar, R. M. (1999). An examination of case study research. Nurse Researcher, 7(2), 61-77.

Burgess, M. E. (1984). Nursing in New Zealand society. Auckland: Longman Paul.

Burke, L. M., \& Harris, D. (2000). Education purchasers' views of nursing as an all graduate profession. Nurse Education Today, 20, 620-628.

Burnard, P. (1991). A method of analysing interview transcripts in qualitative research. Nurse Education Today, 11(6), 461-466.

Burnard, P. (1995). Interpreting text: An alternative to some current forms of textual analysis in qualitative research. Social Sciences in Health, 1(4), 236-245.

Burnard, P. (1996). Teaching the analysis of textual data: An experiential approach. Nurse Education Today, 16, 278-281.

Callin, M. (1996). From RN to BSN: Seeing familiar situations in different ways. The Journal of Continuing Education, 27(1), 28-33.

Cangelosi, P. R. (2004). The tact of teaching RN-to-BSN students. Journal of Professional Nursing, 20(3), 167-173.

Carlisle, C. (1991). Post-registration degrees in nursing: A time for evaluation. Nurse Education Today, 11(4), 295-302.

Carpenter, H. (1971). An improved system of nursing education for New Zealand. Wellington: Department of Health. 
Chandler, J. (1991). Nurse Education Tomorrow Conference 1990: Reforming nurse education 1 - The reorganisation of nursing knowledge. Nurse Education Today, 11(2), 83-88.

Chick, N., \& Kinross, N. (2006). Chalk \& cheese: Trail-blazing in NZ nursing: A story told through memoir. Christchurch: Xpress Printing House.

Chiu, L. H. (2005). Motivation for nurses undertaking a post-registration qualification in Malaysia. International Nursing Review, 52(1), 46-51.

Cragg, C. E., Plotnikoff, R. C., Hugo, K., \& Casey, A. (2001). Perspective transformation in RNto-BSN distance education. Journal of Nursing Education, 40(7), 317-322.

Currie, K., \& Bennett, J. (2000). Degrees of difficulty. Nursing Management, 7(5), 34-38.

Dale, A. E. (1995). A research study exploring the patient's view of quality of life using the case study method. Journal of Advanced Nursing, 22, 1128-1134.

Davey, B., \& Robinson, S. (2002). Taking a degree after qualifying as a registered general nurse: Constraints and effects. Nurse Education Today, 22(8), 624-631.

Davidhizar, R., \& Vance, A. (1999). Restructuring clinical time to professionalize the RN-BSN student. Health Care Supervisor, 17(3), 26-32.

Davis, B. D., \& Burnard, P. (1992). Academic levels in nursing. Journal of Advanced Nursing, 17(12), 1395-1400.

Delaney, C., \& Piscopo, B. (2004). RN-BSN programs: Associate degree and diploma nurses' perceptions of the benefits and barriers to returning to school. Journal for Nurses in Staff Development, 20(4), 157-163.

Denzin, N. K., \& Lincoln, Y. S. (1998). Strategies of qualitative inquiry. Thousand Oaks, CA: Sage Publications Inc.

Denzin, N. K., \& Lincoln, Y. S. (Eds.). (2000). Handbook of qualitative research (2 ${ }^{\text {nd }}$ ed.). Thousand Oaks, CA: Sage Publications Inc.

Department of Health. (1986). The review of the preparation and initial employment of nurses. Wellington: Author.

de Vaus, D. A. (2001). Research design in social research. London: Sage Publications Inc.

De Vore, C. (1995). Independent midwifery practice: A critical social approach. Unpublished master's thesis, Massey University, Palmerston North, New Zealand.

Diekelmann, N. L. (1993) Transforming RN education: new approaches to innovation. In N. Diekelmann \& M. Rather (Eds.). Transforming RN education: Dialogue and debate (pp. 42-58). New York: National League for Nursing Press.

Dixon, A. (1996). Critical case studies as voice: The difference in practice between enrolled and registered nurses. Unpublished doctoral dissertation, Flinders University of South Australia, Adelaide, Australia. 
Dixon, A. M., \& Bramwell, R. S. (2000). Higher education: Making an informed choice. Journal of Child Health Care, 4(3), 111-116.

Domino, E. (2005). Nurses are what nurses do - Are you where you want to be? AORN Journal, 81(1), 187-201.

Donley, R., \& Flaherty, M. J. (2002). Revisiting the American Nurses Association's first position on education for nurses. Online Journal of Issues in Nursing, 7(2).

Dowswell, T., Bradshaw, G., \& Hewison, J. (2000). Child care responsibilities and participation in continuing education and training: Issues relating to motivation, funding and domestic roles. Journal of Advanced Nursing, 32(2), 445-453.

Dowswell, T., Hewison, J., \& Hinds, M. (1998). Motivational forces affecting participation in postregistration degree courses and effects on home and work life: A qualitative study. Journal of Advanced Nursing, 28(6), 1326-1333.

Education Act. (1989). New Zealand Statutes. Wellington: Government Printer.

Education Amendment Act. (1990). New Zealand Statutes. Wellington: Government Printer.

Employment Contracts Act. (1991). New Zealand Statutes. Wellington: Government Printer.

Esmond, P., \& Sandwich, E. (2004). Response to The 1965 entry into practice proposal - is it relevant today? [Letter to the editor] [Electronic Version]. Online Journal of Issues in Nursing, 9(2). Retrieved June 2, 2006, from http://www.nursingworld.org/ojin/letters/t18e10.htm.

Eyres, S. (1993). Women's ways of knowing and teaching RN students. In N. Diekelmann \& M. Rather (Eds.), Transforming RN education: Dialogue and debate (pp. 211-230). New York: National League for Nursing Press.

Fernandez, M. (2005). Dinner with the Council of Deans of Nursing and Midwifery (Australia and New Zealand), 21 February [Speech]. Retrieved July 22, 2006, from http://www.ednm.edu.au/pdfs/MariaFernandezspeech21Feb05.pdf.

French, P. (1998). A study of the regulation of nursing in New Zealand 1901-1997. Unpublished master's thesis. Victoria University of Wellington, Wellington, New Zealand.

Gape, N., \& Hewin, P. (1995). A matter of degree: Has occupational therapy graduated as a profession? British Journal of Occupational Therapy, 58(2), 50-54.

Giger, J. N., \& Davidhizar, R. E. (1990). Conceptual and theoretical approaches to patient care: Associate versus baccalaureate degree prepared nurses. Journal of Advanced Nursing, 15(9), 1009-1015.

Girot, E. A. (2000). Assessment of graduates and diplomates in practice in the UK - Are we measuring the same level of competence? Journal of Clinical Nursing, 9, 330-337. 
Glasper, E. A., \& O'Connor, S. (1996). Nursing should be an all-graduate profession. British Journal of Nursing, 5(1), 5-6.

Glass, N. (1998). The contested work place: Reactions to hospital based RNs doing degrees. Collegian, 5(1), 24-31.

Gomm, R., Hammersley, M., \& Foster, P. (Eds.). (2000). Case study method: Key issues, key texts. London: Sage Publications Inc.

Gould, D., Smith, P., Payne, S., \& Aird, T. (1999). Students' expectations of post-registration degree programmes. Journal of Advanced Nursing, 29(6), 1308-1317.

Hammersley, M., \& Gomm, R. (2000). Introduction. In R. Gomm, M. Hammersley, \& P. Foster, (Eds.), Case study method: Key issues, key texts (pp 1-16). London: Sage Publications Inc.

Hardwick, S., \& Jordan, S. (2002). The impact of part-time post-registration degrees on practice. Journal of Advanced Nursing, 38(5), 524-535.

Hardy, M., \& Bryman, A. (Eds.). (2004). Handbook of data analysis. London: Sage Publications Inc.

Harrington, J. H. (1996). Socialization into the professional role as experienced by the RN/BSN [Research abstract]. Pennsylvania Nurse, 51(11), Retrieved April 15, 2006, from CINAHL Plus Full Text database.

Hayes, P., Kienholz, A., Engel, J., \& Mishra, R. K. (1993). Diverse thinking styles of nurses. In N. Diekelmann \& M. Rather (Eds.). Transforming RN education: Dialogue and debate (pp. 137-150). New York: National League for Nursing Press.

Health Practitioners Competence Assurance Act. (2003). New Zealand Statutes. Wellington: Government Printer.

Health \& Disability Services Act. (1993). New Zealand Statutes. Wellington: Government Printer.

Hegge, M. (1995). Restructuring registered nurse curricula. Nurse Educator, 20(6), 39-44.

Hill, Y., Dewar, K., \& MacGregor, J. (1996). Orientation to higher education: The challenges and rewards. Nurse Education Today, 16, 328-333.

Hodges, H. (1996). Journal writing as a mode of thinking for RN-BSN students: A levelled approach to learning to listen to self and others. Journal of Nursing Education, 35(3), 137-141.

Horne, C.D. (1993). Ideological barriers to nursing education for returning RN students. In N. Diekelmann \& M. Rather (Eds.), Transforming RN education: Dialogue and debate (pp. 61-78). New York: National League for Nursing Press.

Horsburgh, M. (1991). Polytech by degrees. New Zealand Nursing Journal, 83(11), 27.

Hospitals Amendment Act. (1996). New Zealand Statutes. Wellington: Government Printer. 
Hughes, B. (1978). Nursing education: The collapse of the Diploma of Nursing at the University of Otago, 1925-1926. The New Zealand Journal of History, 12(1), 17-33.

Idour, M. (1997). "Stepping beyond the known". The lived experience of returning registered nurse students: An interpretive descriptive study. Unpublished doctoral dissertation. Massey University, College of Education, Palmerston North, New Zealand.

International Council of Nurses. (2006). Nursing education: Past to present. Geneva, Switzerland: Author.

Jacobs, S. (1998). Advanced nursing practice in New Zealand: 1998. Nursing Praxis in New Zealand, 13(3), 4-12.

Jacobs, S. (2005). Advanced nursing practice and the Nurse Practitioner: New Zealand nursing's professional project in the late $20^{\text {th }}$ Century. Unpublished doctoral dissertation. Massey University, Palmerston North, New Zealand.

Jinks, A. M. (1994). Conceptualization of differing levels of educational attainment: What are the characteristics of nurses and midwives who have undertaken diploma and degree educational programmes? Journal of Nursing Management, 2, 279-285.

Joel, L. A. (2002). Education for entry into nursing practice: Revisited for the 21 st century. Online Journal of Issues in Nursing, 7(2).

Johnstone, R. B., \& Onwuegbuzie, A. J. (2004). Mixed methods research: A research paradigm whose time has come. Educational Researcher, 1(2), 112-133.

Jones, C., \& Lyons, C. (2004). Case study: Design? Method? Or comprehensive research strategy? Nurse Researcher, 11(3), 70-77.

Kennedy, S., \& Taylor, A. (1987). An evaluation of advanced diploma in nursing courses. Wellington: Department of Education.

Kent, J. (1992). An evaluation of pre-registration midwifery education in England: Research design: A case study approach. Midwifery, 8, 69-75.

Koch, T. (1998). Story telling: Is it really research? Journal of Advanced Nursing, 28(6), 1182.

Konrad, S. (2005). Post-RN degree builds on practice experience: Going back to school. Alberta $R N, 61(2), 14-15$.

Kvale, S. (1996). Interviews, An introduction to qualitative research interviewing. California: Sage Publications Inc.

Lavelle, M., Patterson, P., \& Iphofen, R. (1997). On reflection. Adults Learning, 8, 267-268.

Leonard, T. (2003). RN to BSN - Advise on returning to school. AORN Journal, 77(3), 598-608. 
Lillibridge, J., \& Fox, S. D. (2005). RN to BSN education: What do RNs think? Nurse Educator, $30(1), 12-16$.

Lincoln, Y. S., \& Guba, E. G. (1985). Naturalistic inquiry. California: Sage Publications Inc.

Loustau, A. (1993). Evaluating the academic experience for returning registered nurses. In N. Diekelmann \& M. Rather (Eds.), Transforming RN education: Dialogue and debate (pp. 198-210). New York: National League for Nursing Press.

Lowe, K. (2003). University qualifications don't make better nurses. Kai Tiaki Nursing New Zealand, 9(8), 4-5.

Lubbe, S. (2003). The development of a case study methodology in the IT field: A step by step approach. Retrieved April 7, 2006, from http://www.usabilityviews.com/uv005541.html

Luck, L., Jackson, D., \& Usher, K. (2006). Case study: A bridge across the paradigms. Nursing Inquiry, 13(2), 1003-109.

Lusk, B., Russell, R. L., Rodgers, J., \& Wilson-Barnett, J. (2001). Preregistration nursing education in Australia, New Zealand, the United Kingdom, and the United States of America. Journal of Nursing Education, 40(5), 197-202.

MacLean, T. B., Knoll, G. H., \& Kinney, C. K. (1985). The evolution of a baccalaureate program for registered nurses. Journal of Nursing Education, 24(2), 53-57.

Mahaffey, E. H. (2002). The relevance of associate degree nursing education: Past, present, future. Online Journal of Issues in Nursing, 7(2).

Maltby, H. J., \& Andrusyszyn, M. A. (1997). In my opinion. Perspective transformation: Challenging the resocialization concept of degree-seeking registered nurses. Nurse Educator, 22(2), 9-11.

Marquis, B., Lillibridge, J., \& Madison, J. (1993). Problems and progress as Australia adopts the bachelor's degree as the only entry to nursing practice. Nursing Outlook, 41, 135-140.

McGuire, R. (2004). Back to school. Nursing Standard, 18(26), 20-21.

McLaughlin, M. (2003). Tertiary education policy in New Zealand. Retrieved June 18, 2008, from http://www.fullbright.org.nz/voices/axford/docs/mcLaughlin.pdf.

Melosh, B. (1989). Not merely a profession. Nurses and resistance to professionalism. American Behavioural Scientist, 32(6), 668-679.

Merriam, S. B. (1998). Qualitative research and case study applications in education. San Francisco: Jossey-Bass Inc.

Midwives Act. (1904). New Zealand Statutes. Wellington: Government Printer.

Ministerial Taskforce on Nursing. (1998). Report of the Ministerial taskforce on nursing: Releasing the potential of nursing. Wellington: Ministry of Health. 
Mitchell, J. C. (2000). Case and situation analysis. In R. Gomm, M. Hammersley, \& P. Foster. (Eds.), Case study method: Key issues, key texts (pp. 165-186). London: Sage Publications Inc.

Morris, A. H., \& Faulk, D. (2007). Perspective transformation: Enhancing the development of professionalism in RN-BSN students. Journal of Nursing Education, 46(10), 445-451.

Morse, J., Barrett, M., Mayan, M., Olson, K., \& Spiers, J. (2002). Verification strategies for establishing reliability and validity in qualitative research. International Journal of Qualitative Methods, 1(2), Article 2. Retrieved August 19, 2007, from http://www.ualberta.ca/ ijqm/

National Professonal Development and Recognition Programmes Working Party. (2004). National framework for nursing professional development \& recognition programmes \& designated role titles. Report to the National Nurses Organisations. Wellington: National Nurses Organisations

Nelson, K. M. (2003). Innovation in service delivery: The expansion of general practice services for people with serious and ongoing mental illness. Unpublished doctoral dissertation. Victoria University of Wellington, Wellington, New Zealand.

News. (2002). Figures show massive decline in post basic education. Australian Nursing Journal, 10(2), 6.

New Zealand Qualifications Authority. (1991). Designing the framework. Wellington: Author.

Nicholson, M. P. (2003). The privilege of nursing. Canadian Nurse, 99(7), 10-11.

Nurses Act. (1977). New Zealand Statutes. Wellington: Government Printer.

Nurses and Midwives Amendment Act. (1944). New Zealand Statutes. Wellington: Government Printer.

Nurses and Midwives Registration Act. (1925). New Zealand Statutes. Wellington: Government Printer.

Nurses Registration Act. (1901). New Zealand Statutes. Wellington: Government Printer.

Nursing by degrees. (1991/1992). New Zealand Nursing Journal, Kai Tiaki, 84(11), 25-26.

Nursing Council of New Zealand. (1996a). Report of the Nursing Council of New Zealand for the year ended 31 March 1996. Wellington: Author.

Nursing Council of New Zealand. (1996b). Performance-based practising certificates: A means to ensure public confidence in the continuing competence of nurses and midwives. Discussion paper. Wellington: Author.

Nursing Council of New Zealand. (1998). Framework, guidelines and competencies for postregistration nursing education. Wellington: Author. 
Nursing Council of New Zealand. (1999a). Framework for post-registration nursing education. Wellington: Author.

Nursing Council of New Zealand. (1999b). Handbook for post-registration nursing practice programme providers. Wellington: Author.

Nursing Council of New Zealand. (2000). New Zealand registered nurses, midwives and enrolled nurses: Survey of educational qualifications. Wellington: Author.

Nursing Council of New Zealand. (2001a). Towards a competency assurance framework for nursing. Wellington: Author.

Nursing Council of New Zealand. (2001b). Guidelines for competence-based practising certificates for registered nurses. Wellington: Author.

Nursing Council of New Zealand. (2002). New Zealand registered nurses, midwives and enrolled nurses: Workforce statistics. Wellington: Author.

Nursing Council of New Zealand. (2003). Report of the Nursing Council of New Zealand for the year ended 31 March 2003. Wellington: Author.

Nursing Council of New Zealand. (2006). Report of the Nursing Council of New Zealand for the year ended 31 March 2006. Wellington: Author.

O'Callaghan, D., Hau, J. M., \& Lebold, M. M. (1993). Factors influencing the retention and progression of students in an RN-MS program. In N. L. Diekelmann \& M. L. Rather (Eds.), Transforming RN education: Dialogue and debate (pp. 179 - 197). New York: National League for Nursing Press.

Oulton, J. (1997) International trends in nursing professional development. International Nursing Review, 44(2), 47-51.

Owen, G. M. (1988). For better, for worse: Nursing in higher education. Journal of Advanced Nursing, 13(1), 3-13.

Papps, E. (1997). Knowledge, power, and nursing education in New Zealand: A critical analysis of the construction of the nursing identity Unpublished doctoral dissertation. University of Otago, Dunedin, New Zealand.

Papps, E., \& Kilpatrick, J. (2002). Nursing education in New Zealand - Past, present and future. In E. Papps (Ed.), Nursing in New Zealand: Critical issues, different perspectives (pp. 113). Auckland: Pearson Education New Zealand.

Parish, C. (2003). Degrees of preparation. Nursing Standard, 18(4), 12-13.

Pegram, A. (1999). What is case study research? Nurse Researcher, 7(2), 5.

Pelletier, D., Donoghue, J., \& Duffield, C. (2005). Understanding the nursing workforce: A longitudinal study of Australian nurses six years after graduate study. Australian Journal of Advanced Nursing, 23(1), 37-43. 
Pennington, E., Kruszewski, A., Allor, T. Barnfather, J., Moore, C., Zenas, C. et al. (1993). Twenty years of success and still growing. In N. Diekelmann \& M. Rather (Eds.), Transforming RN education: Dialogue and debate (pp. 167-178). New York: National League for Nursing Press.

Price, B. (2003). Supporting nurses study: Lay supporters and their work. Nurse Education Today, 24, 14-19.

Ragin, C. C. (1992). Introduction: Cases of "what is a case". In C. C. Ragin \& H. S. Becker (Eds.), What is a case? Exploring the foundations of social inquiry (pp. 1-17). Cambridge: Cambridge University Press.

Rather, M. L. (1993). "Harbingers of entry into practice". The lived experience of returning RN students. In N. Diekelmann \& M. Rather (Eds.), Transforming RN education: Dialogue and debate (pp. 97-120). New York: National League for Nursing Press.

Rather, M. L. (1994). Schooling for oppression: A critical hermeneutical analysis of the lived experience of the returning RN student. Journal of Nursing Education, 33(6), 263-271.

Reid, A. (1965). Report on nursing education in New Zealand. Wellington: University Grants Committee.

Rendon, D. (1988). The registered nurse student: A role congruence perspective. Journal of Nursing Eeducation, 27(4), 172-177.

Richardson, S. (2001). Post-graduate education benefits everyday practice. Kai Tiaki Nursing New Zealand, 7(3), 6.

Robinson, S., Murrells, T., Hickey, G., Clinton, M., \& Tingle, A. (2003). The tale of two courses: Comparing careers and competencies of nurses prepared via three-year degree and three-year diploma courses. Report to Department of Health. Nursing Research Unit, King's College, London University. Retrieved August 20, 2007, from http://www.umds.ac.uk/schools/nursing/nnru/people/sr.html

Rodgers, M., \& Nealand, S. (1993). Innovation in registered nurse education: from oppression to empowerment. In N. Diekelmann \& M. Rather (Eds.), Transforming RN education: Dialogue and debate (pp. 231-241). New York: National League for Nursing Press.

Rosenberg, J. P., \& Yates, P. M. (2007). Schematic representation of case study research designs. Journal of Advanced Nursing, 60(4), 447-452.

Rusin, M. L. (1993). RN-BSN curriculum development: A dynamic, student-centered approach. In N. Diekelmann \& M. Rather (Eds.). Transforming RN education: Dialogue and debate (pp. 153-166). New York: National League for Nursing Press.

Russell, R. L. (1990). From Nightingale to now: Nurse education in Australia. Sydney: Harcourt Brace Jovanovich.

Russell, R. L. (2005). From hospital to university - The transfer of nurse education. Retrieved June 2, 2006, from http://www.cdnm.edu.au/pdfs/HistoryNursingEducation.pdf 
Salmon, B. E. (1983). New Zealand universities and nursing education: The first seven decades. In P. Carroll, A. Fieldhouse \& S. Shaw (Eds.), A profession in transition: Issues in nursing in New Zealand over two decades, 1961-1981. A selection from the writings of $E$. Beatrice Salmon (pp. 60-63). Wellington: The C. L. Bailey Nursing Education Trust.

Sandelowski, M. (1986). The problem of rigour in qualitative research. Advances in Nursing Science, 8(3), 27-37.

Schneider, Z., Elliot, D., Beanland, C., LoBiondo-Wood, G., \& Haber, J. (2003). Nursing research: Methods, critical appraisal and utilisation ( $2^{\text {nd }}$ ed.). Sydney, Australia: Mosby.

Schofield, J. W. (2000). Increasing the generalizability of qualitative research. In R. Gomm, M. Hammersley, \& P. Foster. (Eds.), Case study method: Key issues, key texts (pp. 69-98). London: Sage Publications Inc.

Scott, C. (1998). Specialist practice: Advancing the profession? Journal of Advanced Nursing, 28(3), 554-562.

Seaton, P. (1998). The experiences of registered nurses in polytechnic baccalaureate degree programmes: An interpretive phenomenological study. Unpublished master's thesis, Massey University, Palmerston North, New Zealand.

Sims, D. (2004). The benefits and challenges of one New Zealand undergraduate clinical education model: A case study. Unpublished master's thesis, Victoria University of Wellington, Wellington, New Zealand.

Sinclair, B. P. (2002). Perspectives: Strategies for going back to school. AWHONN Lifelines, 5(6), 7-8.

Skinner, J. (1998). The jewel in the crown: A case study of the New Zealand College of Midwives standards review process in Wellington. Unpublished master's thesis, Victoria University of Wellington, Wellington, New Zealand.

Smith, K. D. (2005). Rethinking entry-into-practice issues. Nursing Forum, 40(1), 29-37.

Social Security Act. (1938). New Zealand Statutes. Wellington: Government Printer.

Social Security Amendment Act. (1941). New Zealand Statutes. Wellington: Government Printer.

Soy, S. K. (1997). The case study as a research method. Unpublished paper, University of Texas at Austin. Retrieved April 7, 2006, from http://www.gslis.utexas.edu/ ssoy/usesusers/1391d1b.htm

Spence, D. (2004a). Advancing nursing practice through postgraduate education (Part one). Nursing Praxis in New Zealand, 20(2), 46 - 55.

Spence, D. (2004b). Advancing nursing practice through postgraduate education (Part two). Nursing Praxis in New Zealand, 20(3), 21-30.

Stake, R. E. (1995). The art of case study research. Thousand Oaks, CA: Sage Publications Inc. 
Stake, R. E. (1998). Case studies. In N. K. Denzin, \& Y. S. Lincoln. (Eds.), Strategies of qualitative inquiry (pp. 86-109). Thousand Oaks, CA: Sage Publications Inc.

Stake, R. E. (2000). The case study method in social inquiry. In R. Gomm, M. Hammersley, \& P. Foster. (Eds.), Case study method: Key issues, key texts (pp. 19-26). London: Sage Publications Inc.

Stake, R. E. (2005). Qualitative case studies. In N. K. Denzin, \& Y. S. Lincoln. (Eds.), Handbook of qualitative research ( $2^{\text {nd }}$ ed.), (pp. 443-466). Thousand Oaks, CA: Sage Publications Inc.

Stanley, H. (2003). The journey to become a graduate nurse: A study of the lived experience of part-time post-registration students. Nurse Education in Practice, 3, 62-71.

State-Owned Enterprises Act. (1986). New Zealand Statutes. Wellington: Government Printer.

Stein-Parbury, J. (2000). Nursing around the world: Australia [Electronic Version]. Online Journal of Issues in Nursing, 5. Retrieved 16 April, 2006, from http://www.nursingworld.org/ojin/topic12/tpc12_3.htm.

Struthers, J. (2003). University qualifications do enhance nurses' practice. Kai Tiaki Nursing New Zealand, 9(10), 3-4.

Taylor, A. J., Small, D. K., White, J. E., Hall, P. M., \& Fenwick, P. R. (1981). An evaluation of nursing courses in technical institutes. Wellington: Department of Education.

Taylor, H. R., Westcott, E., \& Bartlett, H. P. (2001). Measuring the socialization of graduate and diplomatic nurses using the Corwin Role Orientation Scale. Journal of Advanced Nursing, 33(1), 20-28.

Tellis, W. (1997a). Introduction to case study [Electronic Version]. The Qualitative Report, 3(2), 111. Retrieved April 23, 2006, from http://www.nova.edu/sss/QR/QR3-2/tellis1.html.

Tellis, W. (1997b). Application of a case study methodology [Electronic Version]. The Qualitative Report, 3(3), 1-17. Retrieved April 7, 2006, from http://www.nova.edu/sss/QR/QR33/tellis2.html.

Thompson, A. (2001). Specialist pathways. Nursing Times, 97(7), 54-56.

Thompson, D. (1992). Beyond motivation: A model of registered nurses' participation and persistence in baccalaureate nursing programs. Adult Education Quarterly, 42(2), 94-105.

Timmins, F., \& Nicholl, H. (2005). Stressors associated with qualified nurses undertaking parttime degree programmes - some implications for nurse managers to consider. Journal of Nursing Management, 13(6), 477-482.

United Kingdom Central Council for Nursing Midwifery and Health Visiting. (1986). Project 2000: A new preparation for practice. London: Author.

VanCott, M. L., \& Lengacher, C. (1993). Review of research related to educational re-entry for the registered nurse: 1985-1991. In N. Diekelmann \& M. Rather (Eds.), Transforming RN 
education: Dialogue and debate (pp. 79-96). New York: National League for Nursing Press.

Vision 2000 Committee. (1991). Vision 2000: Project 1991 forum report 14/15 March. Wellington: New Zealand Nurses Association.

Vision 2000 Committee. (1992). A framework for nursing and midwifery education in New Zealand. Wellington: Author.

Waddell, D. L., \& Hayes, J. M. (2000). Point/counterpoint: Does "online" nursing education short change the RN to BSN student? Georgia Nursing, 60(3), Retrieved April 15, 2006, from http://web21.epnet.com/citation.asp?tb

Warren, J. (2004). Organisational incentives and rewards as motivators for registered nurses to obtain a baccalaureate or higher nursing degree Unpublished doctoral dissertation. University of Maryland, Maryland, United States of America.

White, M. J., \& Gomez, G. (2002). Critical thinking: Outcomes of critical thinking and professional attitudes in RN/BSN completion programs. Nurse Educator, 27(2), 71-72.

Williams, B. G. (2000). The primary of the nurse in New Zealand 1960s - 1990s: Attitudes, beliefs and responses over time. Unpublished doctoral dissertation. Victoria University of Wellington, Wellington, New Zealand.

Wilkinson, J. A. (2007). The New Zealand nurse practitioner polemic: A discourse analysis. Unpublished doctoral dissertation. Massey University, Wellington, New Zealand.

Wood, P. J. (1990). Decision-making styles and continuing education: Implications for career guidance. Nursing Praxis in New Zealand, 5(3), 18-23.

Woolley, A. S. (2004). A retrospective look at the entry dilemma. Nursing Forum, 39(3), 33-36.

Workforce Development Group. (1988). Nursing education in transition: The transfer of nursing education to the general system of education 1973-1988: The Department of Health's perspective. Wellington: Department of Health.

Worrell, J. D., McGinn, A., Black, E., Holloway, N., \& Ney, P. (1996). The RN-BSN student: Developing a model of empowerment. Journal of Nursing Education, 35(3), 127-130.

Yin, R. K. (1994). Case study research: Design and methods (2nd ed.). Thousand Oaks, CA: Sage Publications, Inc.

Yin, R. K. (1999). Enhancing the quality of case studies in health services research. Health Services Research, 34(5 Pt 2), 1209-1224.

Yin, R. K. (2003). Case study research: Design and methods (3rd ed.). Thousand Oaks, CA: Sage Publications, Inc.

Zucker, D. M. (2001). Using case study methodology in nursing research [Electronic Version]. The Qualitative Report, 6(2), 1-12. Retrieved April 7, 2006, from http://www.nova.edu/sss/QR/QR6-2/zucker.html. 